\title{
Biomarker Chemistry and Flux Quantification Methods for Natural Petroleum Seeps and Produced Oils, Offshore Southern California
}

By Thomas D. Lorenson, Ira Leifer, Florence L. Wong, Robert J. Rosenbauer, Pamela L. Campbell, Angela Lam,

Frances D. Hostettler, Jens Greinert, David P. Finlayson, Eliza S. Bradley, and Bruce P. Luyendyk

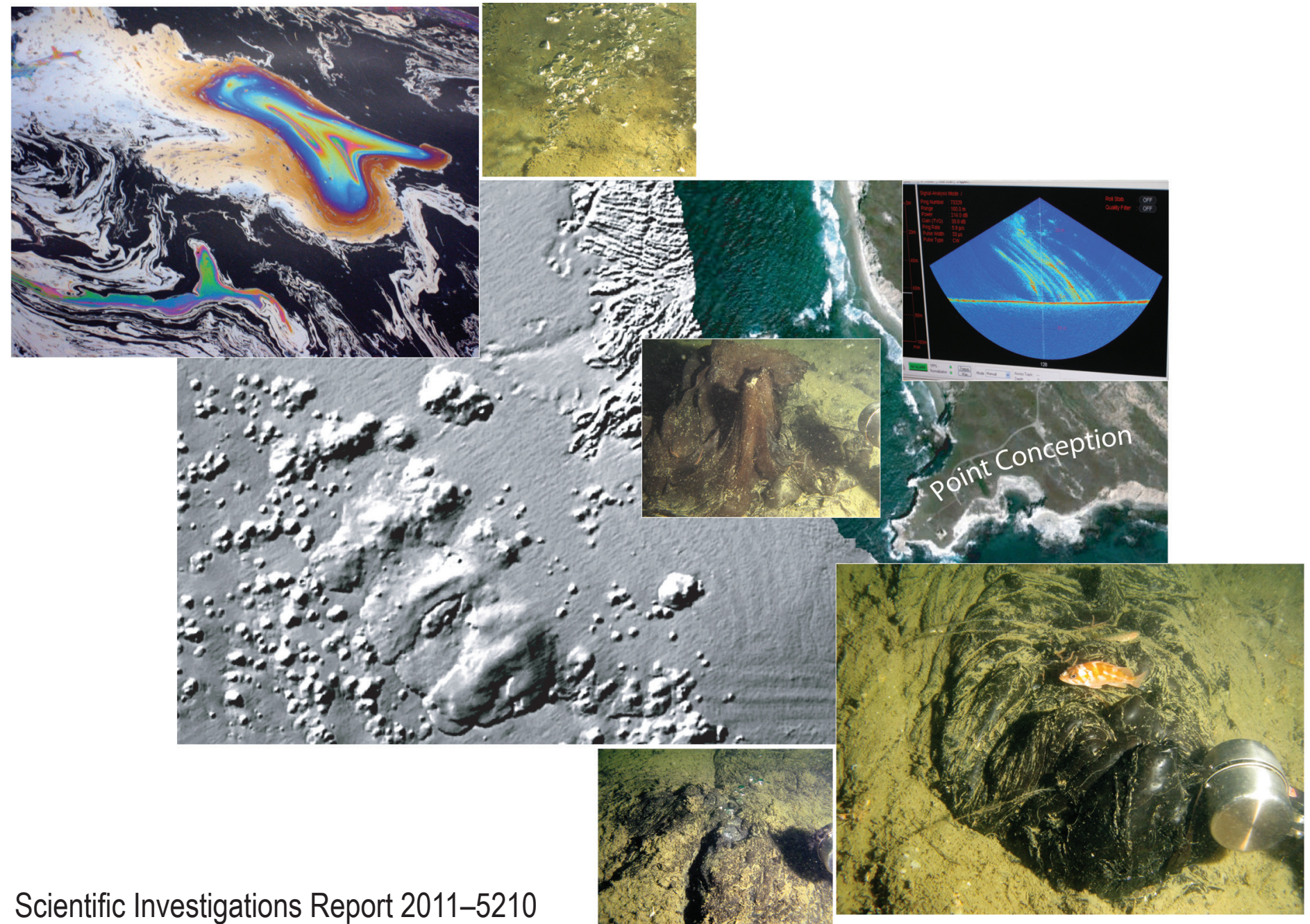

Bureau of Ocean Energy ManDgement OCS Study BOEM 2011-016

U.S. Department of the Interior U.S. Geological Survey

U.S. Department of the Interior Bureau of Ocean Energy Management 
COVER

Clockwise from top left to bottom right:

Oil sheen on sea surface over Trilogy seep; gas seepage at sea floor from Triology seep; a pinnacle-like natural asphaltic oil extrusion from the sea floor; sonar image of oil and gas rising from the sea floor into the water column at La Goleta seep; shaded-relief sea floor image offshore Point Conception showing natural asphalt mounds (lower left) and bed rock (upper center); two examples of asphaltic extrusion with gas emission and a small rock fish hovering over an active seep, offshore Cojo anchorage, east of Point Conception. 


\section{Biomarker Chemistry and Flux Quantification Methods for Natural Petroleum Seeps and Produced Oils, Offshore Southern California}

By Thomas D. Lorenson, Ira Leifer, Florence L. Wong, Robert J. Rosenbauer, Pamela L. Campbell, Angela Lam, Frances D. Hostettler, Jens Greinert, David P. Finlayson, Eliza S. Bradley, and Bruce P. Luyendyk

Scientific Investigations Report 2011-5210

Bureau of Ocean Energy ManDgement OCS Study BOEM 2011-016 


\title{
U.S. Department of the Interior \\ KEN SALAZAR, Secretary
}

\author{
U.S. Geological Survey \\ Marcia K. McNutt, Director
}

\section{U.S. Geological Survey, Reston, Virginia 2011}

For product and ordering information and more information on the USGS - the Federal source for science about the Earth, its natural and living resources, natural hazards, and the environment:

World Wide Web: http://www.usgs.gov

Telephone: 1-888-ASK-USGS (1-888-275-8747)

This report and any updates to it are available online at:

http://pubs.usgs.gov/sir/2011/5210/

To order this and other USGS information products, visit http://store.usgs.gov

Any use of trade, product, or firm names is for descriptive purposes only and does not imply endorsement by the U.S. Government.

Although this report is in the public domain, permission must be secured from the individual copyright owners to reproduce any copyrighted material contained within this report.

Sugested citation:

Lorenson, T.D., Leifer, I., Wong, F.L., Rosenbauer, R.J., Campbell, P.L., Lam, A., Hostettler, F.D., Greinert, J., Finlayson, D.P., Bradley, E.S., and Luyendyk, B.P., 2011, Biomarker chemistry and flux quantification methods for natural petroleum seeps and produced oils, offshore southern California: U.S. Geological Survey Scientific Investigations Report 2011-5210, 45 p. and OCS Study BOEM 2011-016.

This report is also available from the Bureau of Ocean Energy Management, Pacific OCS Region, by referencing OCS Study BOEM 2011-016. The report may be downloaded from the BOEM website through the Environmental Studies Program Information System (ESPIS) and is also available in PDF on the BOEM Pacific website. Additionally, requests for the report can be made through the following contacts:

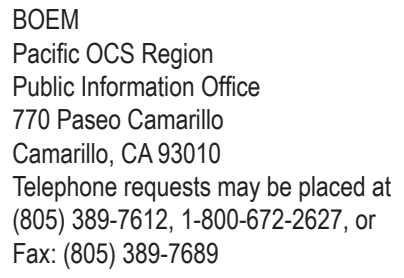




\section{Contents}

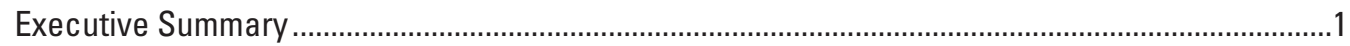

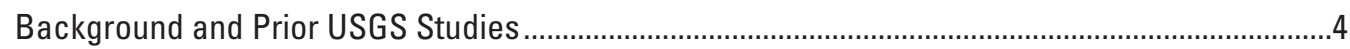

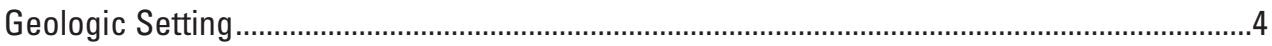

Chemometric Model for Oil Families ................................................................................

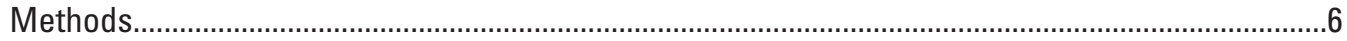

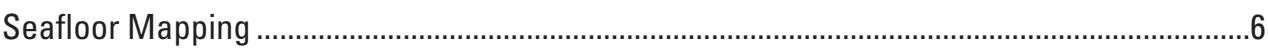

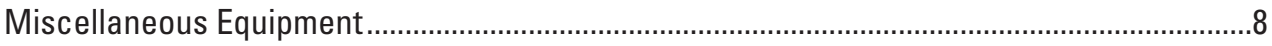

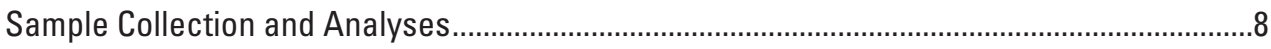

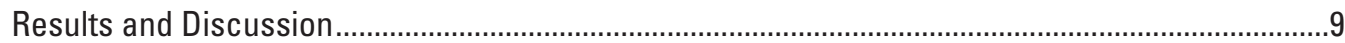

Locating and Sampling Seeps-Remotely Operated Vehicle (ROV) and

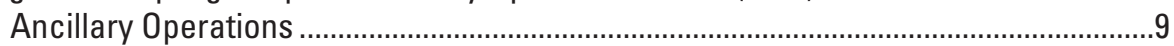

Seeps in the Santa Barbara Basin ..........................................................................................

Seeps in the Northwestern Santa Barbara Basin ...........................................................

Seeps Near Coal Oil Point ................................................................................................

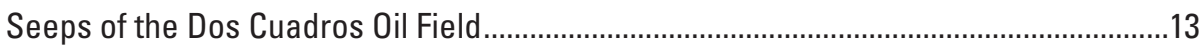

Biomarker Analyses and Chemometric Modeling ……........................................................13

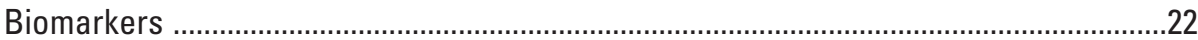

Application of the Chemometeric Model to New Samples ...................................................23

Application of the Chemometeric Model to Produced Oils from Offshore Southern

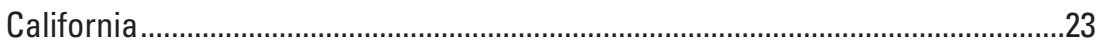

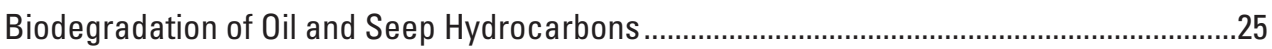

Gas and Oil Emissions from Seeps Offshore Coal Oil Point ………….............................................25

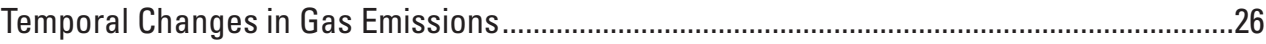

Oil Emission Measured at Coal Oil Point.............................................................................26

Measuring Current Gas and Oil Seep Discharge ..........................................................................27

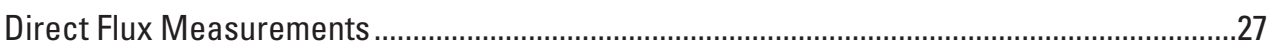

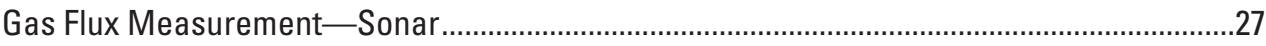

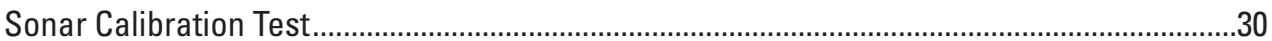

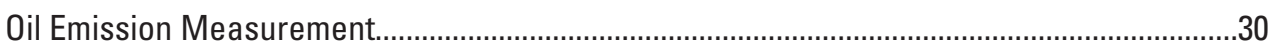

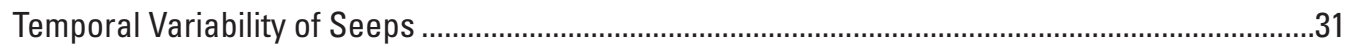

Tarball Accumulation Data .....................................................................................................

Recommended Steps in Remotely Quantifying Seep Emissions ....................................................34

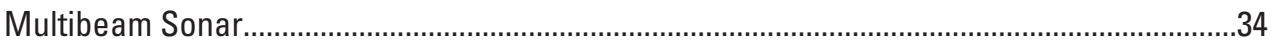

Remote Sensing Derivation of Oil Thickness .....................................................................

Quantitative Oil-Spill Mapping...............................................................................................37

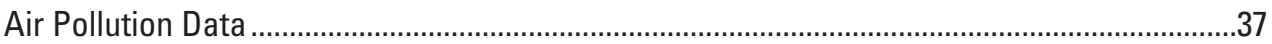

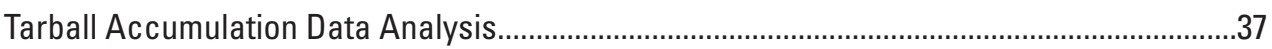

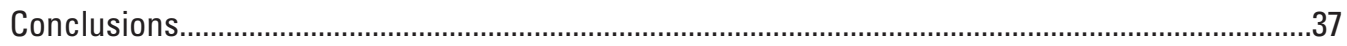

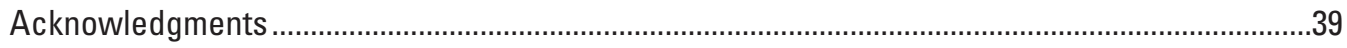

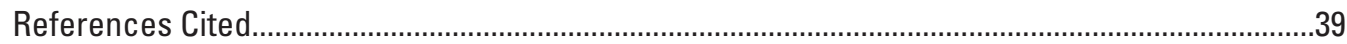

Appendix 1. Geochemical Parameters used in Tarball Studies ..........................................................44 


\section{Figures}

1. Maps showing locations of seep and produced-platform oil samples discussed in this study ........2

2. Stratigraphic columns for the Santa Barbara-Ventura area ..........................................................5

3. The chemometric decision tree uses a 388-sample training set to classify new oil, seep, tarball, or source-rock extract samples based on 19 source-related biomarker and isotope ratios.......6

4. Chromatograms of Platform Ellen A-58R oil and seep oil from the La Goleta seep field ...................7

5. Photographs of offshore seeps and related ROV operations...............................................................10

6. Maps of methane and carbon dioxide anomalies in the atmosphere approximately $2 \mathrm{~m}$ above sea level..

7. Water-column, bottom-bounce, normalized-sonar-return amplitude map of Coal Oil Point gas plumes.

8. Coal Oil Point seep field and underlying geologic structure showing the Monterey

Formation, the seep-gas spatial distribution at seabed, and subsurface areas

of major faults.

9. Two-way heirarchical cluster diagram of produced oils from offshore platforms and selected onshore oil fields

10. Summary map of produced oils classified by oil family

11. Map showing samples with sample numbers, classified by oil family, that were collected in February 2008

12. Map showing seep samples, classified by oil family, collected 2004-2010 in the vicinity of Point Conception......

13. Maps showing samples, classified by oil family, collected in the vicinity of Sacate beach. ..........19

14. Maps showing location of samples, classified by oil family, collected in the vicinity of Coal Oil Point.

15. Maps showing locations of samples, classified by oil family, collected from operating platforms south of Santa Barbara

16. Maps showing locations of samples, classified by oil family, collected from operating OCS platforms (Edith, Ellen, Eureka) south of Long Beach.

17. Histogram showing the distribution of modeled chemometric families as sample versus the percentage of occurrence of model type...

18. Sonar return for a transect line through Trilogy seep (775 s) with respect to transect time...........28

19. Schematic showing sonar beam during tow through seep field with along-track current.............29

20. Images of Edgetech sonar during the MBARI sonar-bubble calibration study.............................29

21. Map of ship tracklines, mainly traversed during four acoustic surveys of seeps south of Coal Oil Point during 2007-2010, and seep locations and numbers collected during 2008-2010..

22. Composite amplitude maps of gas plumes rising up through the water column at Triology seep as recorded by multiple overlapping passes with the Reson 7125 multibeam sonar ...................32

23. Aerial images of the oil boom collection experiment at Horseshoe seep, July 13, 2006................33

24. Mean and maximum total hydrocarbon concentrations for $5^{\circ}$ binned wind direction...........................34

25. Illustrations showing light scattering in oil on water ........................................................................35

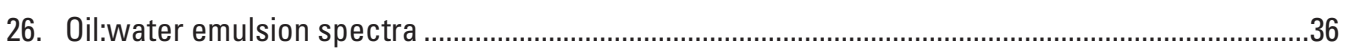

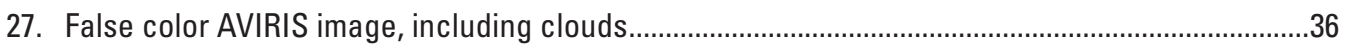

28. Total Hydrocarbon of 2008 sample from West Campus Station as a function of wind direction showing high temporal variability in seep-field emissions. 


\section{Tables (see separate Excel files at http://pubs.usgs.gov/sir/2011/5210/)}

1. Location, classification, and geochemical data for crude oil, seep oil, and tarball samples, offshore Southern California

2. Produced oil information for samples collected in the study area

3. Location and description of ROV samples, water samples, and towed video operations and samples 2008-2010

4. Distribution of modeled chemometric families by each sample type with percentages of sample types represented in each family. 
This page left blank intentionally. 


\title{
Biomarker Chemistry and Flux Quantification Methods for Natural Petroleum Seeps and Produced Oils, Offshore Southern California
}

\author{
By Thomas D. Lorenson'1, Ira Leifer², Florence L. Wong', Robert J. Rosenbauer', Pamela L. Campbell', Angela \\ Lam $^{1}$, Frances D. Hostettler', Jens Greinert ${ }^{3}$, David P. Finlayson', Eliza S. Bradley², and Bruce P. Luyendyk ${ }^{2}$
}

\section{Executive Summary}

Sustained, natural oil seepage from the seafloor is common off southern California, and is of great interest to resource managers, who are tasked with distinguishing natural from anthropogenic oil sources. The major purpose of this study was to build upon the work previously funded by the Bureau of Ocean Energy Management (BOEM) and the U.S. Geological Survey (USGS) (Peters and others, 2008; Lorenson and others, 2009) that has refined the oil-fingerprinting process to enable differentiation of the highly similar Monterey Formation oils from Outer Continental Shelf (OCS) production and adjacent natural seeps.

In these initial studies, biomarker and stable carbon isotope ratios were used to infer the age, lithology, organicmatter input, and depositional environment of the source rocks for 388 samples of produced crude oil, seep oil, and tarballs mainly from coastal California (fig. 1). The analysis resulted in a predictive model of oil source families that could be applied to samples of unknown origin.

Results of the original model identified three distinct types, herein called "tribes", of ${ }^{13} \mathrm{C}$-rich oil samples that were inferred to originate from thermally mature equivalents of the upper siliceous, middle shale, and lower calcareous units of the Monterey Formation. Tribe 1 contains four oil families that have geochemical traits of clay-rich, marine-shale source rock deposited under suboxic conditions with substantial higher-plant input. Tribe 2 contains four oil families that have intermediate traits, except for abundant 28,30-bisnorhopane, indicating suboxic to anoxic marine-marl source rock with hemipelagic input. Tribe 3 contains five oil families that have traits of distal marine-carbonate source rock,

\footnotetext{
${ }^{1}$ U.S. Geological Survey

${ }^{2}$ University of California Santa Barbara

${ }^{3}$ Royal Netherlands Institute for Sea Research
}

deposited under anoxic conditions with pelagic but little or no higher-plant input. Tribes 1 and 2 occur mainly south of Point Conception in paleogeographic settings (shelf, slope, and basin), where deep burial of the Monterey Formation source rock favored generation from all three units or their equivalents. In this area, oil from the upper siliceous unit and middle shale unit (tribes 1 and 2) may overwhelm that from the lower calcareous unit member (tribe 3), because the latter is thinner and less oil-prone than the overlying units. Tribe 3 oils occur mainly north of Point Conception, where shallow burial caused preferential generation from the underlying lower calcareous unit member or another unit with similar characteristics. Samples that do not fit within the model are classified as family 0 (Peters and others, 2008; Lorenson and others, 2009, fig. 3). These samples can be identified as Monterey Formation oils and likely are derived from natural seeps, but they cannot be classified strictly due to advanced biodegradation of the biomarkers used in the model. Each of these samples retains the bulk carbon-isotopic composition derived from oil and bitumen in the Monterey Formation.

Specific objectives of this study follow:

1. Identify new areas of hydrocarbon seepage that are known to occur near OCS platforms not sampled during the previous study;

2. Geochemically fingerprint new representative oils from the OCS platforms;

3. Geochemically fingerprint select coastal tar residues associated with unusual coastal oiling events;

4. Sample additional submarine seeps to strengthen correlations between offshore active seeps and coastal residues; and

5. Quantify the discharge rates of select natural seeps and attempt to scale such results into a regional perspective of natural oil and gas seepage rates. 
A total of 106 new oil samples were collected and analyzed for biomarkers: 28 samples from seeps (27 submarine, one from a sea cliff); 47 samples from representative production zones and depths from OCS oil and gas platforms; and 31 samples from random tarballs that were deposited during a storm event in February 2008. In cooperation with the U.S. Coast Guard and the California Office of Spill Prevention and Response, we collected and analyzed selected tarballs from this event. The model results showed that the tarballs most likely originated from natural seeps and that they likely were driven northward from central and southern California by ocean currents. Other random tarball analyses of samples collected in southern California, at the request of government agencies, also were shown to originate from natural seepage.

The 106 additional sample data were added to the model in an attempt to more exhaustively identify all platformproduced oil samples within known oil families (Peters and others, 2008; Lorenson and others, 2009, fig. 3). All platform oils, most tarballs, and about half of the seep samples collected from the seafloor were sucessfully classified by the model. Seafloor seep samples are often viscous, asphaltic hydrocarbon residues owing to biodegradation. In many asphaltic seafloor seeps (46\%), the biomarkers were so significantly biodegraded that the sample could not be classified. Tarballs, resulting mainly from less-biodegraded oil reaching the sea surface, were positively identified by the model about 97 percent of the time. We conclude that the original model is robust for determining oil or tarball samples originating from southern California.

Regulators wish to clearly distinguish naturally occurring seep oils from anthropogenically derived platform-produced oils. The biomarker parameters are sometimes sufficient to allow unique discrimination of individual platform oils. However, platform samples and seep samples from sources geographically close to each other have biomarker parameters too similar to definitively differentiate them on that basis alone. In some cases, the degree of biogeochemical degradation
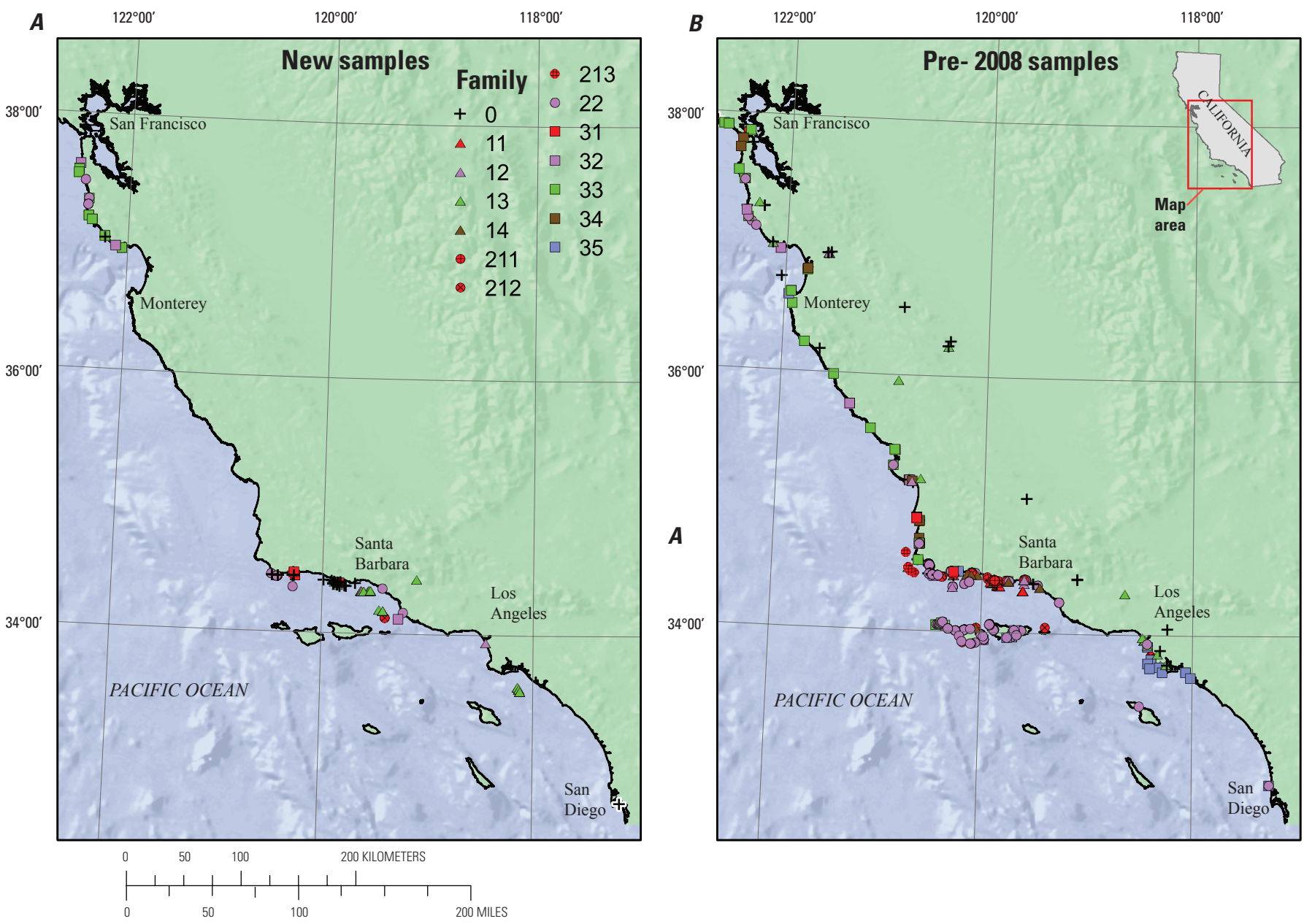

Figure 1. Maps showing locations of seep and produced-platform oil samples discussed in this study; location of study area (red outline) is shown in inset map. Oil, seep, and tarball tribes and families are described in text. $A$, Location of samples analyzed during this study. B, Location of samples analyzed prior to 2008 (discussed in Peters and others, 2008; Lorenson and others, 2009). 
or weathering that the oils or tars have experienced can be utilized. Nonweathered and nonbiodegraded oils contain $n$-alkane hydrocarbons and pristane and phytane isoprenoids. All of the platform oils in our sample set contain these components. In contrast, the seep oils or asphaltic residues have been exposed to significant biodegradation in the reservoir, resulting in the loss of at least the $n$-alkanes and isoprenoids. Therefore, the combination of chemometric fingerprinting and the presence or absence of $n$-alkanes and isoprenoids help to differentiate anthropogenic production oils from natural seep oils and tars. As biodegradation proceeds, biomarker compounds are sequentially attacked, resulting in nonclassification within our model.

The tarballs that we collected during our previous surveys are thought to be of very recent deposition based on circumstantial evidence. They were often found to be lying on top of the sand without any extraneous matter, and they were near the previous tidal-cycle high-swash line. We assumed tarballs with dull reflectance were qualitatively older. Sandimpregnated tar clasts that were occasionally seen on the beach were assumed to be the oldest tarballs with a density greater than water. Based on these observations and the knowledge that natural oil seepage becomes much denser with weathering, we conclude that most of the tarballs we sampled had been deposited on the beach for a few days at most. The fate of older tarballs was assumed to be mixing with beach sand and further weathering resulting in removal from the beach, offshore sinking, and deposition of ever smaller tarball fragments until they become physically indistinguishable from the environment. We surmise that an oil spill from nonnatural sources (produced or tankered oil) would be subject to a short lifespan on the beach just as natural tarballs and could be recognized by the less biodegraded chemical nature of the oil relative to natural oil seepage.

Oils representing all OCS platforms with the exception of Habitat (producing gas and condensate) and Grace (off production) have been included in this updated study. The platform oils sampled, east to west, are Eureka, Ellen, Edith, Gina, Gail, Gilda, Grace, Hogan, Houchin, Henry, Hillhouse, Platform B, and Platform C. The remaining platform oils previously sampled and analyzed are from Platforms Irene, Hildago, Harvest, Hermosa, Heritage, Harmony, Hondo, and Platform A. Two platforms in state waters, Holly (active) and Hilda (decommissioned), were included in the original studies (Peters and others, 2008; Lorenson and others, 2009) due to their proximity to many natural oil seeps.

Platform-produced oils are only classified in tribes 1 and 2, within families $11,12,13,14,211,212,213$, and 22. Tribe 1 oils are restricted to the Los Angeles Basin and the eastern Santa Barbara-Ventura Basin. Family 13 is the most common family from this area and the most common oil family overall $(\sim 40 \%)$. The western Santa Barbara-Ventura Basin (west of Platform Holly) and the Southern Santa Maria Basin oils are mainly from tribe 2 . Tribe 3 is not represented by any oil in southern California and, therefore, must have sources outside of this area, likely in little-explored basins offshore from the central coast of California.

The use of newly acquired, high-resolution seafloor maps has significantly boosted our ability to find and then sample seafloor oil seeps. Often, sustained oil seeps build extrusive, coalescing asphalt accumulations on the seafloorthe largest as thick as $18 \mathrm{~m}$ and as wide as $1 \mathrm{~km}$ in the Santa Barbara Channel. These mapping surveys have shown that the seeps most commonly occur just west of Point Conception to Coal Oil Point and generally within the 3-nauticalmile $(5.56-\mathrm{km})$ limit of California State waters. Other active seeps in southern California were observed south and west of Point Arguello and south of Santa Barbara, Carpinteria, and Summerland. Our natural seep samples came from water depths ranging from 10 to $72 \mathrm{~m}$ below sea level. Unexplored areas where seafloor mapping reveal mound-like structures occur north and west of Point Conception, south of St. Augustin Creek, within the deeper regions of the Santa Barbara Channel, south of Santa Barbara, and just west of Carpinteria. These areas are likely locations of persistent oil seepage and warrant future attention.

Several trial experiments were conducted to explore new ways to quantify total emission rates of natural seeps using both single-beam and multibeam sonar systems. These intercalibration experiments revealed that the single-beam sonar return was generally insensitive to bubble-flow rates and that very small bubble plumes were invisible to the sonar. In contrast, multibeam sonar had far greater sensitivity than the single-beam sonar and allowed for correction of geometric uncertainties. We experimented with the Submetrix SwathPlus-L, a $117-\mathrm{kHz}$ sidescan sonar used by the USGS from 2007-2009 to map nearshore seafloor bathymetry. Results indicate that, while better at imaging gas, reproducible calibration was not possible using this system. In 2010, the USGS mapped select actively discharging seep areas within the Coal Oil Point seep field with the Reson Seabat 7111 multibeam system, which produced impressive 3 -D video visualizations of gas plumes in the water column. The relative intensity of the sonar returns could be quantified; however, we are still in need of a controlled calibration experiment to relate intensity to gas and oil volume. We conclude that future efforts in remotely quantifying seep emissions should focus on multibeam sonar technology.

Our studies support the hypothesis that natural oil seepage from seafloor vents are responsible for the majority of tarball accumulation on southern California beaches. Oil fingerprinting provides the crucial tool to verify the origin of this deposited oil. While our study results are persuasive, they are not conclusive, because they depend on the assertion that beached or floating tarballs, by their inherent characteristics, are very recently deposited. We found three primary areas of seepage currently active in the Santa Barbara Channel: Point Conception, Sacate and Gaviota beaches, and Coal Oil Point. We also found that only a small fraction of tarballs did not correlate with California derived oils and are most 
likely from unknown ship or land-based discharges into the ocean. Produced oil from offshore platforms can often be ruled out as the origin of tarballs through the fingerprinting process, because platform oil is not significantly biodegraded. The ability to distinguish between biodegraded oils diminishes with time, and, under typical conditions, most spilled platform oil could resemble seep oil residues and seep-derived tarballs in about one month. The ability, however, to distinguish between seep-derived oil residues and platform oils within this time span is extremely valuable to regulators responding to an oil spill incident. The four platforms north of Point Conception produce oil that can be fingerprinted on the basis of chemistry alone without the need to consider biodegradation, and can thus be distinguished from known natural oil seeps in and offshore California.

Finely calibrated multibeam sonar techniques can produce detailed images of discharging plumes that could possibly be modeled to obtain volumes and discharge rates.

\section{Background and Prior USGS Studies}

Our research builds upon the favorable results of a 5 -yr study (Peters and others, 2008; Lorenson and others, 2009) that has refined the oil fingerprinting process to enable differentiation of the highly similar Monterey Formation oils from OCS production wells and adjacent natural seeps. Figure 1 depicts the sample distribution from both the original and our studies. Our goals were to (1) focus on areas of hydrocarbon seepage that are known to occur near OCS platforms not sampled during the previous study; (2) geochemically fingerprint representative oils from the OCS platforms; (3) geochemically fingerprint coastal tar residues associated with unusual coastal oiling events; (4) continue to directly sample submarine seeps to provide refined chemical correlations between offshore active seeps and coastal residues; and (5) measure the rate of natural seepage of individual seeps and attempt to assess regional natural oil and gas seepage rates.

For the prior studies, a total of more than 650 oils were analyzed for biomarker parameters by gas chromatography/ mass spectrometry, then statistically analyzed by a chemometric technique that groups oils of similar chemical makeup together in a statistically rigorous manner. In these studies, the USGS has analyzed coastal tar residues along the California coast, including an extensive survey of the shoreline of Santa Barbara County (Lorenson and others, 2004) and the Channel Islands (Hostettler and others, 2004). Tar residues have been collected along the coast from Eureka south to San Diego. Starting in 2001, high-resolution samples were collected quarterly at four beaches and four rocky areas in western Santa Barbara County. In 2002, samples were collected monthly from 10 beaches covering the length of Santa Barbara County.
Geochemical analyses of oil residue biomarkers from these samples have been compared with onshore and offshore seeps in the Santa Barbara-Ventura Basin Province and with a small set of reference crude oils. Previous to 2001, the USGS had undertaken reconnaissance studies of the coastal tar residues along the California coast, from San Diego in the south to Eureka in the north. Results indicate that all of the analyzed coastal tar residues collected adjacent to the offshore Santa Maria and Santa Barbara Basins were originally derived from the Miocene Monterey Formation except one. None of the residues can be definitively linked to oils produced by industry activity offshore southern California or elsewhere.

\section{Geologic Setting}

The geologic history and petroleum potential of the region is fundamental to understanding the sources of oil seepage. The Santa Barbara-Ventura Basin extends approximately $260 \mathrm{~km}$ from Los Angeles on the east to Point Conception on the west and approximately $65 \mathrm{~km}$ from the coast south to the Channel Islands. Almost all of the OCS-platform oil samples analyzed in this study were collected from the Santa Barbara-Ventura Basin. The basin contains a composite sedimentary section that is over 12,000 m thick, ranges in age from Cretaceous to Holocene, and is mainly of marine origin; however one significant nonmarine formation and several volcanic units are also present. Although the composite section is relatively complete, erosion (resulting in local unconformities) and structural complications have removed a significant volume of rock in many areas. Major regional unconformities exist in the middle Upper Cretaceous, Paleocene, and Oligocene sections. The stratigraphic terminology within the basin is complicated (fig. 2), because of the complex structural geology, facies changes within formations, time-transgressive nature of many stratigraphic units, and widely scattered exposures that led to multiple names for rock units (Galloway, 1998b). The sedimentary section is asymmetrically shaped; the northern portion is significantly thicker, which results in oil and gas generation mainly to the north. The principal hydrocarbon source and reservoir rock in the basin is the Miocene Monterey Formation, a prolific source of visible oil and gas seeps.

Several potential source rocks are present in the Santa Barbara-Ventura Basin. The Miocene Monterey Formation is the thickest source rock, has the highest total organic carbon (TOC) values in the basin (commonly $5 \%$ and as much as $23 \%$ ), and is the most prolific oil-producing rock in California. The Rincon Shale, also of Miocene age, may be a secondary source of oil, however it has a much lower TOC range that averages about 2.8 percent. The upper Miocene Sisquoc Formation ranges from about 1 to 6 percent TOC (Tennyson and Issacs, 2001). Each of these formations can produce oil and gas, however the Monterey Formation has been proven to be the major source of oil and gas in the region. Eocene source rocks are also present, but we found no evidence for any substantial contribution of oil and gas. 
The Los Angeles Basin-San Pedro Bay subarea is the site of three OCS platforms (Eureka, Ellen, Edith) and Elly, which has no producing wells and only processes production from Ellen and Eureka. The Neogene geologic history of the basin is similar to that of the Santa Barbara-Ventura Basin, however the sedimentary section is much thinner, about 3,300 $\mathrm{m}$ thick, and lacks sedimentary rocks older than Oligocene. In addition to the Monterey Formation, a basin-wide, organic-rich, nodular shale of middle Miocene age directly underlying the Monterey Formation has been cited as a significant source of light, low-sulfur oil (Drewry, 1997).

\section{Chemometric Model for Oil Families}

The discipline of chemometrics was applied to the biomarker data to better understand the origin and distribution of oil samples, including crude oil from wells, seeps, and floating or beached tarballs from coastal California and to build upon the work of Hostettler and others (2004). The objectives of our study were to (1) classify the samples into

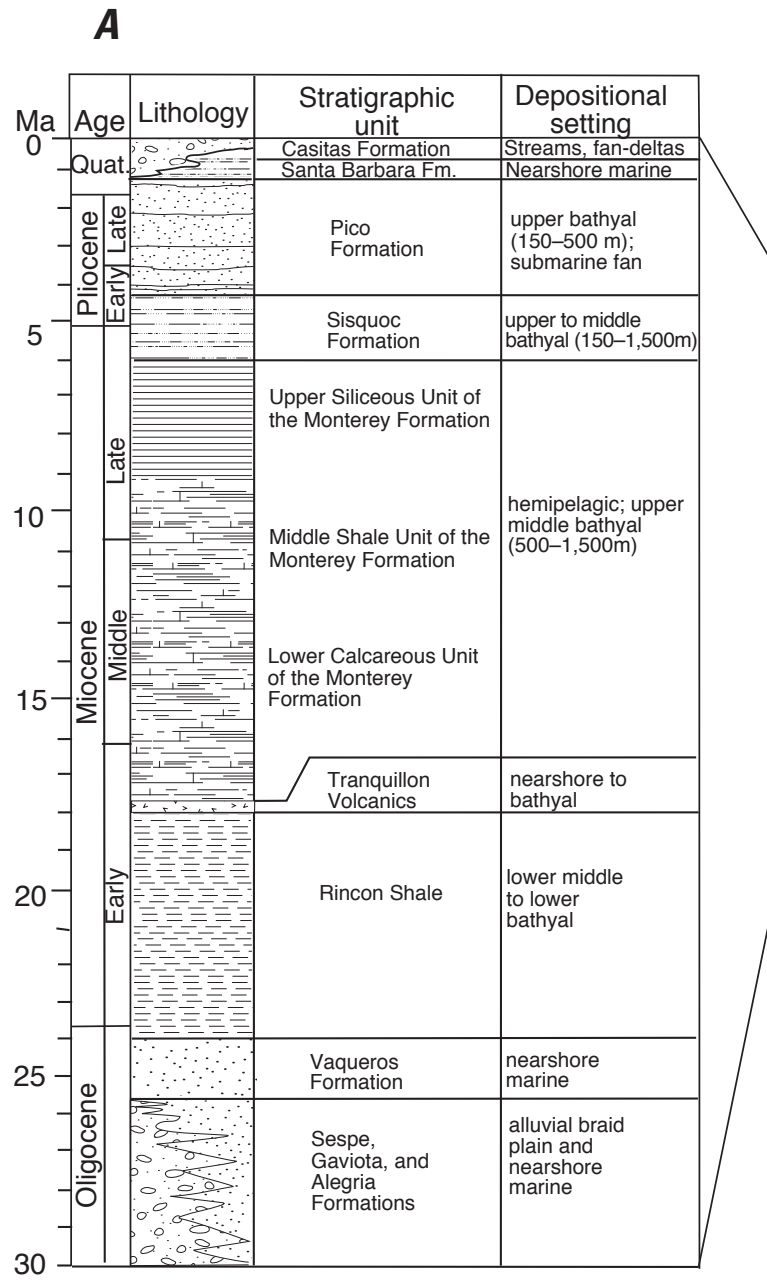

$B$

\begin{tabular}{|c|c|c|c|c|c|}
\hline \multicolumn{2}{|r|}{ Age } & $\begin{array}{c}\text { Stratigraphic } \\
\text { unit }\end{array}$ & Lithology & $\begin{array}{c}\text { Thickness } \\
\text { (ft) }\end{array}$ & Description \\
\hline \multirow{3}{*}{ 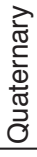 } & Recent & Alluvium & 0000 & $0-250$ & Gravel, sand, silt \\
\hline & $\begin{array}{l}\text { Upper } \\
\text { Pleistocene }\end{array}$ & Casitas Formation & $\begin{array}{r}0 \\
000 \\
0\end{array}$ & $0-3,000$ & Gravel, pebbly sandstone \\
\hline & Lower & $\begin{array}{l}\text { Santa Barbara } \\
\text { Formation }\end{array}$ & & $0-2,200$ & $\begin{array}{l}\text { Fine sand, minor siltstone } \\
\text { and claystone }\end{array}$ \\
\hline & \multirow{2}{*}{$\begin{array}{c}\text { Upper } \\
\text { Pliocene } \\
\text { Lower }\end{array}$} & Pico Formation & & $0-2,000$ & $\begin{array}{l}\text { Siltstone, fine santact) } \\
\text { conglomerate }\end{array}$ \\
\hline & & Sisquoc Formation & & $0-3,000$ & Diatomaceous clay shale \\
\hline & \multirow{3}{*}{$\begin{array}{l}\text { Middle } \\
\text { Miocene } \\
\text { Lower }\end{array}$} & $\begin{array}{l}\text { Monterey } \\
\text { Formation }\end{array}$ & 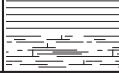 & $1,700-3,000$ & $\begin{array}{l}\text { Soft fissile to hard platy siliceous } \\
\text { shale, organic and calcareous } \\
\text { shale }\end{array}$ \\
\hline & & Rincon Shale & 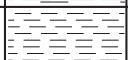 & 1,700 & Dark mudstone \\
\hline & & \begin{tabular}{l|} 
Vaqueros \\
Formation \\
\end{tabular} & & $0-900$ & Sandstone, pebble conglomerate \\
\hline \multirow{7}{*}{ 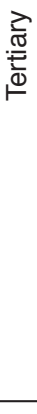 } & \multirow[t]{2}{*}{ Oligocene } & \begin{tabular}{|r|}
$\begin{array}{l}\text { Sespe } \\
\text { Formation } \\
\text { Alegria } \\
\text { Formation }\end{array}$ \\
\end{tabular} & 20 & 2,500 & $\begin{array}{l}\text { Sandstone, siltstone, } \\
\text { conglomerate } \\
\text { Sandstone }\end{array}$ \\
\hline & & Gaviota Formation & & $0-1,000$ & Buff sandstone \\
\hline & \multirow{4}{*}{ Eocene } & $\begin{array}{l}\text { Coldwater } \\
\text { Sandstone }\end{array}$ & & $0-3,300$ & $\begin{array}{l}\text { Sandstone, thin beds of } \\
\text { sandy siltstone }\end{array}$ \\
\hline & & $\begin{array}{l}\text { Sacate } \\
\text { Formation } \\
\end{array}$ & & $\begin{array}{l}2,500- \\
3,000\end{array}$ & Claystone, minor sandstone \\
\hline & & $\begin{array}{l}\text { Cozy Dell } \\
\text { Formation }\end{array}$ & $\square$ & $\begin{array}{l}1,800- \\
4,000\end{array}$ & Claystone, minor sandstone \\
\hline & & Matilija Formation & & $\begin{array}{l}1,000- \\
2,000\end{array}$ & Arkosic sandstone \\
\hline & Middle & Anita Formation & & $0-1.000$ & Clay shale, sandstone \\
\hline 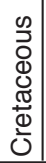 & Upper & $\begin{array}{l}\text { Jalama } \\
\text { Formation }\end{array}$ & $\square$ & 2,200 & $\begin{array}{l}\text { Dark claystone, minor thin } \\
\text { sandstone beds }\end{array}$ \\
\hline
\end{tabular}

Figure 2. Stratigraphic columns for the Santa Barbara-Ventura area. $A$, Neogene sequence. $B$, Entire Mesozoic and Cenozoic sequence (stratigraphy revised from Dibblee, 1966; Minor and others, 2009, modified from Tennyson and Isaacs, 2001). 
equivalents of the upper siliceous unit, middle shale unit, and lower calcareous unit of the Monterey Formation. Tribe 1 contains four oil families that have geochemical traits of clay-rich marine-shale source rock deposited under suboxic conditions and substantial higher-plant input. Tribe 2 contains five oil families that have intermediate traits, except for abundant 28,30-bisnorhopane, indicating suboxic to anoxic marine-marl source rock and hemipelagic input. Tribe 3 contains five oil families that have traits of distal-marine carbonate source rock deposited under anoxic conditions and pelagic but little or no higher-plant input. Tribes 1 and 2 occur mainly south and east of Point Conception in paleogeographic settings where deep burial of the Monterey Formation source rock favored oil generation from all three units or their equivalents. In this area, oil from the upper siliceous unit and middle shale unit (tribes 1,2 ) may overwhelm that from the lower calcareous unit (tribe 3 ), because the latter is thinner and less oil-prone than the overlying units. Tribe 3 oils occur mainly north of Point Conception, where shallow burial caused preferential generation from the underlying lower calcareous unit member or another unit with similar characteristics. Figure 4 shows chromatograms of Platform Ellen A-58R oil and seep oil from the La Goleta seep field (sample 09-113, table 1), each of which are within family 13 . The chromatograms look quite different and illustrate the need for chemometric analysis.

\section{Methods}

\section{Seafloor Mapping}

The shaded-relief bathymetry used as the background for our figures was generated at various times from 2006 to 2008 by California State University, Monterey Bay (CSUMB), Fugro Pelagos, and the USGS as part of the California Seafloor Mapping Program (http://walrus.wr.usgs.gov/ mapping/csmp/), using either the $244-\mathrm{kHz}$ Reson 8101 or the 400-kHz Reson 7125 multibeam echosounders. The central Coal Oil Point region was mapped by the USGS in 2006 using both $117-\mathrm{kHz}$ and $234.5-\mathrm{kHz}$ SEA (AP) Ltd. SWATHplus-M phase-differencing sidescan sonars. These mapping missions collected both bathymetry and acoustic backscatter

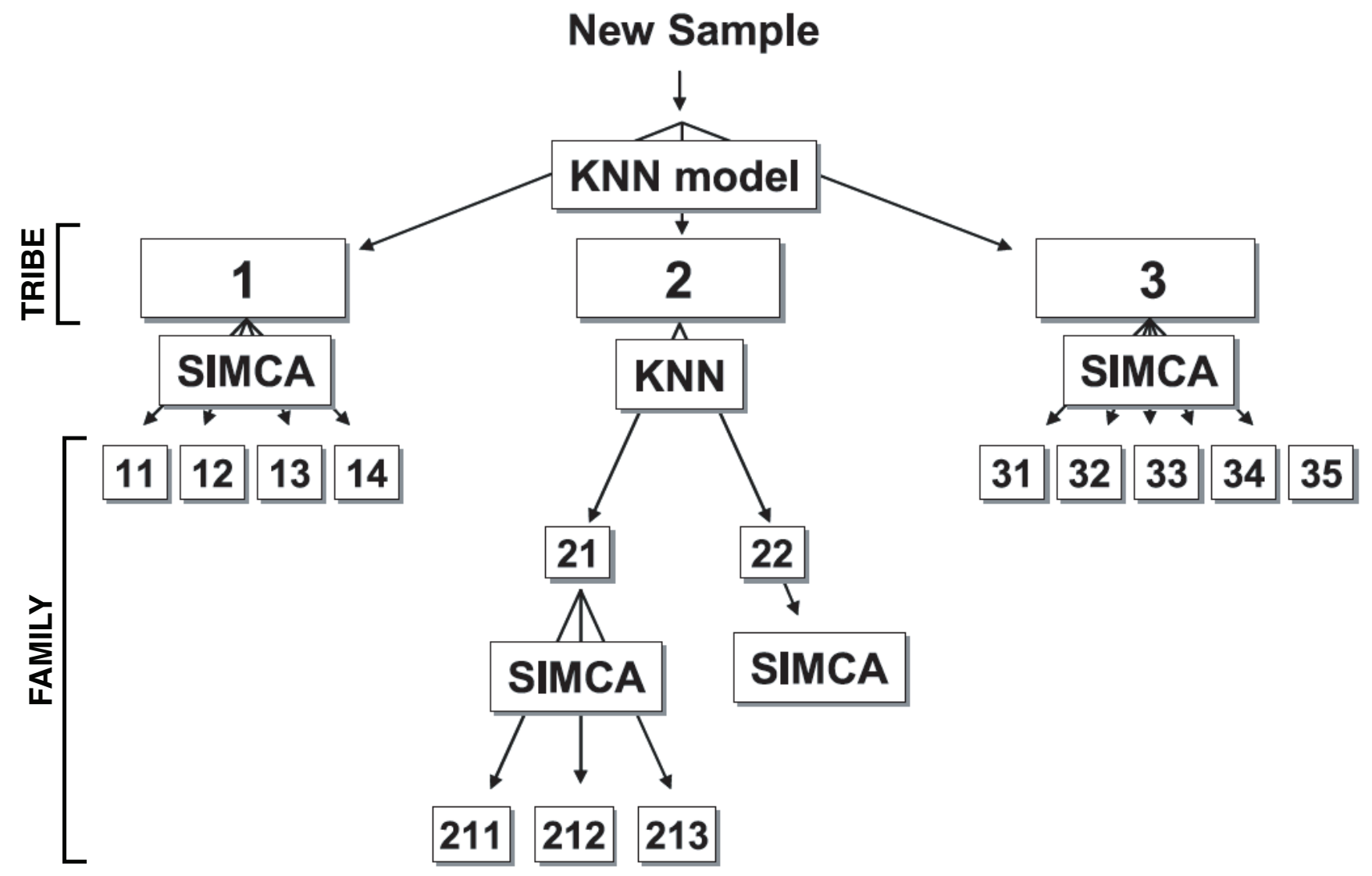

Figure 3. The chemometric decision tree uses a 388-sample training set to classify new oil, seep, tarball, or source-rock extract samples based on 19 source-related biomarker and isotope ratios. KNN, K nearest neighbor; SIMCA, soft independent modeling of class analogy (see Peters and others, 2008). Statistical criteria for SIMCA fit (confidence in the assignment of a sample to a given family) are based on a ratio of residuals as described in Peters and others (2008). Modified from Peters and others (2008). 

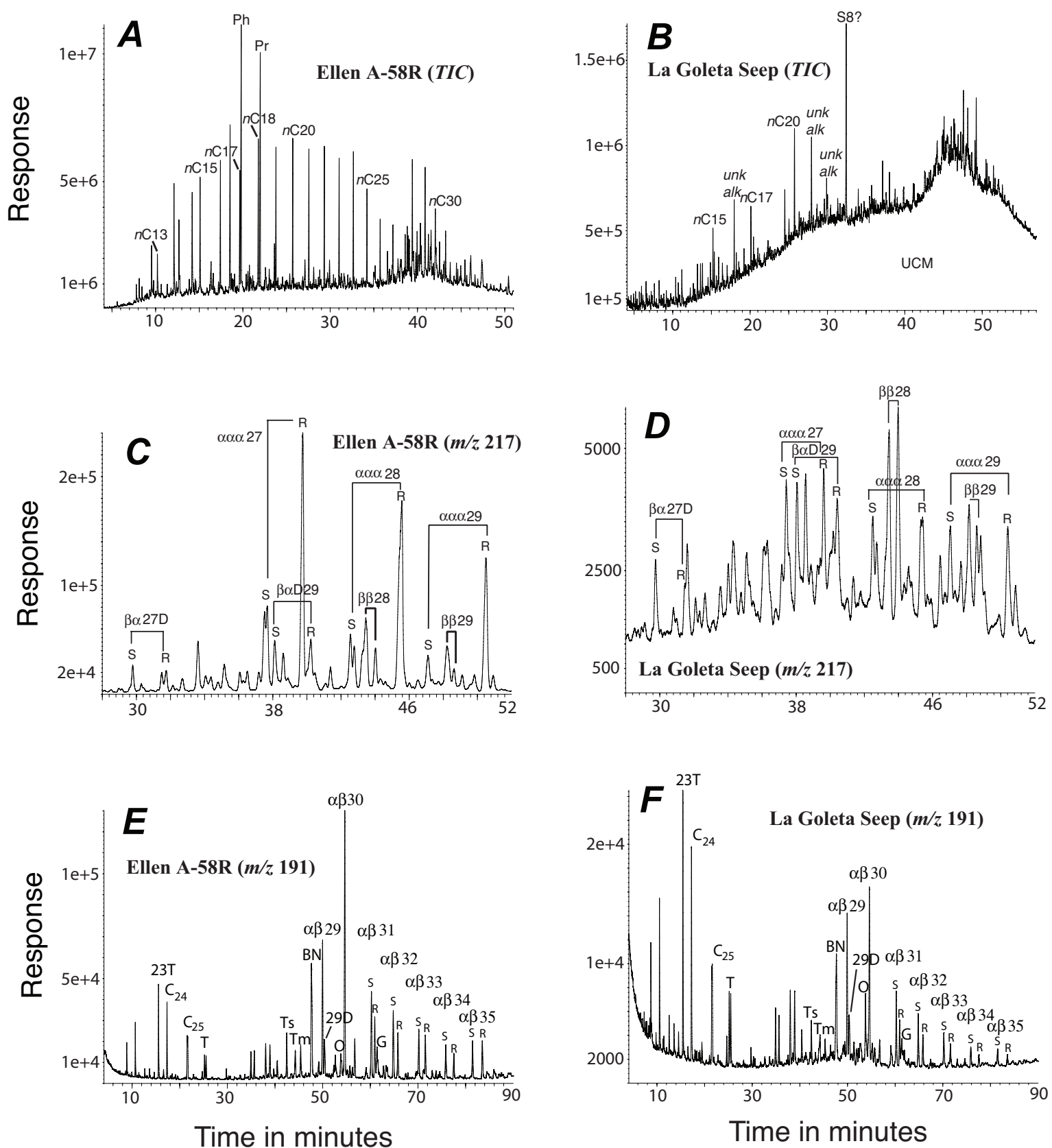

Figure 4. Chromatograms of Platform Ellen A-58R oil (sample 10-232, table 1) and seep oil from the La Goleta seep field (sample 09-113, table 1); each are within the family 13. Total ion chromatographs (TIC) Selected ion monitoring (SIM) chromatograms of $\mathrm{m} / \mathrm{z}$ 191 , Hopanes $(A, C, E)$, and $m / z 217$, Steranes $(B, D, F)$. The oil sample from Platform Ellen has minor biodegradation as seen by the dominance of the isoprenoids pristine and phytane, relative to the $n$-alkanes, indicating the oil is just at initial stages of biodegradation. The Sterane suite also indicates that biodegradation has not occurred with these compounds; aaaR's are (esp. $C_{27}$ ) dominant, with low $\beta \alpha D 27$ compounds. Finally the Platform Ellen A-58R oil is fairly immature oil, because the $C_{27}$ to $C_{29} \alpha \alpha \alpha$ R's are dominant over the $C_{27}$ to $C_{29} \alpha \alpha \alpha S^{\prime}$ 's. The hopane suite looks very typical of oils from the Monterey Formation with relatively high concentrations of BN and $\alpha \beta C 35$. The TIC of the La Goleta seep oil shows a high UCM indicative of significant biodegradation. The presence of unknown branched $n$-alkanes may indicate that the sample is moderately biodegraded. Both the steranes and hopanes are impacted by biodegradation. The more easily biodegraded $C_{27}$ to $C_{29} \alpha \alpha \alpha R$ 's are reduced relative to the $C_{27}$ to $C_{29} \alpha \alpha \alpha S^{\prime}$ 's and the relative loss of $C_{30}$ to $C_{29}$ and the $C_{23}-$ $C_{25}$ tricyclics. Compounds identified in appendix 1. Chemical constituents: $\alpha \beta 29$ through $\alpha \beta 35$ (S \& R epimers), $\alpha \beta$-hopanes with carbon numbers; hopanes, $\mathrm{C}_{29}$ to $\mathrm{C}_{35^{\prime}}$ regular hopanes; $23 \mathrm{~T}, \mathrm{C}_{20}$ through $\mathrm{C}_{26^{\prime}}$ tricyclic terpanes; $\mathrm{nCx}$, normal alkane series; $\mathrm{Ph}$, phytane; $\mathrm{Pr}$, pristine; $S 8$, cyclic sulfur; Steranes, $C_{27}$ to $C_{29}$, regular steranes; T, triplet; Ts and Tm, defined in appendix 1; UCM, unresolved complex mixture; unk alk, unknown alkane, likely branched or cyclic. 
data from about the 10-m isobath to beyond the 3-nauticalmi limit of California's state waters. During the 2006 mapping mission, the original soundings were referenced to the mean lower low water (MLLW) tidal datum, but through post-processing using the National Oceanic and Atmospheric Administration (NOAA) VDATUM tool, the soundings were transformed to the NAVD 1988 vertical datum (geoid03). The soundings were gridded into 2-m-resolution bathymetric surface models and imported into a GIS software. All of the bathymetric surface models have been transformed to a common projection and datum, and the files were merged into one overall 2-m-resolution bathymetric surface model. An illumination with an azimuth of $300^{\circ}$ and $45^{\circ}$ above the horizon was then applied to the surface to create the shadedrelief maps.

\section{Miscellaneous Equipment}

Other equipment included a Benthos Stingray remotely operated vehicle (ROV) equipped with highdefinition video and still cameras, an in situ gas sampling apparatus, and a manipulator claw. The ROV operated in water depths of 20 to $80 \mathrm{~m}$. In 2010, water samples were collected near selected high-volume seeps with Niskin bottles destined for dissolved methane analysis. At the same time, atmospheric methane and carbon dioxide measurements were collected from ambient air near the bow of the R/V Parke Snavely, with real time analyses made by a Picarro G1301 cavity ringdown spectrometer.

\section{Sample Collection and Analyses}

From 2008 to 2010, we collected and analyzed samples from 106 production oils, offshore seep residues, and tarballs. The samples are listed in table 1 with accompanying metadata and chemical fingerprint data in its entirety. Production oils were sampled directly from sampling ports at their respective sites of production. We chose production-oil samples to insure a representative range of oils from the various reservoirs and pool depth produced by each platform (table 2). Seep asphalt or hydrocarbons were collected by a remotely operated vehicle (ROV) manipulator, typically as a grab sample, while being guided from the surface ship. Tarballs were collected by hand and then separated from sand with a clean knife. Floating oil sheen was collected on polypropylene oiladsorbent sheets. All samples were placed in commercially precleaned glass jars for transport to the laboratory. Samples were dissolved in dichloromethane (DCM), filtered through glass wool to remove particulates, and air-dried under a hood to remove the DCM. After filtration and removal of DCM, a portion of the clean extract was removed to determine bulk stable carbon isotope composition. The results are reported in table 1 in the $\delta$ notation in parts per thousand (\%) relative to the Pee Dee Belemnite (PDB) standard. Stable carbon isotope ratios of whole oil samples were determined by the combustion technique of Sofer (1980), using a Finnigan Delta E isotope ratio mass spectrometer.

A second portion of the extract $(\sim 25 \mathrm{mg})$ was dissolved as completely as possible by sonication and mechanical agitation in $5 \mathrm{ml}$ of hexane. Asphaltenes were removed from the oil or seep samples by precipitation using $n$-hexane. Saturated and aromatic hydrocarbon fractions were separated using gravity-flow column chromatography by elution with hexane and dichloromethane, respectively. This solution was then loaded onto a liquid chromatography column for compound class separation. Each column was layered at the bottom with about $5 \mathrm{~mm}$ of activated copper (to remove elemental sulfur) and with $2.5 \mathrm{~g}$ of $5 \%$ deactivated neutral alumina and $2.5 \mathrm{~g}$ and $5.0 \mathrm{~g}$ of 62 and 923 silica gels, respectively. The 100-200 mesh silica gel in the column was activated by heating to $400^{\circ} \mathrm{C}$ prior to use. Two separate fractions were collectedsaturate (hexane eluent) and aromatic (30\% dichloromethane and $70 \%$ hexane eluent).

Sterane and terpane biomarker analyses of the $\mathrm{C}_{15+}$ saturated hydrocarbon fraction were performed by split injection on a Hewlett-Packard (HP, now Agilent) 6890 gas chromatograph interfaced to a HP 5973 mass spectrometer. The HP-2 column (50 m x $0.2 \mathrm{~mm}$ (164 ft x $0.0078 \mathrm{in}$.); $0.11-\mu \mathrm{m}$ film thickness) was temperature programmed from $150^{\circ}$ to $325^{\circ} \mathrm{C}$ at $2^{\circ} \mathrm{C} / \mathrm{min}$. The mass spectrometer was run in selected ion mode, monitoring ion mass-to-charge ratios $(\mathrm{m} / \mathrm{z})$ of $177,191,205,217,218$, 221,231 , and 259. Response factors were determined by comparing the mass spectral response at $\mathrm{m} / \mathrm{z} 221$ for a deuterated (labeled with ${ }^{2} \mathrm{H}$, commonly abbreviated "d") standard (d4- $\mathrm{C}_{29}$ 20R sterane; Chiron Laboratories, Norway) to terpane ( $\mathrm{m} / \mathrm{z}$ $191)$ and sterane (m/z 217) authentic standards. Compound identifications were made either by comparison with known standards or with published reference spectra.

The $n$-alkanes and isoprenoids, and a suite of $\beta$-carotenoid-related compounds, were profiled with extracted ion (EI) chromatograms (m/z 57 and 125 , respectively, from the total ion chromatograph (TIC) chromatogram). Selected biomarker ratios, listed below, were calculated from GC/MS/SIM chromatograms of $\mathrm{m} / \mathrm{z} 191$ (terpanes/hopanes) and 217 (steranes) using peak heights. The 25,28,30-trisnorhopane $\left(\mathrm{T}_{177}\right)$ and the presence or absence of a 25-norhopane series was monitored by $\mathrm{m} / \mathrm{z}$ 177. Extracted ion profiles from TICs of the aliphatic and aromatic hydrocarbon fractions were used for the following ions: $\mathrm{m} / \mathrm{z} 253$ for monoaromatic steroids (M, summed from contributions in both the aromatic and aliphatic fractions), $\mathrm{m} / \mathrm{z} 231$ for triaromatic steroids (T), m/z 242 for monomethyl chrysenes $\mathrm{m} / \mathrm{z} 212$ and 206 for dimethyl-dibenzothiophenes and phenanthrenes, and $\mathrm{m} / \mathrm{z} 226$ and 220 for trimethyl-dibenzothiophenes and phenanthrenes, respectively. Either summed areas or peak heights (see appendix 1) of the compounds were used to determine the parameter ratios. The biomarker and isotope values were used to correlate the samples and group them according to their probable source locations. 


\section{Results and Discussion}

\section{Locating and Sampling Seeps-Remotely Operated Vehicle (ROV) and Ancillary Operations}

During 2008, 2009, and 2010, we utilized the ROV and new seafloor maps to locate and sample viscous seafloor hydrocarbon deposits, mainly biodegraded oil residues and some hydrocarbon gas. The purpose of this effort was to document the existence of seeps in previously unknown areas and to expand the range of seeps included in the biomarker library. Table 3 lists the location and description of the samples. The sampled seeps are located in the north margin of the Santa Barbara Channel from near Point Conception to offshore Santa Barbara Point. Figure 5 shows some of the many seeps encountered, often biodegraded asphalt-like mounds, and some aspects of ROV operations. During cruise S-13-SC-10 (June 2010), ancillary methane concentration measurements were collected from ambient air near the bow of the R/V Parke Snavely, and water samples were collected near selected high-volume seeps. The atmospheric methane and carbon dioxide data in figure 6 clearly show that methane and carbon dioxide concentration spikes near seep sites and that, overall, seeps maintain a slightly higher concentration near the coast relative to regional atmospheric average values (1.85 and 380 ppm for methane and carbon dioxide, respectively; Bradley and others, 2010).

\section{Seeps in the Santa Barbara Basin}

The offshore Santa Barbara Basin contains two types of hydrocarbon seeps in surficial marine sediments and the water column: active and passive (Saenz, 2002). Active seeps emit hydrocarbon gas and oil manifested as pockmarks, small craters, and reef-building asphalt mounds. These hydrocarbon seeps presumably occur, where generation and migration of hydrocarbons from source rocks are ongoing today and where migration pathways have developed along structural conduits through the overlying sediments of late Neogene and Quaternary age. Primary controls for the location and distribution of hydrocarbons in near-surface sediments are active faults and eroded or fractured anticlinal folds.

Active seeps in the study area were detected near the water-sediment interface and within the water column using a variety of geophysical methods. Numerous water-column anomalies were observed on seismic reflection profiles and side-scan sonar records. As illustrated by Saenz (2002), watercolumn anomalies are present as small, discrete $\mathrm{V}$-shaped plumes, zones of plumes, and large diffuse zones. Water-column anomalies represent the seismic response of gas bubbles rising and expanding in the water column. These plumes are identical to those mapped by Fischer and Stevenson (1973), Fischer (1976), and other workers off Coal Oil Point and Goleta Point in the Santa Barbara Basin. In the Coal Oil Point area, the rising gas and oil are visible on the sea surface and have been collected, analyzed $\left(\mathrm{C}_{1}-\mathrm{C}_{20}\right)$, and mapped using an experimental sniffer system (P.J. Fischer, unpub. data, 1976; Sigalove, 1985; Saenz, 2002). Our studies conducted in the area during 2002 (Lorenson and others, 2009) recorded elevated methane from the seeps within the Santa Barbara Channel moving westward with the currents as described by Mau and others (2007) and Clark and others (2000). The use of water-column gas discharge has evolved over the course of this study from merely seep detection to attempts to quantify gas and oil discharge remotely.

\section{Seeps in the Northwestern Santa Barbara Basin}

In the northwestern Santa Barbara Basin, asphalt mounds and coalescing mounds are present on the seafloor (Vernon and Slater, 1963; Saenz, 2002; Lorenson and others, 2009). These mounds are irregularly distributed along an east-westtrending, faulted anticline offshore Point Conception and overlie exposed Monterey Formation seafloor outcrops. Extensive areas of active seepage have been located by sidescan sonar imagery and multibeam bathymetry and sampled by a ROV. Tar accumulations are most abundant near Point Conception, where sheets of tar cover large areas and are accompanied by minor gas flux. Individual mounds are typically 10 to $100 \mathrm{~m}$ in diameter and no more than $2.5 \mathrm{~m}$ high and have concentric flows of asphalt extruding from the center. Occasionally, the pronounced viscous extrusion of asphaltic oil forming near the center of an active mound produces whip-like extrusions (fig. $5 E$ ) that can break off and float to local beaches or remain attached and become incorporated into the mound. Regionally, coalescing asphalt-mound accumulations are as much as $18 \mathrm{~m}$ thick and completely cover an estimated area of 8.4 $\mathrm{km}^{2}$ (Draut and others, 2009). The volume of extruded asphalt is estimated to be about $27 \mathrm{M} \mathrm{m}^{3}$ or the equivalent volume of 170 million barrels of oil. Older areas of asphalt extrusion are heavily colonized by marine invertebrates and resemble reef communities found on submarine rock outcrops. Adjacent sand-covered areas support fewer invertebrates and fish. Offshore Point Arguello, several distinctive, mound-like seafloor features appear on the geophysical records. In this area, interpreted gas seeps seen as water-column anomalies are also associated with tar mounds (Saenz, 2002). As observed, on subbottom and side-scan sonar records, these mounds are gently rounded and have a vertical relief of 1-5 m (Saenz, 2002).

\section{Seeps Near Coal Oil Point}

We sampled numerous offshore seeps around Coal Oil Point (fig. 7), one of the most prolific seep fields in the world (Landes, 1973). Oils from these seeps are mainly less dense and geochemically distinct from that near Point Conception. These perennial and continuous oil and gas seeps have been active for at least 500,000 years (Boles and others, 2004). 

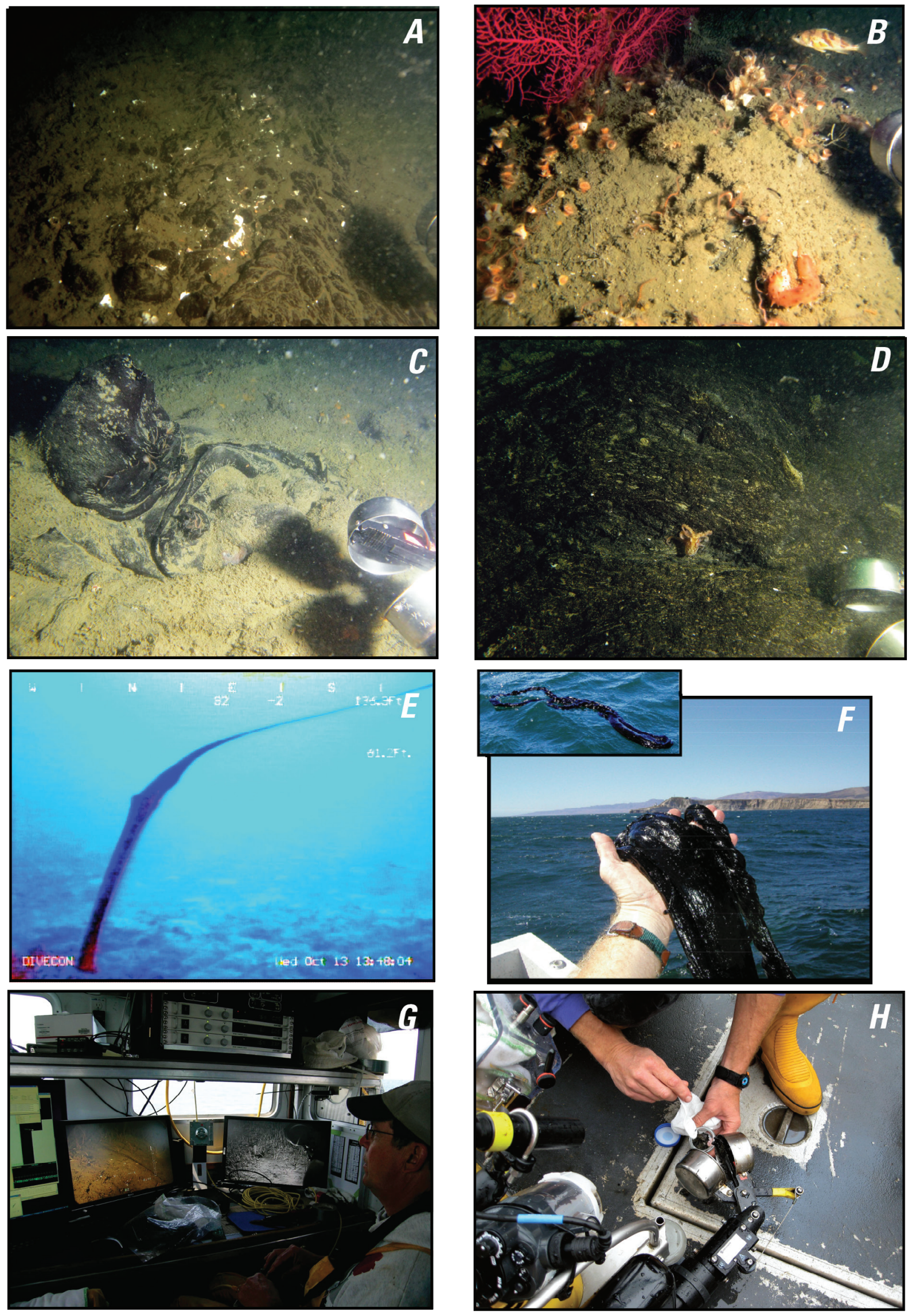
Prior to written history, the native Chumash Indians used asphalt found on Coal Oil Point beaches and elsewhere to caulk their canoes, as well as for many other uses (Galloway, 1998a). Between the 16th and 18th centuries, several European explorers noted the presence of petroleum oil slicks and surfacing bubbles offshore modern Santa Barbara County. Asphalt mining flourished within Santa Barbara County during the mid-1800s, and its products were used to pave the first streets of San Francisco and Santa Barbara (Galloway, 1998a). During the 1920s and 1930s, the Ellwood Oil Field, located west of Coal Oil Point, was developed on the coastline and in shallow waters from more than 16 oil piers (Bartlett, 1998). During the next three decades, wells were drilled at Coal Oil Point from piers and submarine platforms. Production of the South Ellwood Offshore Oil Field in State waters began in 1967 with the construction of Platform Holly (Galloway, 1998a) and continues today. The wells at the east and west extents of the original Ellwood Oil Field were abandoned by 1971 and 1993, respectively (Bartlett, 1998). In the Coal Oil Point seep field, the reservoir in the Monterey Formation is overlain by the relatively impermeable Sisquoc Formation, which forms a cap rock for hydrocarbon accumulation. Hydrocarbons migrate from subsurface accumulations to the seabed by pathways, such as faults, fractures, joints, bedding planes, and outcrops (Boles and Horner, 2009; Fischer, 1977).

The subsurface structure of the field was interpreted in the mid-1980s utilizing 1983-vintage 2-D and 3-D seismic data. Integrated geologic studies continued in the early 1990s based on the original structural interpretation. Venoco, Inc., acquired the South Ellwood Offshore Oil Field in 1997 and initiated a modern reservoir characterization study of the field (Horner and Ershaghi, 2002). The earlier 3-D seismic data (Christensen and others, 2000; Kamerling and others, 2003) was reprocessed and reinterpreted by including reservoir production and pressure data. This allowed construction of a new, 3-D geologic model incorporating the new seismic interpretation, as well as logs, dipmeter, core, and outcrop information (Christensen and others, 2000; Kamerling and others, 2003). Liefer and others (2010) investigated the relation between geology and seepage by constructing a subsurface geologic model (fig. 8), using data from a 3-D seismic survey, 2-D seismic reflection lines, surface geology, and 168 wells, and comparing it to high-resolutionsonar seepage maps. The major geologic structures are two approximately northwest to southeast-trending anticlines separated by a syncline that is faulted on both flanks. The colocation of the farthest offshore seepage distribution with the South Ellwood Anticline crest suggests that folding of the oil-bearing Monterey and Sisquoc Formations plays a dominant role in controlling seepage in this area.

Detailed migration pathways to the seafloor at Coal Oil Point can be inferred from the high-resolution mapping of both the subsurface geology and the seep vents. Recharge of the hydrocarbon reservoir in the South Ellwood Anticline occurs through updip migration along bedding planes primarily from the deeper Monterey Formation to the south (Ogle and others, 1987). Recharge also occurs from the east and west - the Coal Oil Point seep field is at an east-west fold crest of the Monterey Formation (Ogle and others, 1987). As a result, along-coast migration likely occurs along both syncline and anticline axes, allowing recharge to occur (Leifer and others, 2010).

4 Figure 5. Photographs of offshore seeps and related ROV operations. A, Viscous asphalt, sediment, and shell fragments extruding from small mounds near the outfall of the Goleta sewage line. Water depth is about $40 \mathrm{~m}$; the field of view is about $30 \times 25 \mathrm{~cm}$. Sample 10-159. B, A gas seep issuing from a sediment-covered, invertebrate-colonized asphalt mound south of Santa Barbara at $75 \mathrm{~m}$ depth where the asphalt mounds coalesce into features as large as $80 \mathrm{~m}$ diameter and $3 \mathrm{~m}$ relief. Larger mounds are found elsewhere in the Santa Barbara Channel offshore Point Conception and on the mid-channel high. The size of the red Gorgonian coral and the multitude of solitary cup corals implies the feature is decades old. Field of view is about $50 \times 40 \mathrm{~cm}$. C, An example of extruding asphalt offshore Point Conception in water depth of $48 \mathrm{~m}$. Similar extrusions occur south of Coal Oil Point but are much less extensive than those found near Point Conception. The morphology suggests viscous flow. Sediment covers this recent flow and the flanks are in the process of colonization by invertebrates. Field of view is about $30 \times 25 \mathrm{~cm}$. D, An example of viscous asphalt extrusion near Point Conception at $35 \mathrm{~m}$ depth. Similar extrusions occur south of Coal Oil Point but are much less extensive than those found near Point Conception. The gas content in this flow inferred by the vesicular texture is greater than that shown in photo $5 \mathrm{C}$. The small octopus represents the variety of sea life that frequents the asphalt flows. Field of view is about $35 \times 30 \mathrm{~cm}$. $\boldsymbol{E}$, An example of viscous asphalt extrusion or "tar whip" south of Point Conception in $40 \mathrm{~m}$ water depth. Field of view is approximately $20 \mathrm{~m}$ and length of extrusion is about $4 \mathrm{~m}$. Some tar whips are buoyant enough to break free, rise to the surface, and float as shown in the inset of photo $5 F$. F, Examples of floating tar whips. Inset photo illutrates a floating tarwhip. The hand-held tar whip illustrates the spongy, taffy-like nature of the extruded, biodegraded oil. Occasionally tar whips can be found on local beaches, but more often smaller portions of this material reach the beach and are manifest as plate-like tarballs. Point Conception is in the background. G, ROV pilot Jonathan Borden maneuvering the Benthos Stringray ROV along the ocean floor. The twin monitors display the live images from the two video cameras mounted on the ROV. $\boldsymbol{H}$, Collecting an asphalt sample from the ROV claw. The ROV (partly visible at lower left) used to sample natural seeps is equipped with camera, video camera, and gas and oil sampling equipment. 

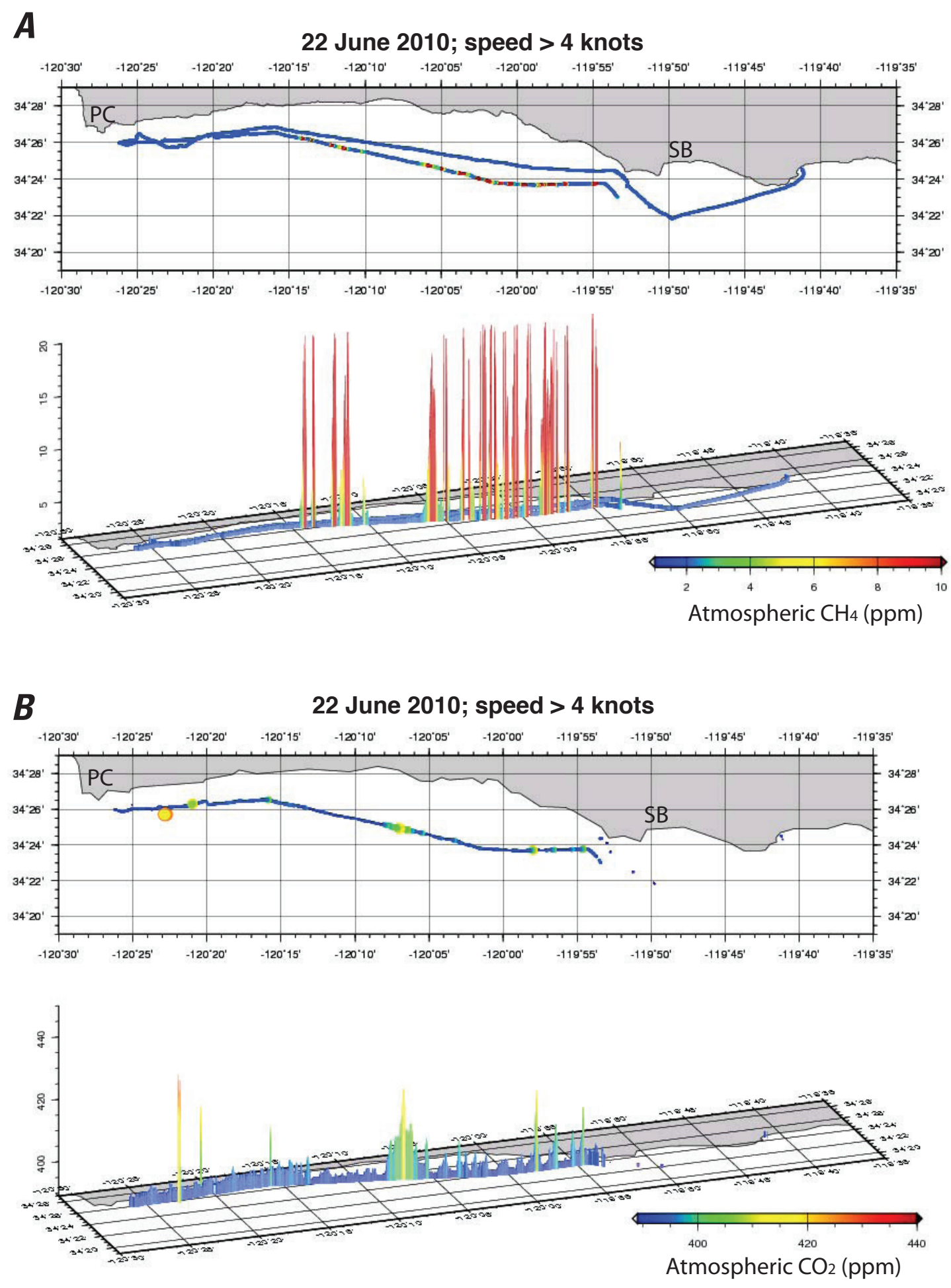

Figure 6. Maps of methane and carbon dioxide anomalies in the atmosphere approximately $2 \mathrm{~m}$ above sea level between Point Conception (PC) and Santa Barbara (SB). A, Map track of data and graph of methane concentration, similar for B. $B$, Carbon dioxide concentration. Background atmospheric values are approximately 1.85 and $385 \mathrm{ppm}$ respectively. Both methane and carbon dioxide anomalies correspond with gas-seep areas transited along the north margin of the Santa Barbara Channel, demonstrating that seeps are sources for these gases in the atmosphere and showing that this tool could be effective in locating seeps elsewhere. The anomalies have yet to be modeled to derive gas flux from the seeps. 
Significant seepage occurs near the crest of the South Ellwood Anticline (offshore seeps) and within the hanging wall of a reverse fault, where the reservoir and capping formations are deformed but without obvious faulting (inshore seeps). Of the two major mapped seep areas, the area farther offshore shows a clearly defined first-order relation between a faulted anticline and seepage locations. However, the inshore seep area does not show an obvious relation with structure other than being located in the hanging wall of a major reverse fault. Leifer and others (2010) suggest seepage here is controlled by critically stressed fractures (Finkbeiner and others, 1997) in the hanging wall of the west-trending Red Mountain and Coal Oil Point Faults. The mapped structures alone do not explain the spatial distribution of the seepage; some of the high permeability pathways at Coal Oil Point are below the resolution of the geologic model.

\section{Seeps of the Dos Cuadros Oil Field}

Platforms A, B, C, and Hillhouse of the Dos Cuadros field are positioned over the crest of a dome with 4-way closure on the regional Rincon anticlinal trend. Before drilling commenced in 1968, natural seepage was documented
(Fisher, 1977; Yerkes and others, 1969). In January 1969, while drilling wells from Platform A, a blowout occurred that resulted in an oil spill and extensive environmental damage to the coastline. During the attempts to stop flow, oil and gas circumvented the conductor casing and began seeping into the ocean hundreds of meters from the well. Seepage of oil continues in this area, and it is unknown whether the current seepage is natural, the result of the blowout, or both. Chemometric analyses of the oil collected at the surface are from the same oil family as the produced oils from Platform A (Lorenson and others, 2009).

\section{Biomarker Analyses and Chemometric Modeling}

The 106 samples in this study were analyzed by our chemometric model resulting in positively classifying all production oil samples, 97 percent of tarballs, and 48 percent of seafloor seep samples. Seafloor seep samples are composed of viscous, often highly biodegraded hydrocarbon residues.

Many of the biomarkers needed for data input into the model are absent and thus the seafloor seep tars or asphalts could not be positively classified by our model 52 percent of the time

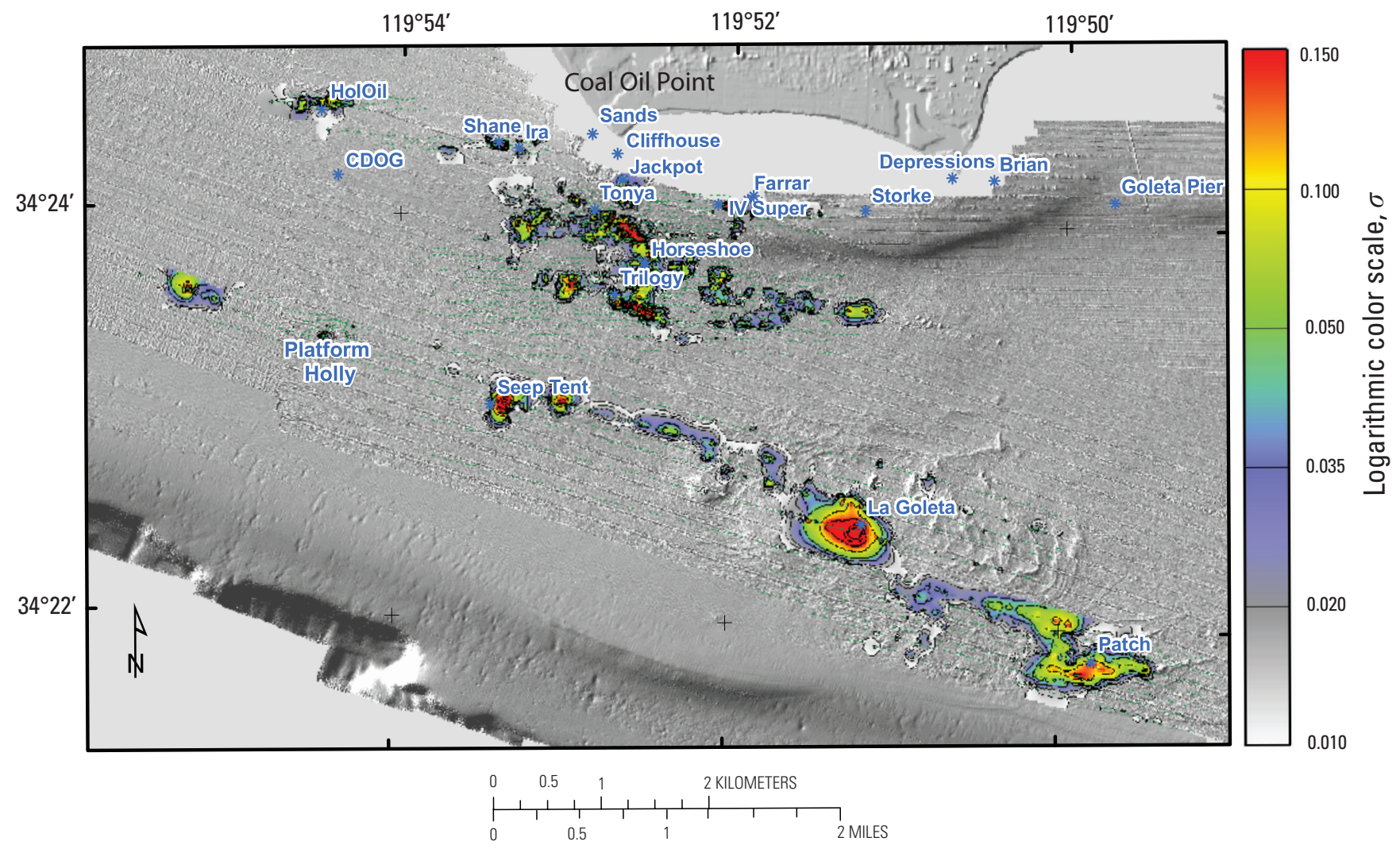

Figure 7. Water-column, bottom-bounce, normalized-sonar-return amplitude $(\sigma$, logarithmic color scale) map of Coal Oil Point gas plumes. Informal names of seep areas are shown. Offshore seep trend surveyed September 2005; inshore seep trend surveyed July 2006. From Leifer and others (2010). 


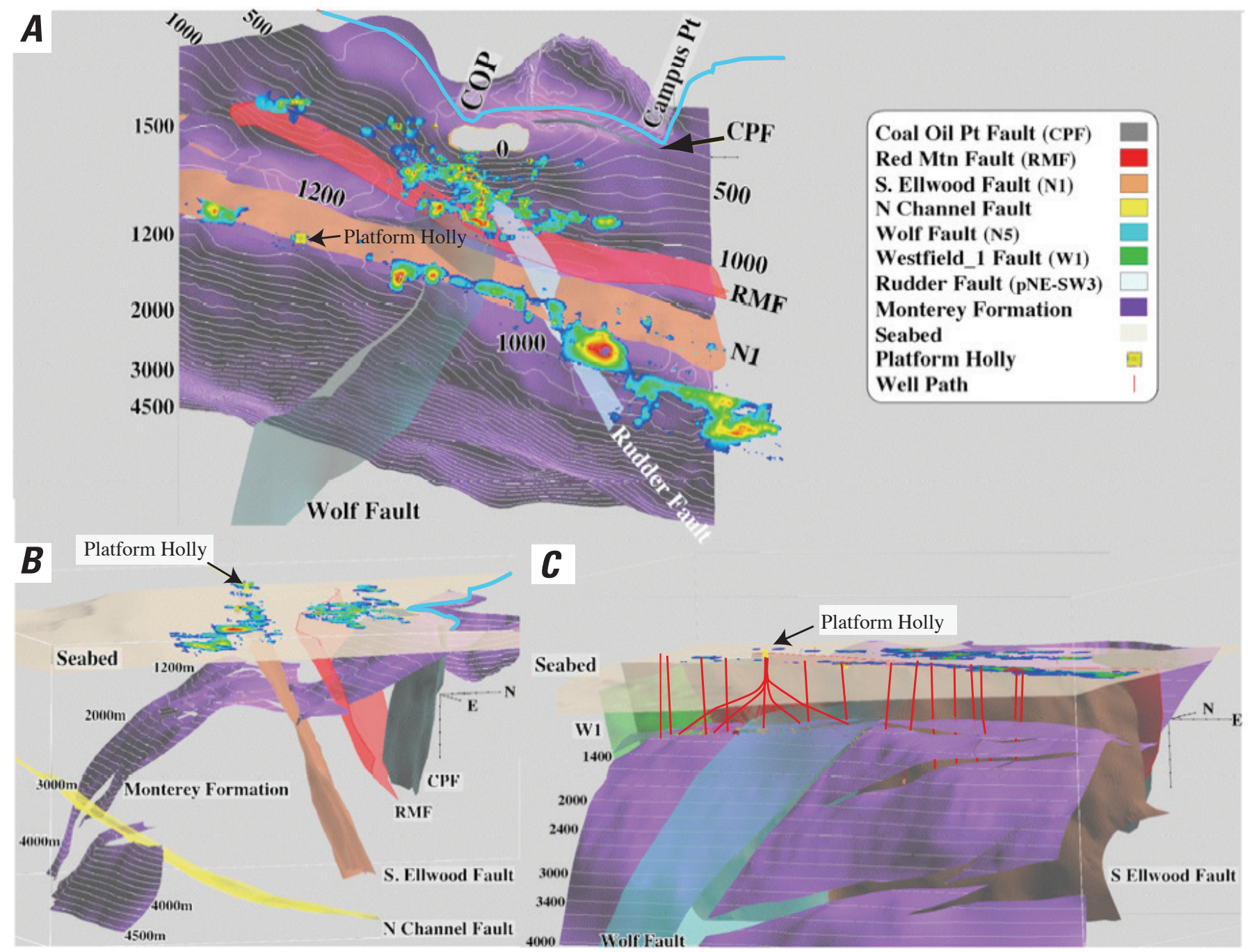

Figure 8. Coal Oil Point (COP) seep field and underlying geologic structure showing the Monterey Formation, the seep-gas spatial distribution (ranging from red for strong emission to blue for weak; see fig.7) at seabed, and subsurface areas of major faults. Not all faults shown. $A$, Map view. $B$, View toward west-northwest with partially transparent seabed and labeled faults. $C$ Oblique northward view showing wells (red lines). Monterey Formation depth contours are $100 \mathrm{~m}$ on $A$ and $C$. Fault codes are from Venoco, Inc.; Platform Holly is operated by Venoco, Inc. From Leifer and others (2010).

Figure 9. Two-way heirarchical cluster diagram of produced oils from offshore platforms and selected onshore oil fields adjacent to the study area. The samples are divided into tribes 1 and 2 as indicated by the red and green lettering. Oil samples are given by sample number, the model-classified family, and the sample description. The 19 biomarker ratios used in this study are noted on the bottom of the column, and the definitions can be found in appendix 1. Each biomarker ratio has an auto-scaled range of values symbolized by the colors blue (low) to red (high). Similarities between samples are easily seen by similar colors; samples differing by greater values are seen by highly contrasting colors. The tielines on the right corrrespond to cluster distance, a measure of genetic smimilarity indicated by the horizontal difference from any two samples on the left to their branch point on the right. 
Two-way HCA Produced Oil Chemometric Classification

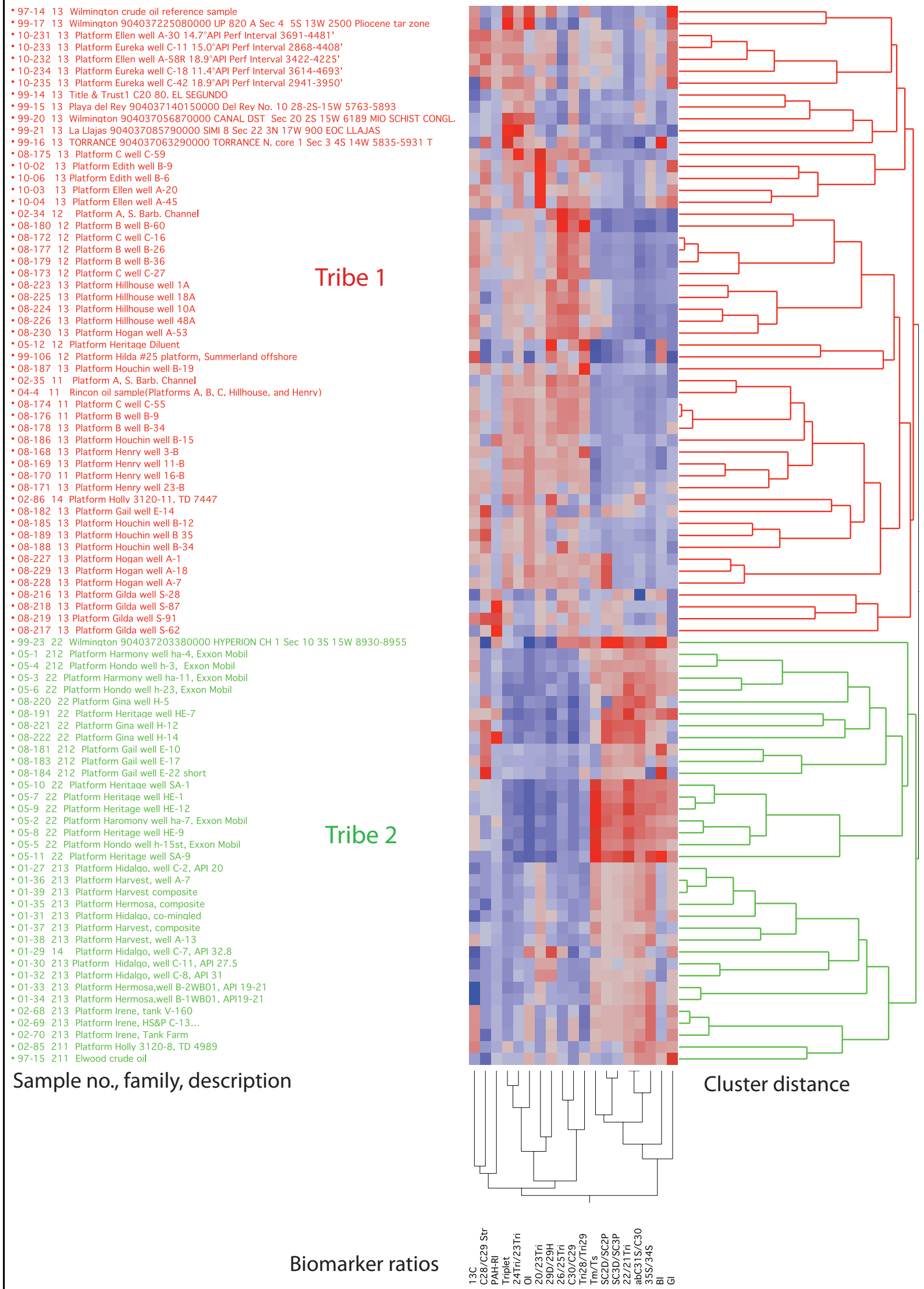




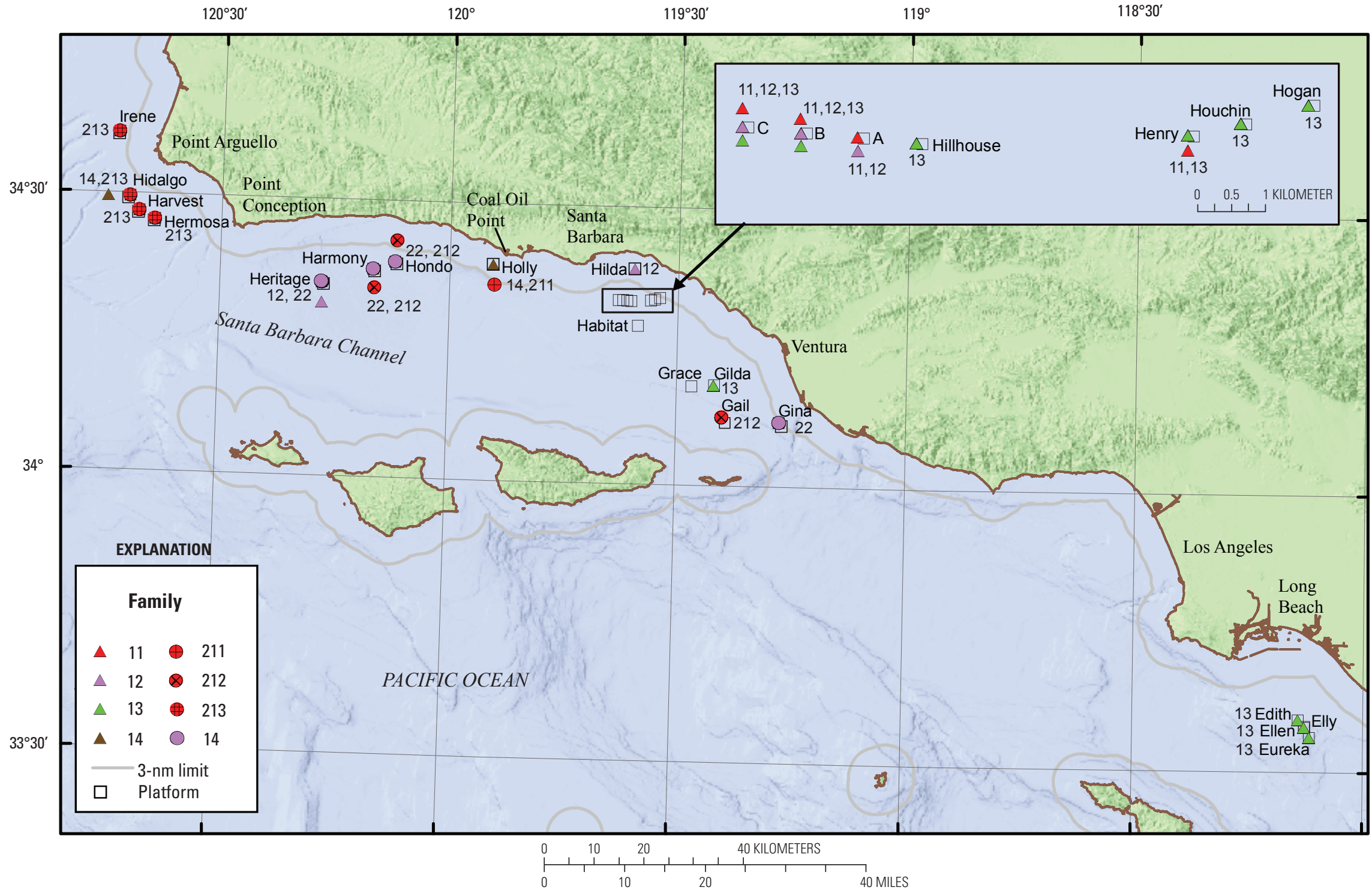

Figure 10. Summary map of produced oils classified by oil family collected from operating outer contintental shelf platforms, state platforms, and selected shut-in platforms. All produced oils are variants of tribe 1 or 2 , with a preponderance of tribe 1 oils east of Coal Oil Point and tribe 2 oils west of Coal Oil Point. 


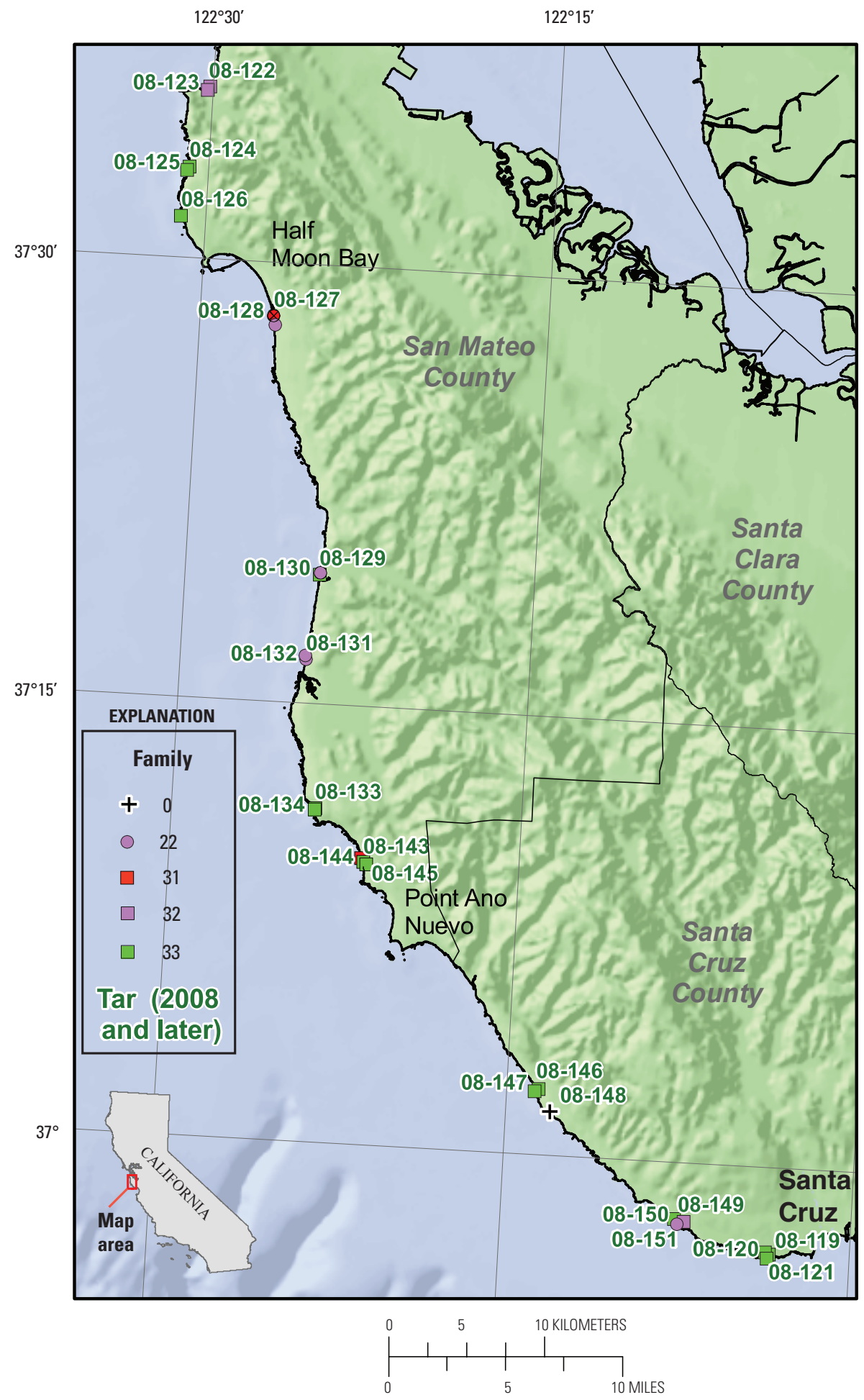

Figure 11. Map showing samples with sample numbers, classified by oil family, that were collected in February 2008 after a winter storm with sustained southerly winds deposited tarballs on the central California coastline between Half Moon Bay and Santa Cruz. The family distribution is primarily from tribe 3, a tribe derived from currently unlocated seep sources thought to occur well north of Point Conception. The remaining samples were from tribe 2 and were thought to have made the transit from the Santa Barbara Channel area to these beaches. Oil, seep, and tarball tribes and families are described in text. 


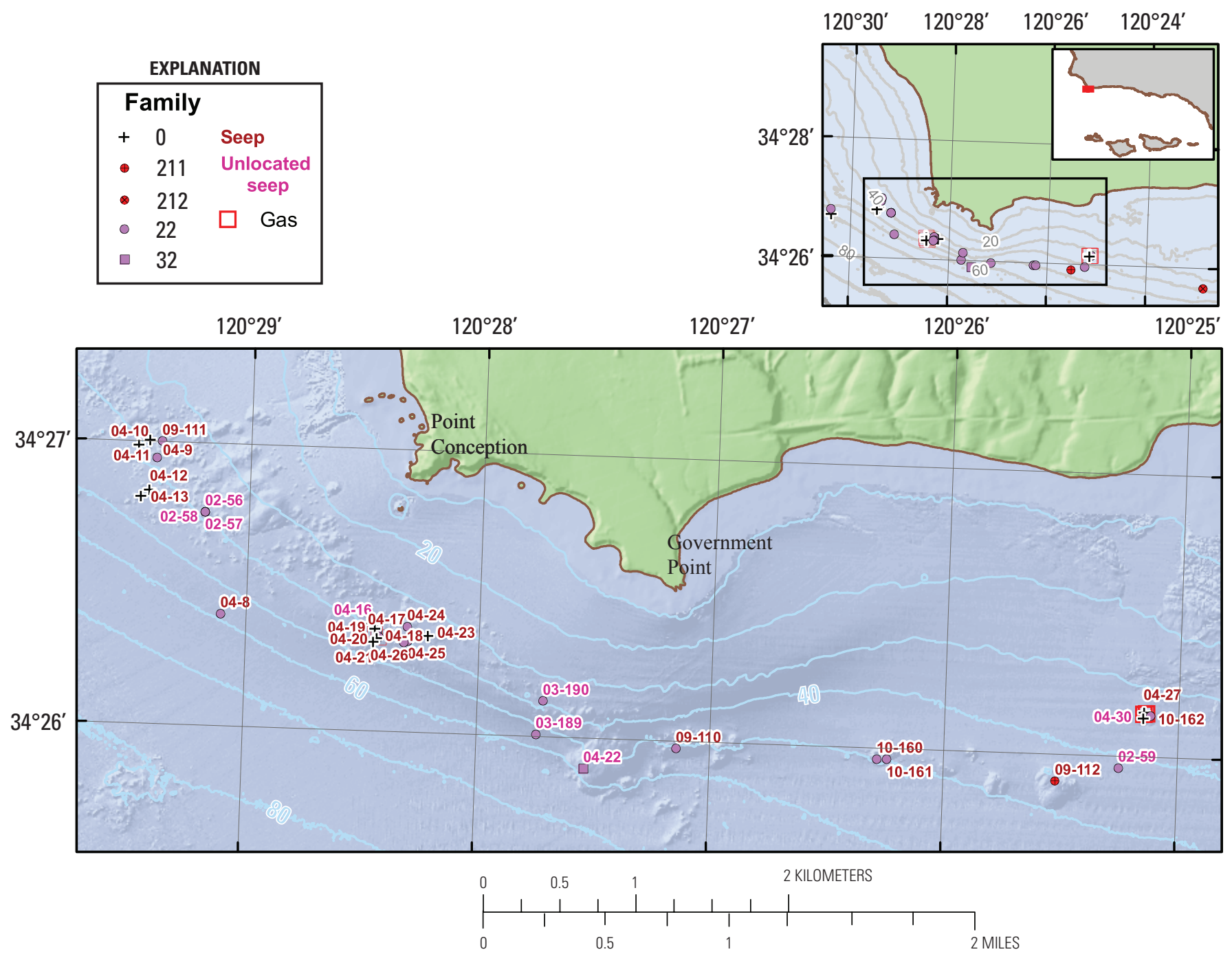

Figure 12. Map showing seep samples, classified by oil family, collected 2004-2010 in the vicinity of Point Conception. The shaded seafloor bathymetry clearly shows the extent and distribution of asphalt mounds on the seafloor, mainly trending northwest along the crest of an anticline straddling Point Conception and Government Point (not shown). More eastern asphalt mounds, designated by samples 10-160 and east to 10-162, are on trend with an unnamed normal fault (not shown). Gas samples were taken from the seep along with sample 04-27. Oil, seep, and tarball tribes and families are described in text; color of lab-sample number corresponds to type of sample (for example, seep, unlocated seep). Sample numbers correspond to biomarker data listed in table 1 . Contour interval is $10 \mathrm{~m}$. 

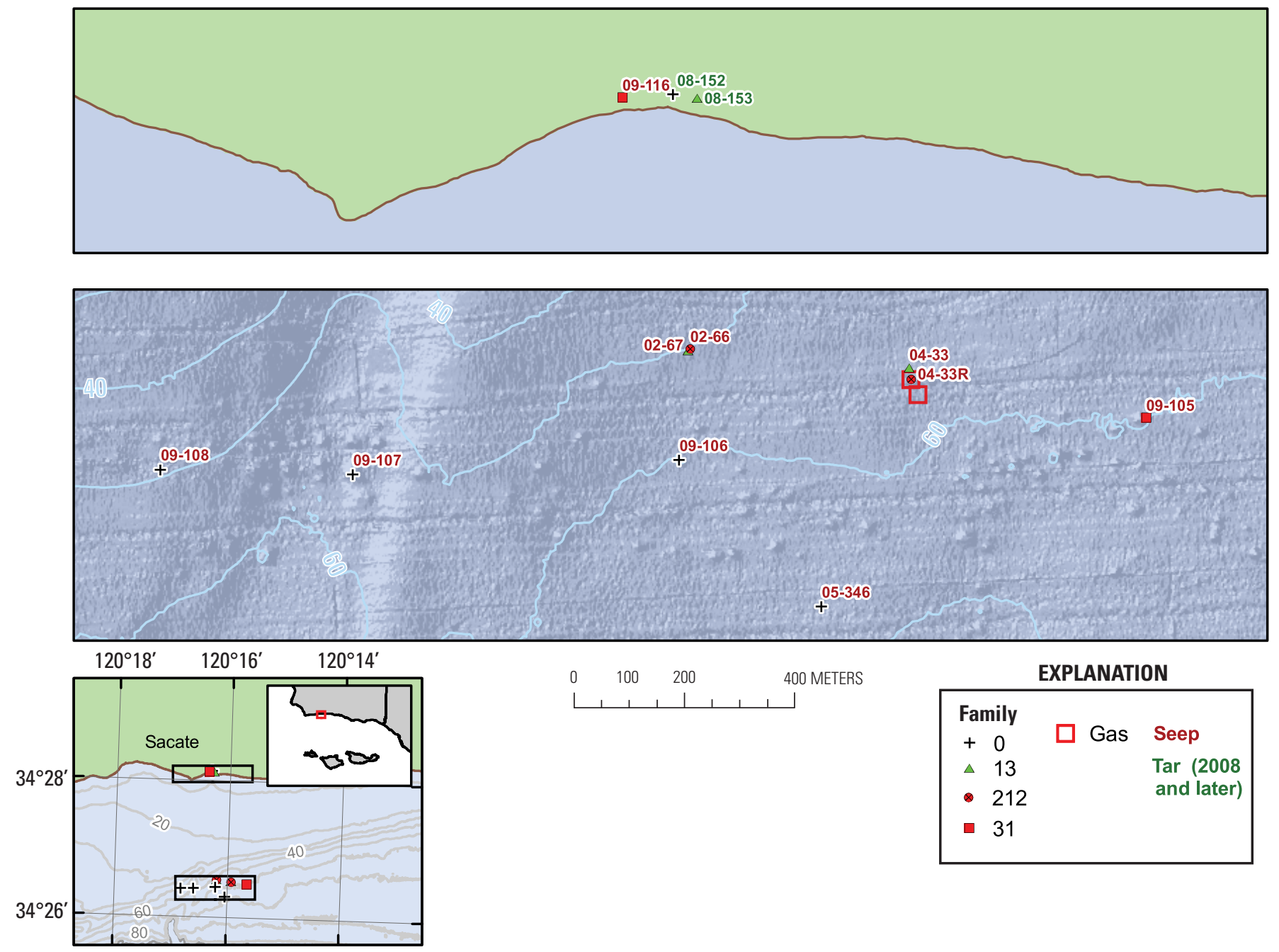

Figure 13. Maps showing samples, classified by oil family, collected in the vicinity of Sacate beach. Seep and tarball tribes and families are described in text; color of lab sample number corresponds to type of sample (for example, seep, tar). Seep samples taken from 2004 to 2010 are shown. Sample numbers correspond to biomarker data listed in table 1. The shaded seafloor bathymetry clearly shows the extent and distribution of asphalt mounds, mainly on trend with east-west folds. The seep field is located just north of the Alegria offshore oilfield (not shown). Gas samples were taken from the seep along with sample 04-33R. Contour interval is $10 \mathrm{~m}$. 
EXPLANATION

\begin{tabular}{|c|c|c|}
\hline \multicolumn{3}{|l|}{ Family } \\
\hline+0 & $\square$ Gas & Oil \\
\hline$\Delta \quad 11$ & $\square$ Water & Seep \\
\hline$\triangle 12$ & & Unlocated \\
\hline$\triangle 13$ & & \\
\hline$\triangle 14$ & & \\
\hline - 211 & & \\
\hline - 22 & & \\
\hline ㅁ 31 & & \\
\hline
\end{tabular}
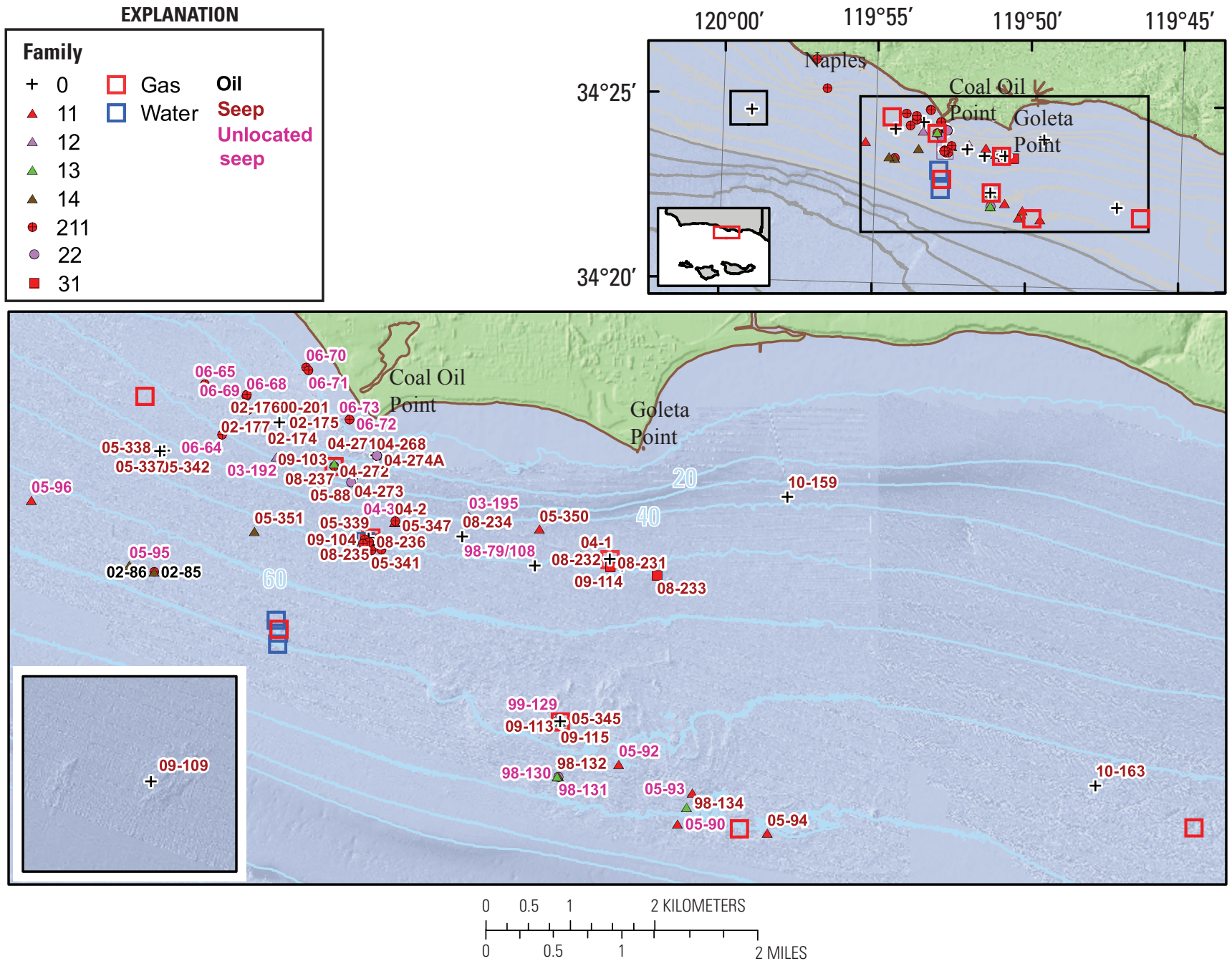

Figure 14. Maps showing location of samples, classified by oil family, collected in the vicinity of Coal Oil Point. The shaded seafloor bathymetry clearly shows the distribution of seeps, mainly on trend with the crest of two folds described in the text. Seep samples were collected during 1998 to 2010. Gas and water samples were collected from seeps in several locations. Inset map at lower left shows location of seep sample 09-109, located on an asphalt mound complex south of Naples beach. Tribes and families are described in text; color of lab sample number corresponds to type of sample (for example, oil, seep, unlocated seep). Sample numbers correspond to biomarker data listed in table 1. Contour interval is $10 \mathrm{~m}$. 


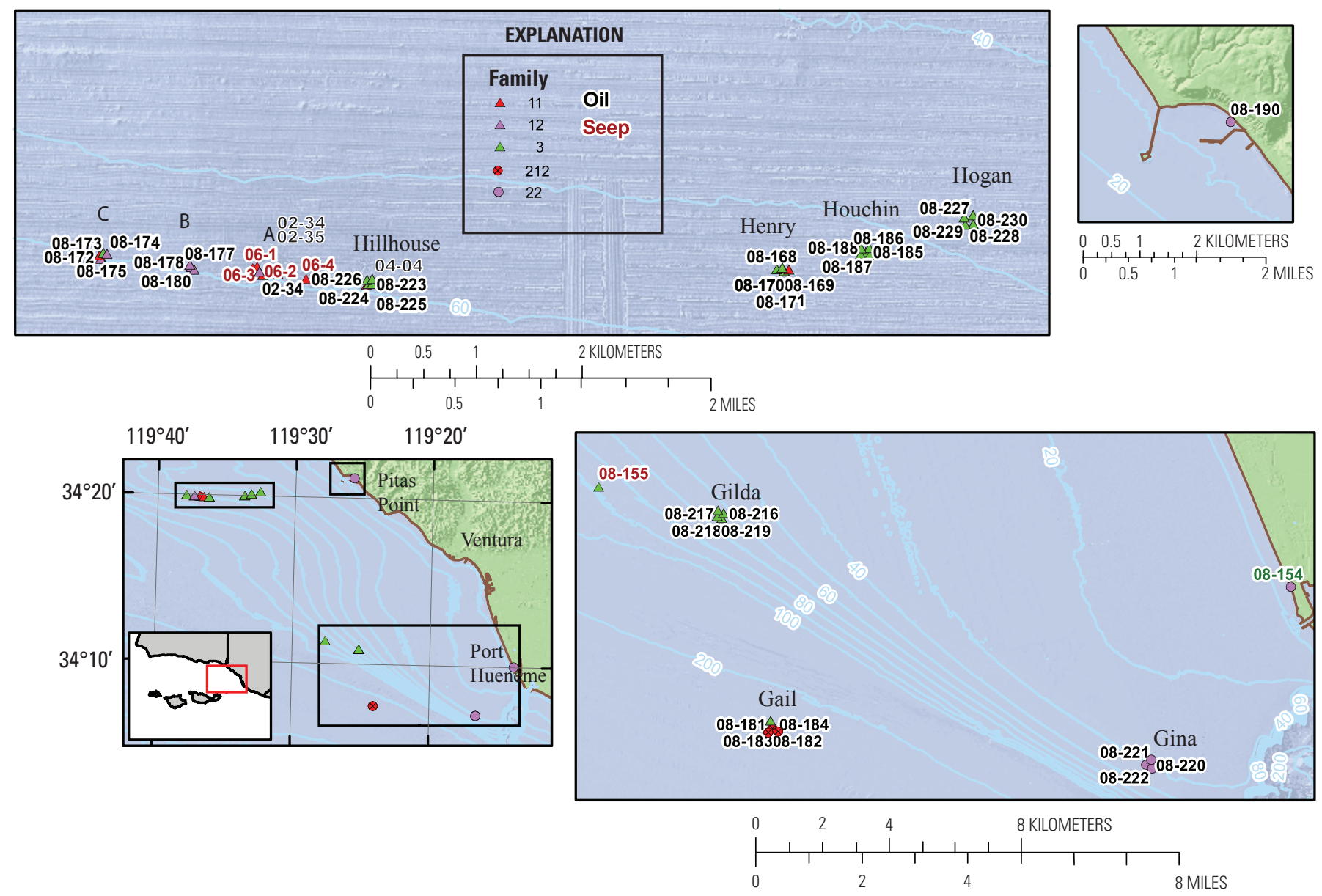

Figure 15. Maps showing locations of samples, classified by oil family, collected from operating platforms south of Santa Barbara. Upper left, from west to east: Platforms $C, B$, A, Hillhouse, Hogan, Henry, and Houchin. Lower right, from west to east: Gilda, Gail, and Gina. Upper right shows the location of a tarball analyzed at the request of the public. Most produced oil is from tribe 1, and a much smaller proportion is classified as tribe 2 . 
and assigned to family 0 (table 4). Based on these results, we feel confident that the original model is robust for classifying oil or tarball samples originating from California and can be applied to this study.

In this study, all of the produced platform oils are compared with those of previously analyzed southern California oils listed in figure 9, which shows a two-way heirarchical cluster diagram of produced oils from offshore platforms and selected onshore oil fields adjacent to the study area. Similarities between samples are easily seen by similar colors. Produced oils from only tribes 1 and 2 are present and, typically, oils from the same platform are most similar. Figure 10 shows a summary map of produced oils, classified by oil family, collected from operating OCS platforms, state platforms, and selected shut-in wells from decommissioned platforms. Table 2 lists all of the oils collected for this study. All produced oils are variants of tribe 1 or 2; a preponderance of tribe 1 oils east of Coal Oil Point and tribe 2 oils west of Coal Oil Point imply different depositional histories of the Monterey Formation source rock in each region. The same general pattern exists with seep hydrocarbons and previously analyzed tarballs. Figures 11 through 16 show the distribution of samples by the chemometric-model results in local context. Sample numbers and other metadata can be referenced in table 1. Table 3 includes all seeps, oils, and tarballs classified during our study. As in the previous study
(Lorenson and others, 2009), the majority of the seep samples are in tribe 2 followed by tribe 1 , with very little in tribe 3 .

\section{Biomarkers}

The biomarker parameters used in the chemometric model are described in Hostettler and others (2004) and Peters and others $(2005,2008)$ and include 14 terpane ratios: 22,29,30-trisnorneohopane/22,29,30-trisnorhopane (Ts/Tm); $\mathrm{C}_{26} 22 \mathrm{~S}$ and $22 \mathrm{R}$ tricyclic terpanes/ $\mathrm{C}_{24}$ tetracyclic terpane $\left(\mathrm{C}_{26} / \mathrm{Tet}\right) ; \mathrm{C}_{20} / \mathrm{C}_{23} ; \mathrm{C}_{22} / \mathrm{C}_{21} ; \mathrm{C}_{24} / \mathrm{C}_{23} ; \mathrm{C}_{26} / \mathrm{C}_{25} ; \mathrm{C}_{28} / \mathrm{C}_{29}$ tricyclic terpanes $\left(\mathrm{C}_{20} / \mathrm{C}_{23} \mathrm{TT}, \mathrm{C}_{22} / \mathrm{C}_{21} \mathrm{TT}, \mathrm{C}_{24} / \mathrm{C}_{23} \mathrm{TT}, \mathrm{C}_{26} / \mathrm{C}_{25} \mathrm{TT}\right.$, and $\mathrm{C}_{28} / \mathrm{C}_{29} \mathrm{TT}$, respectively); 17a, $21 \beta(\mathrm{H})$-30-norhopane/ hopane $\left(\mathrm{C}_{29} \mathrm{H} / \mathrm{H}\right) ; \alpha \mathrm{C}_{31} 22 \mathrm{~S} /$ hopane $\left(\mathrm{C}_{31} \mathrm{~S} / \mathrm{H}\right) ; \mathrm{C}_{35} 22 \mathrm{~S} / \mathrm{C}_{34} 22 \mathrm{~S}$ hopanes $\left(\mathrm{C}_{35} / \mathrm{C}_{34} \mathrm{~S}\right) ; 28,30$-bisnorhopane/hopane $(\mathrm{BNH} / \mathrm{H})$; oleanane/hopane $(\mathrm{Ol} / \mathrm{H})$; gammacerane/hopane $(\mathrm{G} / \mathrm{H})$; and 18a-30-norneohopane/a $\beta$-30-norhopane $\left(\mathrm{C}_{29} \mathrm{Ts}_{\mathrm{s}} / \mathrm{C}_{29} \mathrm{H}\right)$. Other parameters include the whole-oil stable carbon isotope ratio $\left(\mathrm{d}^{13} \mathrm{C}_{\mathrm{PDB}}\right) ; \mathrm{C}_{28} / \mathrm{C}_{29}$ aad $20 \mathrm{R}$ steranes; three aromatic compound ratios - polycyclic aromatic hydrocarbon refractory index (PAH-RI; Hostettler and others, 1999), dimethyldibenzothiophene/dimethylphenanthrene (SC2D/2P); and trimethylbenzothiophene/trimethylphenanthrene (SC3D/3P). The group of parameters includes bulk carbon isotope analyses

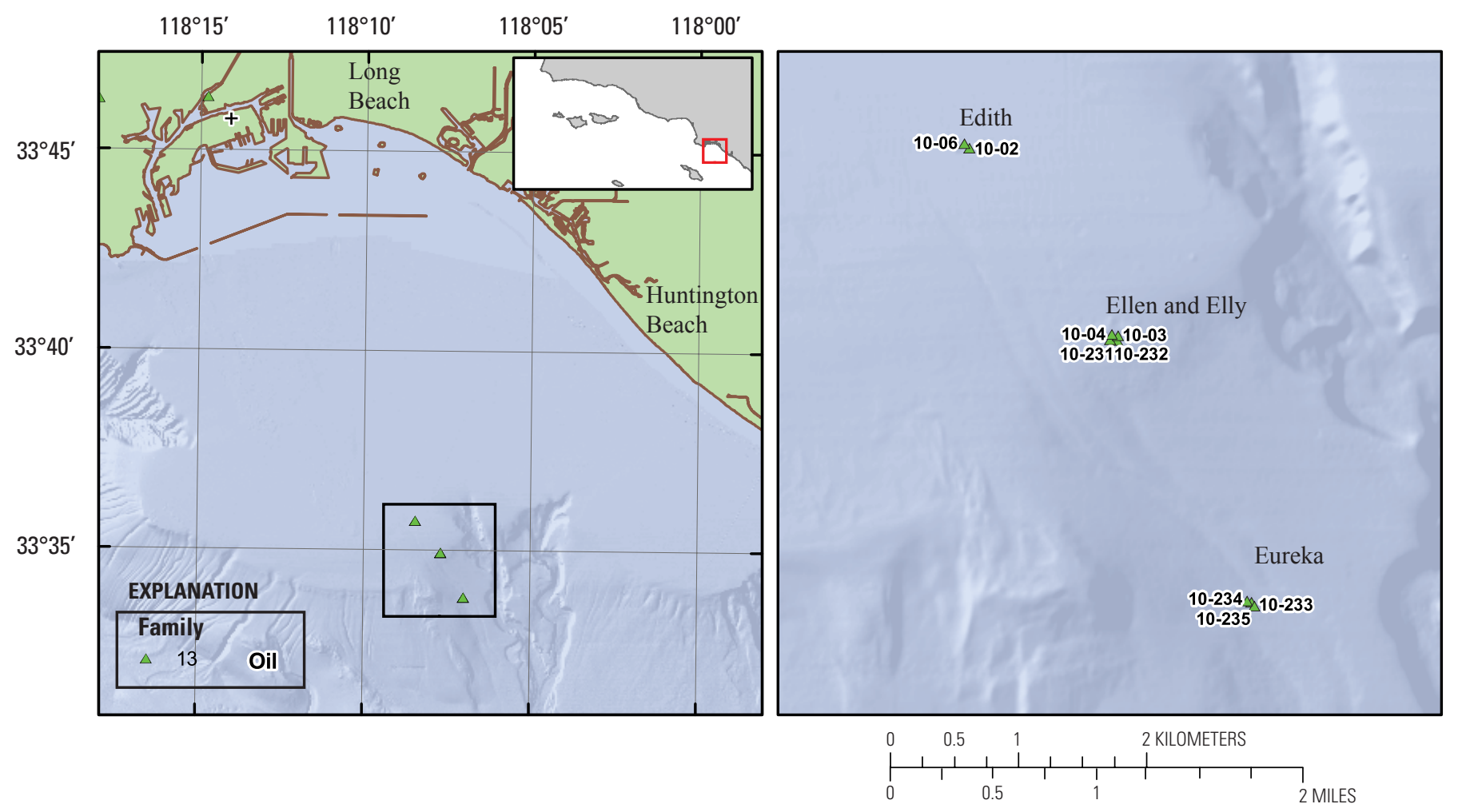

Figure 16. Maps showing locations of samples, classified by oil family, collected from operating OCS platforms (Edith, Ellen, Eureka) south of Long Beach. Produced oil is exclusively from tribe 1, family 13. Platform Elly produces no oil or gas. 
and 29 biomarker ratios. The biomarker parameters are listed in appendix 1, with references to their use.

The various parameters were chosen to include the maximum possible chemical families and constituents common to these hydrocarbon residues. This was necessary for the overall geochemical characterization and because, with a common Miocene Monterey Formation source, many of the differences between groups of oils, seep hydrocarbons, and tarballs are small. The ubiquitous triterpane, $C_{30} \alpha \beta$-hopane, was used to normalize seven of the parameters, thus serving as an internal standard (Wang and others, 1998). Ease of measurement was also a factor in choosing parameters for this study that will maximize its usability. The set of 30 parameters was calculated and are compiled in table 1.

These parameter ratios show that most of the samples exhibit biomarker characteristics of the Miocene Monterey Formation source rock. Particularly notable is the prominence of bisnorhopane (BN) in the saturate fraction, monoaromatic steroids in both fractions, and a prominent but highly variable presence of perylene in the aromatic fraction. Most of the tarball samples lack free $n$-alkanes and isoprenoids, although a few contain enough of the isoprenoids to allow calculation of the pristane/phytane ( $\mathrm{Pr} / \mathrm{Ph})$ ratio. Tarballs are characterized by maturity parameters that indicate low thermal maturity, for example, very high $\mathrm{Tm} / \mathrm{Ts}$, $\mathrm{BI}$, and dibenzothiophene source parameters, combined with very low $\mathrm{T} /(\mathrm{T}+\mathrm{M})$ ratios.

The oil sample from Platform Ellen (fig. 4) is at initial stages of biodegradation as seen by the dominance of the isoprenoids pristine and phytane, relative to the $n$-alkanes. The sterane suite also indicates that biodegradation has not occurred with these compounds; $\alpha \alpha \alpha \mathrm{R}$ epimers are dominant (esp. C27), with low $\beta \alpha \mathrm{D} 27$ compounds. Finally the Platform Ellen A-58R oil is classified as fairly immature oil because the $\mathrm{C} 27$ to $29 \alpha \alpha \alpha \mathrm{R}$ epimers are dominant over the $\mathrm{C} 27$ to $29 \alpha \alpha \alpha \mathrm{S}$ epimers. The hopane suite is typical of oils from the Monterey Formation that have relatively high concentrations of $\mathrm{BN}$ and $\alpha \beta C 35$. The TIC of the La Goleta seep oil shows a high unresolved complex mixture (UCM) that indicates significant biodegradation, which is typical of any of the seep oils or asphalts. The presence of unknown branched $n$-alkanes is also evidence that this sample is moderately biodegraded. Both the steranes and hopanes are impacted by biodegradation; the more easily biodegraded $\mathrm{C} 27$ to $29 \alpha \alpha \alpha \mathrm{R}$ epimers are reduced relative to the $\mathrm{C} 27$ to $29 \alpha \alpha \alpha \mathrm{S}$ epimers and the relative loss of $\mathrm{C} 30$ to $\mathrm{C} 29$ and the $\mathrm{C} 23-\mathrm{C} 25$ tricyclics.

\section{Application of the Chemometeric Model to New Samples}

The distribution of chemometric families by sample type (seeps, unlocated seeps, produced oils, tarballs) is compiled in table 4 and displayed graphically in figure 17 and includes the entire data set of Peters and others (2008) and Lorenson and others (2009). The analysis depicted in figure 17 normalizes the data to the percentage of sample type in each family to eliminate the bias introduced by the uneven number of samples collected for each sample type (sample type/total number of sample within that family). The distribution shows several key relations.

The most common produced oil family (13) comprises almost 39 percent of the produced oil samples, in contrast to only 7.0 percent of all seep samples and 0.4 percent of the tarball samples, which is a substantial finding indicating that undetected oil spillage resulting in tarball deposition belonging to this family is very unlikely. This pattern is often repeated; most produced oil families are poorly represented by tarballs. However, all of these families are represented by natural seeps, which highlights seeps as the most likely source for tarballs. The most frequent tarball family (22) occurs in 55.6 percent of the samples, yet it is represented by only 16.5 percent of all seep samples and 17.5 percent of produced offshore southern California oil samples. This observation corroborates the assertion that platform oils are generally unlikely sources for tarballs; using other means described further on, we can eliminate platform oils as current tarball sources. Figure 17 shows that seeps co-occur with most tarballs of the same families except in families 33,34, and 35, where only tarballs are classified. Family 33, 34, and 35 tarballs are found mainly on the central California coast and most likely come from unidentified seeps north of Point Arguello.

Our sampling strategy is responsible for the large number of seep samples classified as family 0 . Extreme biodegradation, discussed in the next section, results in the family 0 classification of 46.3 percent of seafloor-located seep samples. Many more of the asphaltic seeps were sampled than lessbiodegraded oil droplets rising from the seafloor, because it is much easier to target and sample asphalt mounds on the seafloor than seeps emitting only oil droplets. Asphalt seeps extrude onto the seafloor, often without producing oil droplets, and are positive features that are easily seen using remote imaging. In contrast, only 5.4 percent of unlocated seeps were classified as family 0 , indicating that these samples were derived from less biodegraded natural seep oil droplets. Unlocated seeps are defined as fresh oil sampled at the water surface without visible oil or gas seen rising to the surface in the immediate vicinity of the sample collection site. If asphaltic seeps were responsible for all of the tarballs, then many of the tarballs would be classified as family 0 , yet only 3.4 percent of the tarballs are classified as family 0 . Therefore, it is likely that most of the sampled tarballs are derived from oil droplets rising to the sea surface where they combine, weather, and become tarballs.

\section{Application of the Chemometeric Model to Produced Oils from Offshore Southern California}

All produced oils from offshore southern California within both federal and state lands can be classified by family. Platform-produced oils are only classified in tribes 1 and 2, 
within families $11,12,13,14,211,212,213$, and 22. Tribe 1 oils are restricted to the Los Angeles Basin and the eastern Santa Barbara-Ventura Basin. Family 13 is the most common family from this area and the most common oil family overall $(\sim 39 \%)$ analyzed in this study. The western Santa BarbaraVentura Basin oils (west of Platform Holly) and the southern Santa Maria Basin oils are mainly in tribe 2. Tribe 3 is not represented by any produced oil from southern California, and, therefore, must have sources outside of this area, most likely in the little-explored Santa Maria and Point Sur Basins offshore central California. The only known source for family 213-classified samples are the produced oils from the Point Arguello platforms: Hildalgo, Harvest, Hermosa, and Irene. The only tarball within family 213 came from the Torch oil spill of 1997, when at least 163 barrels of oil leaked from a subsea pipeline. This sample was collected on Surf Beach

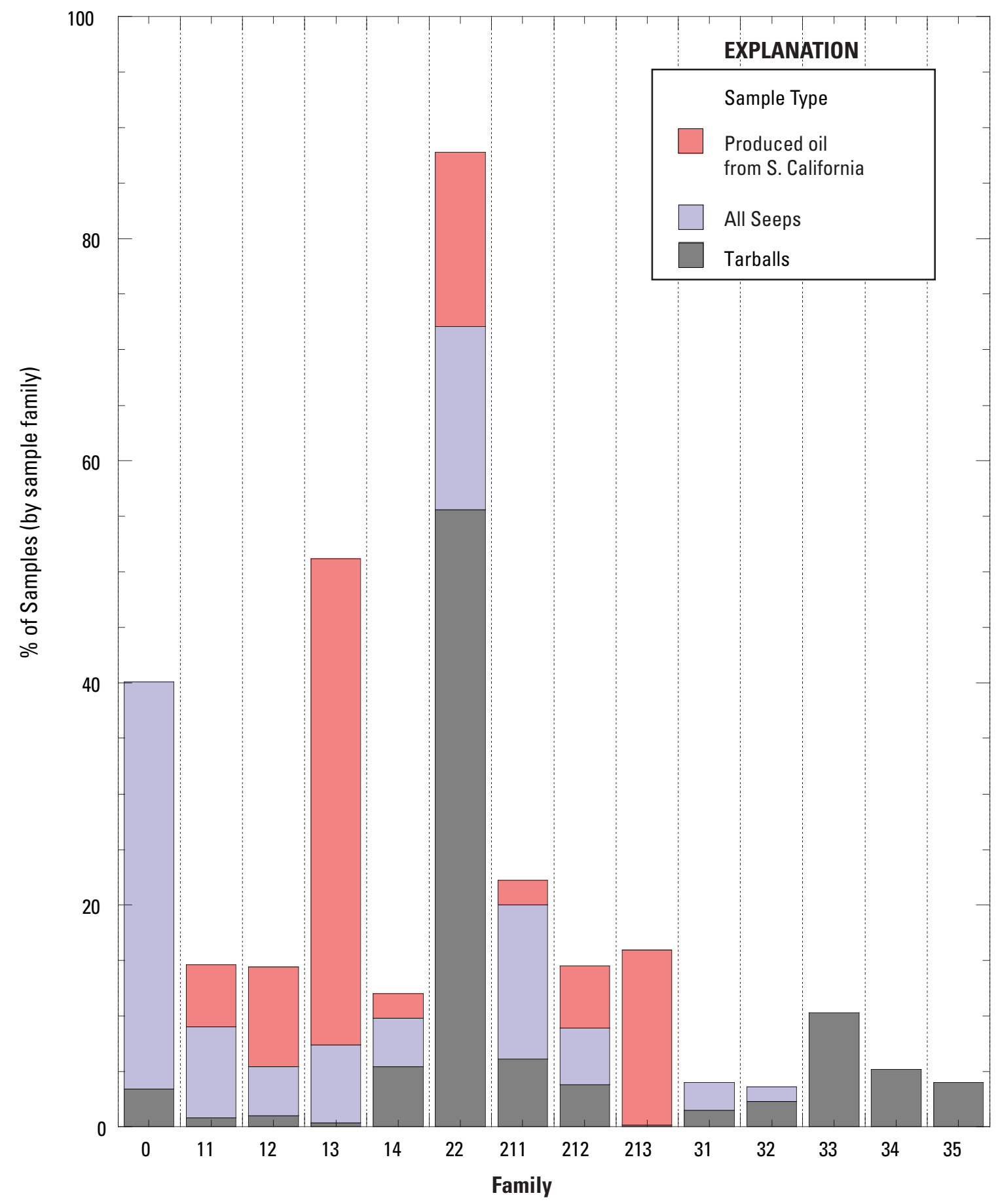

Figure 17. Histogram showing the distribution of modeled chemometric families as sample versus the percentage of occurrence of model type. 
immediately after the spill in 1997, archived at the laboratories of the California Office of Spill Prevention and Response, and analyzed 10 years later in 2007 by this group. The tarball chemometrically matched the oil from Platform Irene, thus tying the tarball to the spill.

The 19 biomarker parameters used in our chemometric model are sometimes sufficient to allow unique discrimination of individual platform oils. However, platform samples and seep samples that have sources geographically close to each other are too similar to each other, with respect to the biomarker parameters, to definitively differentiate them on that criteria only. In some cases, the degree of biogeochemical degradation or weathering that the oils or tars have experienced can be utilized. Unweathered and nonbiodegraded oil contains $n$-alkane hydrocarbons and the isoprenoids pristane and phytane (table 1). All of the platform oils in our sample set contain these components. In contrast, the seep oils or tars have been exposed to significant biodegradation in the reservoir or at the seafloor, resulting in the loss of at least the $n$-alkanes and isoprenoids and often degrading the steranes and hopanes. Therefore, the combination of chemometric fingerprinting and the presence or absence of $n$-alkanes and isoprenoids help to differentiate anthropogenic production oils versus natural seeps oils and tars within a limited timeframe.

The differentiation is not always definitive, because of the close chemical similarity of some samples and the variability in the biodegradation progression, such as near Coal Oil Point, where produced oils from Platform Holly (families 14 and 211) are likely tapping the same oil sources as the prolific seeps south of Coal Oil Point. Similarly, near Platforms A, B, C, Hillhouse, Henry, Houchin and Hogan (Dos Cuadros Field), seep oils and produced oils are genetically very similar and cannot be definitively distinguished after a period of several days of weathering. In contrast, oils from the Point Arguello and Point Pedernales fields (Platforms Irene, Hermosa, Hildago, Harvest) can be distinguished on the basis of chemometric fingerprinting alone. In the middle of this spectrum are oils from all the other platforms, where it is expected that oil weathering would take on the order of two weeks to a month to produce tarballs physically similar to those seen near Point Conception. In this case a much greater degree of weathering is needed to proceed from produced oil to the biodegraded tar characteristic of tarballs stranded on the beach.

\section{Biodegradation of Oil and Seep Hydrocarbons}

All samples analyzed in this study share geochemical source characteristics typical of source rock in the Miocene Monterey Formation. Differences in relative amounts of constituents that reflect different organic-matter inputs, levels of thermal maturity, degrees of biodegradation, and probably slightly different depositional facies allow fingerprinting and correlation by chemometric analysis. Some parameters indicated that they were either nonbiodegraded (such as platform production oils) or mildly biodegraded below the point of sterane loss (such as many of the beached tarballs), which is less than or equal to stage 5 on the scale in Peters and others (2005). The range of individual fingerprint parameters within sample families, however, is somewhat broad, and correlations are not as exact as might be expected, for example, from a spill of a specific crude oil such as the Exxon Valdez. Apparently, seep oil and related shoreline tarballs, even from the same source, have small local variations in constituent concentrations that give broader ranges within the chemical signature.

Shallow accumulations of hydrocarbons are subject to significant biodegradation. The tarball and seep hydrocarbons originate from shallow reservoirs or fracture systems in the seafloor. Typically, the hydrocarbons are relatively thermally immature, which implies that the source rock is thermally immature and within $2-3 \mathrm{~km}$ of the ocean floor. Significant but variable proportions of perylene, a polycyclic aromatic hydrocarbon (PAH) of biogenic origin that is found in surface marine sediments, implies inclusion by migration through these sediments. Biodegradation in these shallow subsurface reservoirs impacts sterane distributions and can cause tars from similar sources to appear different. The family with the greatest number of samples, family 22 , represents a continuum of sterane loss, from abundant regular steranes dominated by $\alpha \alpha \alpha \mathrm{C}_{27} \mathrm{R}$ to samples that have lost most of the regular steranes. A number of tars could not be classified and are characterized by biodegradation even beyond the regular steranes, showing a diminished $\alpha \beta \mathrm{C}_{30}$-hopane and, to a lesser extent, bisnorhopane. A pair of unusual steranes that are prominent in this sample set, $\mathrm{C}_{26}$ 24-nor-5 $\alpha$-cholestane and $\mathrm{C}_{27}$ 27-nor24-methyl-5 $\alpha$-cholestane, are not impacted by biodegradation and maintain a consistent level relative to $C_{30} \alpha \beta$-hopane throughout the data set.

\section{Gas and Oil Emissions from Seeps Offshore Coal Oil Point}

Hydrocarbon generation and seepage occur mainly from the source rock and reservoir in the Monterey Formation through faults, fractures, and outcroppings in the overlying, capping Sisquoc Formation (Leifer and others, 2010). Seeps are located above anticlines along three trends. The inner trend ( $20 \mathrm{~m}$ depth) includes Shane and IV Super seeps. A second trend ( $\sim 40 \mathrm{~m}$ depth) includes the Horseshoe and Coal Oil Point seeps. The deepest trend ( $\sim 70 \mathrm{~m}$ depth) includes the La Goleta and Seep Tent seeps, as well as the Coal Oil Point seep (fig. 13; appendix 1).

Gas seepage escapes the seabed and undergoes changes enroute to the atmosphere. At the seabed, Coal Oil Point seep bubbles are primarily composed of $64-90$ percent $\mathrm{CH}_{4}, 3-26$ percent $\mathrm{CO}_{2}$, and less than 10 percent nonmethane hydrocarbons (NMHC) (Clark and others, 2009). As bubbles ascend, $\mathrm{CO}_{2}$ and, to a lesser extent, hydrocarbons are dissolved in the water column, and there is an influx of dissolved air gases (primarily $\mathrm{N}_{2}, \mathrm{O}_{2}$, and Ar). The dissolved hydrocarbons partly 
diffuse into the atmosphere and can be traced by following ocean surface currents, often to the west of Coal Oil Point (Mau and others, 2007). At the surface, bubbles are 46-74 percent $\mathrm{CH}_{4}, 19-52$ percent air, less than 0.1 percent $\mathrm{CO}_{2}$, and 3.5-7.4 percent NMHC, depending on the seep-bubbleplume characteristics (Clark and others, 2010a). The dominant NMHCs are ethane, $\mathrm{C}_{2} \mathrm{H}_{6}(5 \%$ mole fraction, 0.06 ratio to $\mathrm{CH}_{4}$ ), and propane, $\mathrm{C}_{3} \mathrm{H}_{8}(3 \%, 0.034)$, with $<1$ percent higher $n$-alkanes (Clark and others, 2000).

Surveys with sonar (Hornafius and others, 1999) and direct gas capture (Washburn and others, 2005) suggest that $\sim 1.0-1.5 \times 10^{5} \mathrm{~m}^{3} \mathrm{day}^{-1}$ gas, mainly methane, escapes from $\sim 3$ $\mathrm{km}^{2}$ of seafloor to the atmosphere, and a roughly equal amount dissolves into the coastal ocean (Clark and others, 2000b, 2010a ). As estimated using a 60 percent $\mathrm{CH}_{4}$ mole fraction based on surface composition measurements (Clark and others, 2010a), annual $\mathrm{CH}_{4}$ emissions would be $\sim 0.015$ teragrams ( $\mathrm{Tg}$, $10^{12} \mathrm{gm}$ ). For perspective, Los Angeles County anthropogenic $\mathrm{CH}_{4}$ emission estimates are only an order of magnitude larger, $0.200 \pm 0.006 \mathrm{Tg} \mathrm{CH}_{4} \mathrm{yr}^{-1}$ (Hsu and others, 2009).

\section{Temporal Changes in Gas Emissions}

Seep field gas emissions have changed significantly over time. Comparison of recent surveys with 1940s and 1950s surveys documented by Fischer (1977) show significant prior decreases in seep extent. Data from the Seep Tents (two 30 x 30 m seafloor capture tents) show consistently decreasing emissions from the mid-1980s to mid-1990s (Boles and others, 2001); however, nearby production activities from Platform Holly complicate interpretation (Boles and Horner, 2009). The Coal Oil Point seep field produces a wide diversity of oil and gas seepage rates. Gas seepage spans many orders of magnitude and, although oil-to-gas ratios remain unquantified, oil chromatograms suggest the oil/gas ratio also varies widely (Leifer and others, 2006a). Studies have quantified seep-area (for example, Allen and others, 1970; Fischer and Stevenson, 1973) and emission fluxes (for example, Hornafius and others, 1999; Quigley and others, 1999; Clark and others, 2000) using sonar techniques, ocean chemistry, and direct gas capture using floating buoys. Fischer and Stevenson (1973) noted changes in seepage on decadal time scales in the Coal Oil Point area; a significant decrease in seepage areas between 1946 and 1973 was attributed to offshore production localized to Platform Holly. Using data collected in 1973 and 1995, Quigley and others (1999) demonstrated a decrease in area and number of seeps within $1.5 \mathrm{~km}$ of Platform Holly, which they attributed to production and which would likely increase again after production stops.

\section{Oil Emission Measured at Coal Oil Point}

Global estimate of marine oil emissions from natural hydrocarbon seeps are significant, $\sim 0.6 \mathrm{Mt} \mathrm{yr}^{-1}$, while accidental spills contribute just $0.1 \mathrm{Mt} \mathrm{yr}^{-1}$ (U.S. National Research
Council, Committee on Oil in the Sea, 2003). The Santa Barbara Channel hosts some of the largest and best-studied seeps globally; seepage is estimated to be 100-600 bbl/d (Clester and others, 1996) on the basis of a surface boom capture study and aerial overflights. Values were extrapolated to the entire seep field using sonar-quantified gas fluxes in the study area and the entire field and assuming a field-wide oil/gas ratio, although widely quoted, significant uncertainties exist, particularly given variability of seepage as detailed below.

Allen and others (1970) used a combination of aerial, sea surface, and underwater techniques to estimate a field flux of 50-70 bbl/d. The surveyed area was directly south of Coal Oil Point and covered more than $3,000 \mathrm{~m}^{2}$ of seafloor (not the entire seep field). Underwater-flux estimates were calculated by measuring the volume of oil collected in an inverted gallon jug during a known time. Surface flux estimates were determined by measuring slick width and drift rate from aerial photography and measuring slick thickness through absorbance analysis of oil collected on oil-adsorbent material (cheesecloth). Allen and others (1970) state that their estimate is only an average for the shallow seeps surveyed and that the flux can easily range from $10-100 \mathrm{bbl} / \mathrm{d}$. Fischer (1977) suggested that the Coal Oil Point seep field emits from $25-400 \mathrm{bbl} / \mathrm{d}$ and represents $\sim 60$ percent of the total flux for the entire Santa Barbara Channel. Hornafius and others (1999) used sonar to identify and quantify gas seepage. They used their gas-seepage estimate and an oil-to-gas ratio for the field to estimate oil seepage of $100 \mathrm{bbl} / \mathrm{d}(16,000 \mathrm{~L} / \mathrm{d})$ for all seeps deeper than those studied by Allen and others (1970). Including oil from the shallow seeps surveyed by Allen and others (1970), $150-170 \mathrm{bbl} / \mathrm{d}(\sim 23,800-27,000 \mathrm{~L} / \mathrm{d})$ is emitted from the Coal Oil Point seep field (Hornafius and others, 1999).

Seepage at Coal Oil Point primarily is in the same area as the offshore South Ellwood Oil Field that has been in production from Platform Holly since 1967 and that taps fractured rock reservoirs within the Miocene Monterey Formation. Platforms A, B, C, and Hilhouse atop the crest of an offshore anticline were also placed near natural seeps with the expectation of finding oil at depth. The Monterey Formation is the primary petroleum hydrocarbon source in the Santa Barbara Channel (Ogle and others, 1987). Total production has been $9.49 \times 10^{6}$ $\mathrm{m}^{3}$ of oil $\left(5.97 \times 10^{7} \mathrm{bbl}\right)$ and $1.48 \times 10^{9} \mathrm{~m}^{3}$ of gas $\left(5.22 \times 10^{10}\right.$ $\mathrm{ft}^{3}$ ) as of September 2008 (Marc Kamerling, personal commun., Venoco, Inc., data, 2008).

Since 2000, Del Sontro and others (2007) used sea-surface surveys and (or) sonar to identify additional, informally named major seeps. In addition, areas of less intense seepage and areas of dispersed seepage that have been the focus of scientific research also were informally named. Many of these seep areas have been surveyed at the seabed by divers and submersibles. On the basis of observations collected at the sea surface and seabed for named seeps in the seep field, general seep field characteristics can be described. The shallowest ( 3 to $\sim 12 \mathrm{~m}$ water depth) seeps emit gas with trace hydrocarbons, while deeper seeps emit gas and nontrace oil. Seep oiliness varies significantly between seeps and is visible at 
the sea surface and in chromatograms of seep samples (Clark and others, 2003a; Leifer and others, 2006b). For example, hundreds of oil droplets were seen surfacing in less than 30 min at the main plume of the Patch and La Goleta seep areas, thereby producing a large surface slick. However, Tonya and Shane seeps emit much less oil compared to their gas flux and produce much smaller surface slicks. Plume intensity was based on the surface observation of flux as identified by the apparent upwelling and outwelling flows and the depth of the seep. A seep with high or very high plume intensity does not necessarily cover a larger surface area of the seabed or sea surface. High-intensity plumes have fast upwelling rates and a pronounced outwelling flow at the sea surface. Low-intensity plumes may also have an outwelling flow, but in general it is weak. Many low-intensity plumes cover extensive areas of dispersed seepage.

Exposed asphalt mounds have been confirmed at Jackpot and Ira seeps, a small area southwest of Goleta Point in about $40 \mathrm{~m}$ water depth, and a small area very near the end of the Goleta sewage outfall pipe (fig. 14). Asphalt mounds are small volcano-shaped mounds made almost entirely of asphalt and can be hard or elastic. Jackpot asphalt mounds have a ropey appearance, similar to pahoehoe lava, indicating that oil or asphalt once flowed from the mound's center. During dives, active oil or asphalt seepage was not observed at either seep; however, gas seepage was observed (Del Sontro and others, 2007). The asphalt mounds are similar to those discovered by Vernon and Slater (1963). Unexposed asphalt mounds may be present at other seeps, particularly at those with high sedimentation rates. Shane seep, for example, has a layer of asphalt buried beneath fine-grained sediment near the major seabed features (Leifer and others, 2004). Many seeps have not been visited, and seepage can be intermittent at those that have been observed.

\section{Measuring Current Gas and Oil Seep Discharge}

The major goal of the University of California Santa Barbara (UCSB) research team was to improve understanding of the amount of oil escaping the seabed from the Coal Oil Point seep field. Critical to any such measurement is evaluating how representative the measurements are, which implies characterizing both spatial distribution and temporal variability of seepage. In both cases, measurements and subsequent interpretations require an understanding of the underlying controlling processes to ensure that the application to large survey areas is done correctly.

The study plan included two phases: Phase 1 addresses the actual measurement and the spatial scaling of seepage, and Phase 2 measures the temporal variability of seepage to evaluate trends over yearly time scales. Technological and funding limitations partially prevented completion of Phase 1 , while innovative analysis enabled characterization of the temporal variability in Phase 2. During the study period, new technology has been developed and new assets acquired, which allowed effective completion of Phase 1.

\section{Direct Flux Measurements}

Hydrocarbon emissions from the Coal Oil Point seep field are both liquid petroleum and natural gas, although research has shown significant complexities. For example, observations show that, in general, higher-flow seep plumes have lower gas-to-oil ratios than lower-flow seepage on the basis of ratios of lighter to heavier alkanes (Leifer and others, 2006a), as well as visual observations. This is consistent with the resistance model of seepage presented in Leifer and Boles (2005) for natural gas and in Leifer and Wilson (2007) for mixed oil and gas seepage. Leifer and Wilson (2007) observed an inverse relation between oil and gas emissions and attributed it to oil blockage of migration pathways leading to greater resistance to gas flow. Moreover, Leifer and Wilson (2007) also observed a temporal interplay between the oil and gas emissions, which exhibited the characteristics of intermittent flow (slug flow).

These observations on a small scale have significant implications for the large scale. Specifically, the slug-flow behavior observed in a seepage system implies that any flux measurement needs to extend over a timescale longer than the slug-flow timescale to be representative. An additional complication is the likely interplay between different connected seepage areas, as noted by Leifer and Wilson (2007) on a small scale. Evidence of these behaviors was observed in the Horseshoe Seep area where, during an oil capture experiment, the seep oil to gas ratio varied significantly on a half-hour time scale; a decrease in flux at one seepage area may be compensated by increases in a separate seepage area, requiring a more holistic measurement approach.

\section{Gas Flux Measurement-Sonar}

Quantification of the gas flux followed the approach pioneered by Hornafius and others (1999) and Quigley and others (1999), where the sonar return in a depth window is integrated, binned, and mapped. Chirp sonars were tow-fish mounted and deployed $\sim 10 \mathrm{~m}$ behind the survey vessel. The chirp sonar signal was a $3-15 \mathrm{kHz}$ signal, with wavelengths of $50-10 \mathrm{~cm}$, which prevented resonance with seep bubble sizes, whose maximum diameter is $\sim 2 \mathrm{~cm}$ (Leifer and Boles, 2005). However, the wavelengths used in the chirp sonar are comparable to the dimensions of the bubble plumes and vertical structures within the bubble plumes.

For each ping, the sonar return intensity was recorded every $40 \mathrm{~ms}$, which corresponds to a depth of $6 \mathrm{~cm}$ based on the speed of sound in water. Separately, differential global positioning satellite (GPS) information was recorded continuously. During data processing, each ping is associated with the GPS location of the sonar tow platform, thereby applying the correct position. 
During a survey, the sonar return intensity is recorded during a series of transect lines covering the seep field. Our survey of the seep field lasted three to four days and spanned multiple tidal cycles. Survey lines were plotted parallel to the seepage trends. We calculated the normalized window root mean square (rms) sonar return, $\sigma$, for sonar return intensity over a depth window, and values of $\sigma$ greater than the noise level are identified as seepage (fig. 18). Because the length of a sample is a few centimeters, the rms sonar return represents the contrast between clumps of bubbles or the bubble plume and the surrounding bubble-free fluid. This return is computed for a depth window that can be at two fixed depths (Hornafius and others, 1999) or for a bottom-following window. We used the latter to improve the signal to noise ratio. The depth

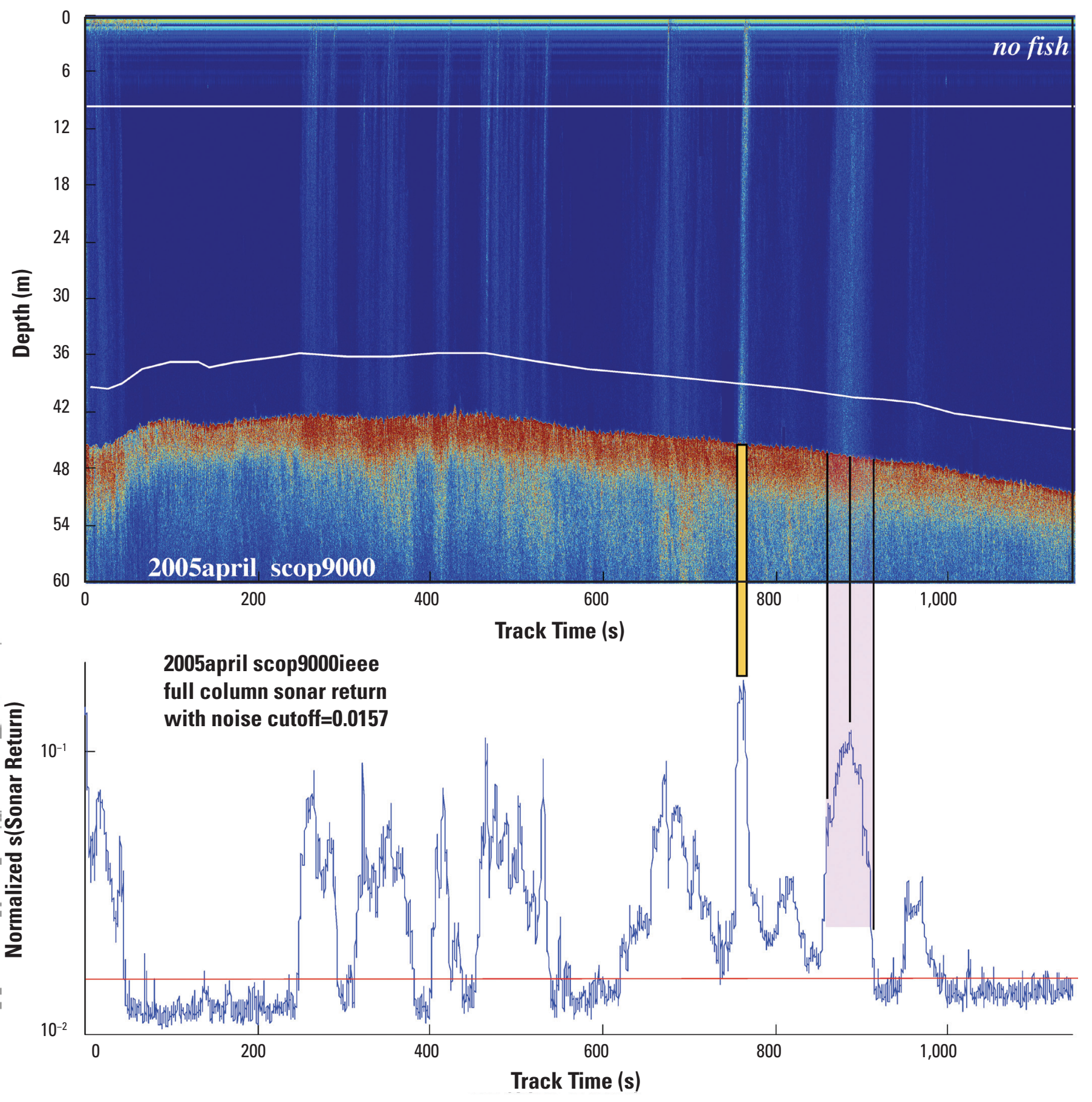

Figure 18. A, Sonar return for a transect line through Trilogy seep (775 s) with respect to transect time. Arbitrary color scheme with red higher and blue lower sonar return. Fish return signals have been removed from this line. $B$, Bottom-bounce normalized, rms sonar return $(\sigma)$ for bottom-following depth window. Red line shows noise level. For location of Trilogy seep see fig. 7. 


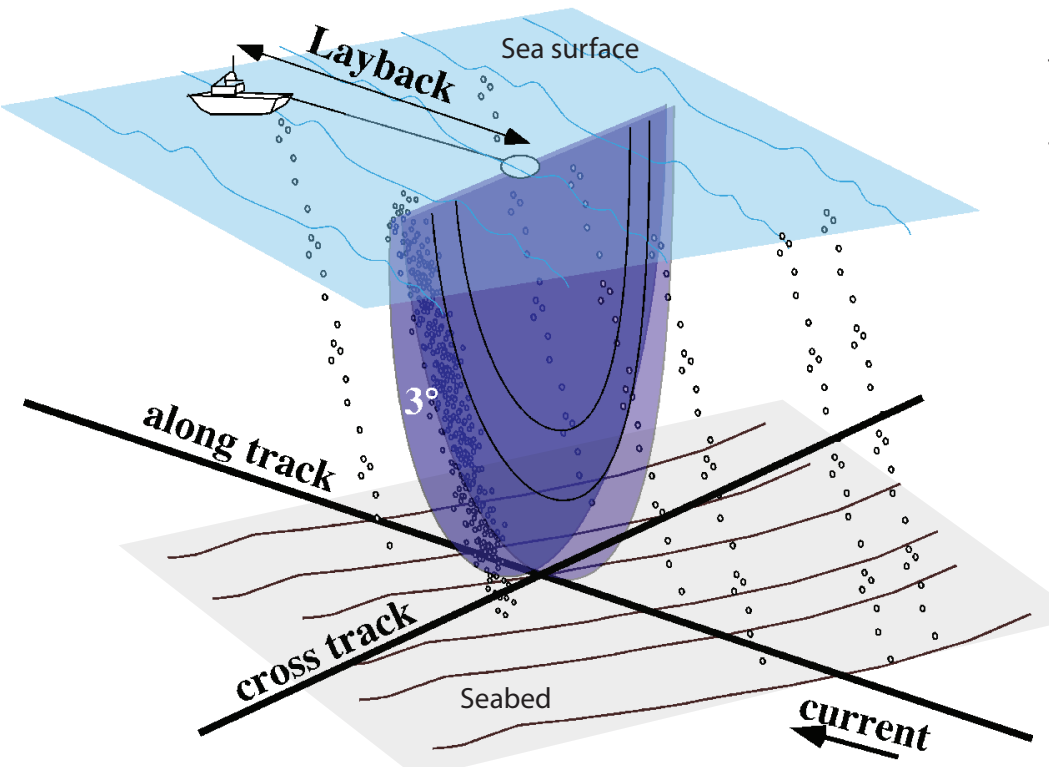

Figure 19. Schematic showing sonar beam during tow through seep field with along-track current, illustrating geometric uncertainty and mixing of signal return from multiple seep plumes in the ping. In this case, the geometry is offset by $3^{\circ}$.
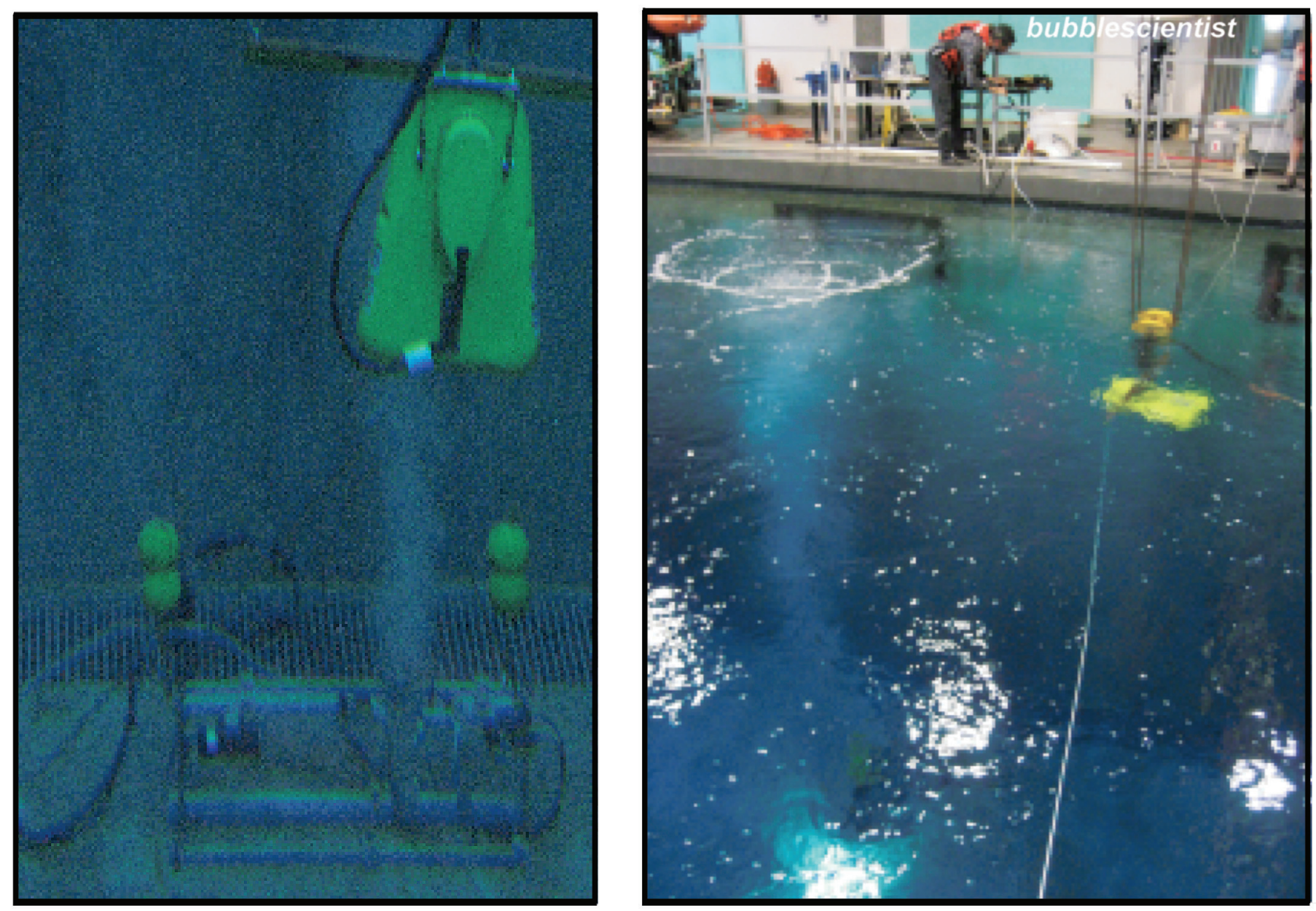

Figure 20. Images of Edgetech sonar during the MBARI sonar-bubble calibration study. Left photo, bubble manifold emitting a stream of bubbles next to sonar unit. Right photo, Surface of the test tank showing the sonar unit approaching a bubble plume. 
window extended from several meters above the bottom to a fixed water depth, set below noise associated with the sea surface. It is important to keep the bottom of the depth window at several meters above the seabed to avoid disturbance by fish, which are frequently present near the seabed, and to prevent seabed features from entering the window. The new depth window increases (smears) the spatial extent of bubble plumes due to currents but misses fewer plumes that currents may transport out of the sonar beam. For deeper seeps, a bottomfollowing depth window should be used with caution, because a depth window that is too thick would average the effects of bubble dissolution on sonar return intensity. Figure 19 illustrates the common geometry of a single-beam chirp sonar showing the uncertainties found when measuring multiple seep plumes.

\section{Sonar Calibration Test}

A calibration study was conducted in the Monterey Bay Aquarium Research Institution (MBARI) test tank, and a single-beam Edgetech chirp sonar (previously used in field studies) was suspended in the water column and moved by a crane to traverse the plume for a range of bubble flow rates (fig. 20). An Imagenex, DeltaT multibeam sonar was mounted with the Edgetech to contrast single versus multibeam data. The intercalibration experiment revealed that the chirp-sonar return was highly insensitive to bubble flow, varying by a factor of $\sim 2$ for a change in bubble flow rate of $10^{5}$. Very small bubble plumes were invisible to the sonar. The best interpretation of this data was that the single-beam sonar was responding to the plume-scale density variations, such as puffs, and that the insensitive response was due to the plume diameter and (or) the size of eddies generated (which leads to density structures in the plume) is weakly dependent on bubble flux.

Analysis of the chirp-sonar data revealed an undocumented, software feature whereby the ping intensity was renormalized on an approximately five-sample frequency timescale (every $10 \mathrm{~cm}$ ). The renormalization may enhance density differences in the single-beam chirp sonar data; however, it cannot be deactivated and makes interpretation of water column data difficult to impossible. In contrast, the DeltaT multibeam sonar had far greater sensitivity to bubble flow than the Edgetech single-beam sonar, due in part to its higher frequency (4-24 Hz). Moreover, multibeam sonar enables correction (and calibration) for the geometric uncertainties inherent in single-beam sonar. Due to these two factors, it was concluded that future efforts should focus on multibeam sonar technology. However, the DeltaT multibeam is an 8-bit system and saturates extremely rapidly. A multi-ping approach was developed, whereby successive pings are ramped in gain to create a pseudo-higher range system. Typically four pings were ramped through $20 \mathrm{~dB}$, providing an effective repeat sonar ping rate for the range needed for these shallow seepage systems of $\sim 4 \mathrm{~Hz}$.
During the course of the study, USGS acquired a Reson Seabat 7125 multibeam sonar, and UCSB acquired an Imagenex, DeltaT multibeam sonar. UCSB personnel mapped a small area around Trilogy seep several times in 2009 using the new DeltaT system. These new systems are actively being tested for their utility in imaging and quantifying gas seep emissions.

The USGS has mapped the Coal Oil Point seep field several times (fig. 21), the last time with the Reson system in June 2010 (cruise S-13-10-SC). We mapped selected seeps, some twice, with a pole-mounted Reson Seabat 7125 multibeam with a $10^{\circ}$ forward rake. Our efforts to date focus on the data reduction and data visualization strategies employed while processing more than $1.2 \mathrm{~TB}$ of raw water-column data collected by the multibeam system primarily over Trilogy, Seep Tent, and La Goleta seeps in water depths that ranged from about 30 to $80 \mathrm{~m}$ (fig. 22). Turnkey software solutions for processing these data are currently unavailable, so most of the processing code was developed by the USGS.

The main challenge in processing the sonar water-column data is ray-tracing the large volume of data, because each ping contains more than 4,500 times as many samples as a conventional multibeam ping. We employed two strategies to make processing tractable on conventional workstations: (1) decimate the raw data based on desired output resolution before raytracing and (2) design the ray-tracing program to run in parallel on multi-core workstations. Utilizing an 8-core, $3.00 \mathrm{GHz}$ Intel Xeon X5365, we achieved a processing throughput rate of $14 \mathrm{MB} / \mathrm{s}$, while utilizing only 12 percent of the available $\mathrm{I} / \mathrm{O}$ bandwidth (the code is CPU-bound). Processing 1.2 TB of raw water-column data to the point of statistical analysis and visualization required about 25 hours of computation and resulted in an output data set of about $200 \mathrm{~GB}$. We demonstrated the utility of this system in water-column seep mapping; the next step is to calibrate the system at sea with known gas emissions from an artificial seep (gas manifold at the seafloor), using known gas flow rates, bubble size, and plume dimensions.

\section{Oil Emission Measurement}

In collaboration with Clean Seas, an oil collection experiment was conducted (fig. 23); two response boats deployed several hundred feet of oil boom in a $U$ configuration around Horseshoe Seep to collect surface oil drifting into the boom (fig. 23). For several hours, the two boats maintained position, while observer scientists in a small boat waited for sufficient oil to accumulate to be able to quantify the amount of oil captured. During the wait, scientists observed that the emissions from the seep area shifted between oil-dominated emissions and gas-dominated emissions on a half-hour timescale. This behavior was similar to the slug-flow behavior observed by Leifer and Wilson (2007) on a longer (tidal) time-scale. Unfortunately, after approximately $90 \mathrm{~min}$, oil ceased accumulating in the oil boom and oil that was collected in the boom sank when waves tugged erratically on the boom. Thereafter, the system achieved rough equilibrium with a continuous supply 
of new oil into the boom replacing sinking oil-in effect, creating a continuous sinking-oil source. This led to the conclusion that oil weathering (evaporation) was responsible for increasing the oil's density, leading to oil sinking.

Supporting this hypothesis were the results of a slicktracking experiment; hollow glass microspheres $(\sim 70 \mu \mathrm{m}$ diameter) were used to mark an oil patch, which also showed a similar weathering-sinking process. Oil that had been tracked for a distance of a few kilometers began widespread sinking in the early afternoon. Although potentially anecdotal, oil sinking occurred within an hour after morning low-level clouds had burnt off, exposing the oil to more solar radiation and photolysis. A potential solution to the oil-sinking phenomenon is to skim the oil collected by the boom to onboard storage containers, allow it to settle, and then quantify the amount of oil collected. However, because such collected oil is classified as hazardous waste and extremely expensive for disposal, the experiment was not conducted. The physics-based remotesensing approach to deriving quantitative oil thicknesses that was developed in support of oil spill response (Clark and others, 2010b) may be applicable to estimating oil emission at Coal Oil Point.

\section{Temporal Variability of Seeps}

Understanding temporal variability, both short term and long term, is critical to evaluating the applicability of an emission value measured on any particular day and to understanding the geological and environmental context. These concepts

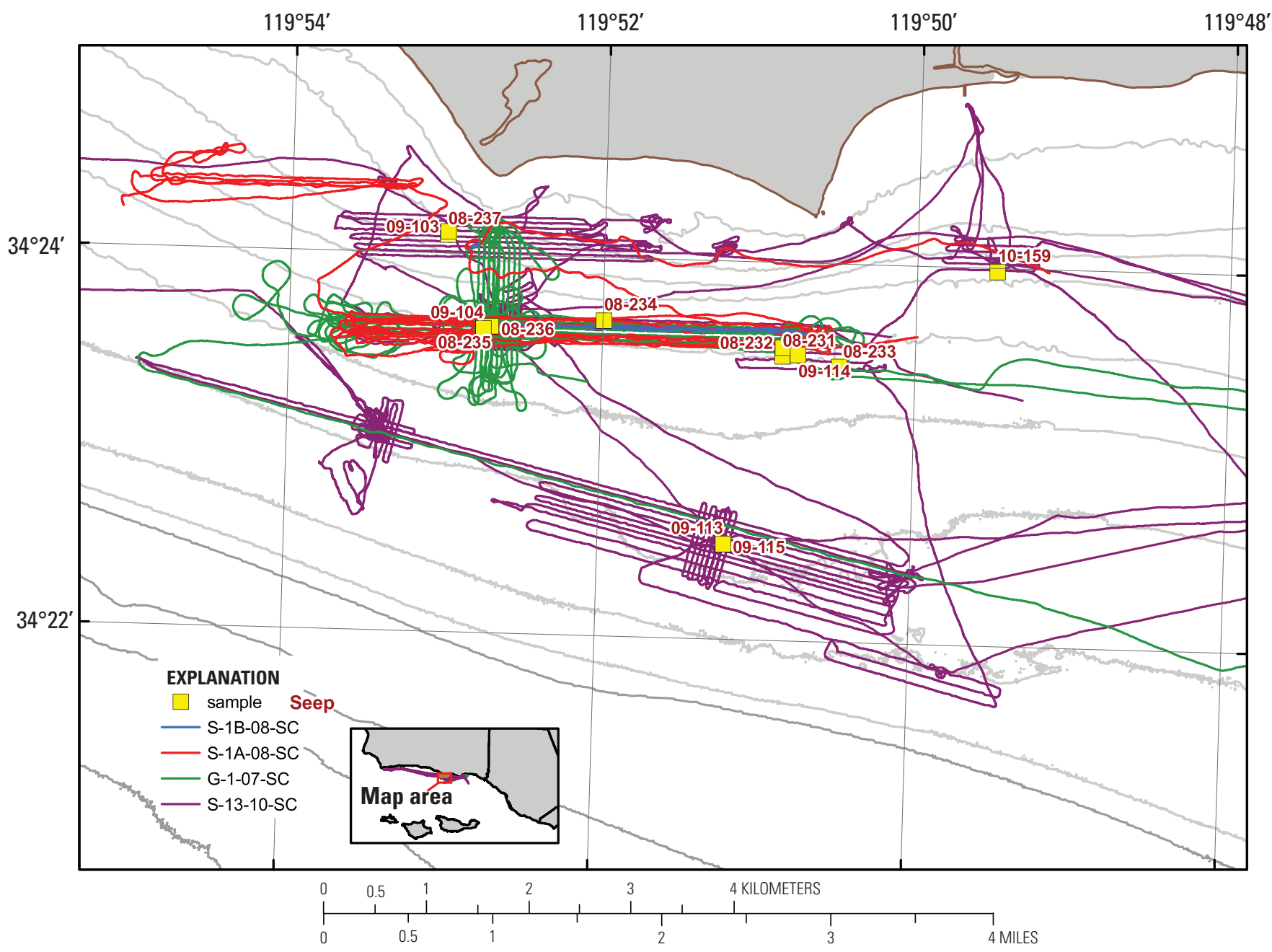

Figure 21. Map of ship tracklines, traversed during four acoustic surveys of seeps south of Coal Oil Point during 2007-2010, and seep locations and numbers collected during 2008-2010. Various instruments were used to image and quantify seep gas emissions. USGS cruise numbers for each ship trackline identify metadata available at http://walrus.wr.usgs.gov/infobank/programs/html/ids2idshtml/ htmls/a_ids.html. 


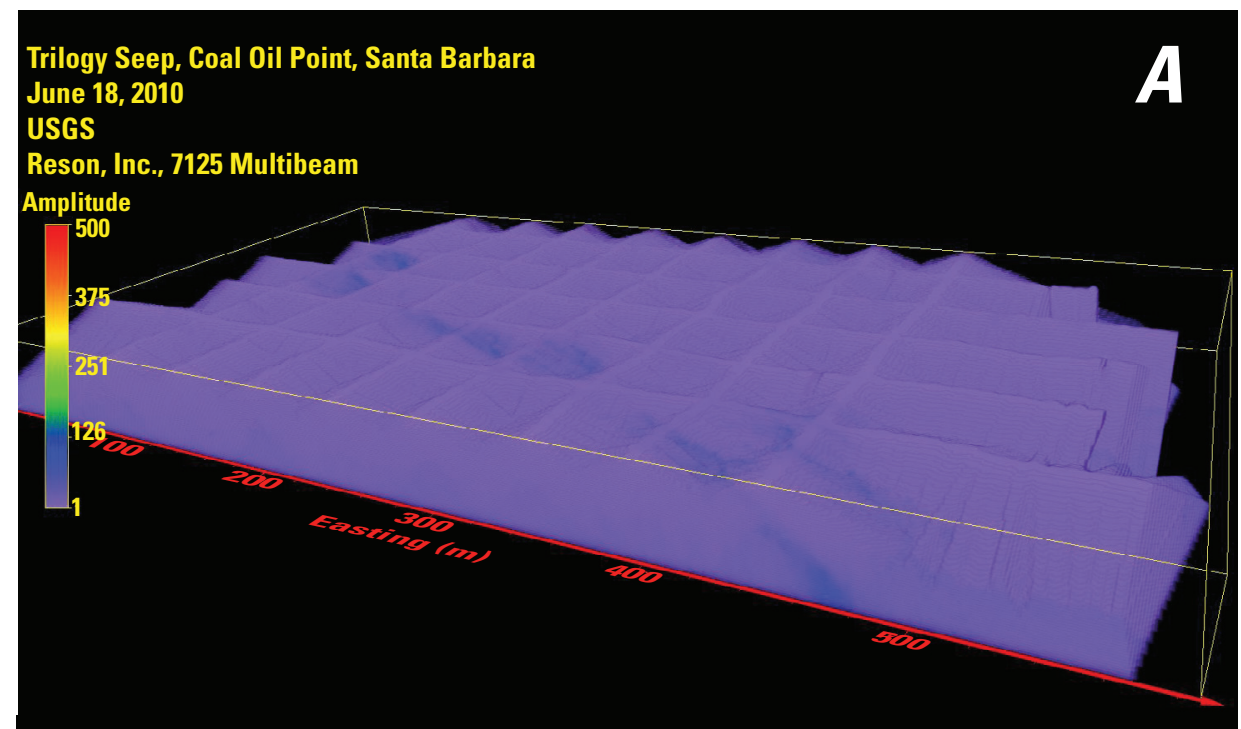

Figure 22. Composite amplitude maps of gas plumes rising up through the water column at Triology seep (see fig. 7) as recorded by multiple overlapping passes with the Reson 7125 multibeam sonar. Dimensions of the block are $600 \times 300 \times 50 \mathrm{~m}$. A, Grid pattern of the survey superposed on the area of the water column; the tent-like 3-D area in purple, shows that not all of the water column can be visualized by the sonar. $B$, Both the gas plumes and the area of the surveyed water column. $C$, Gas plumes showing relative strength of emission by the amplitude response. Note the origin of the plumes is along trends associated with the underlying geologic structures (folds). The

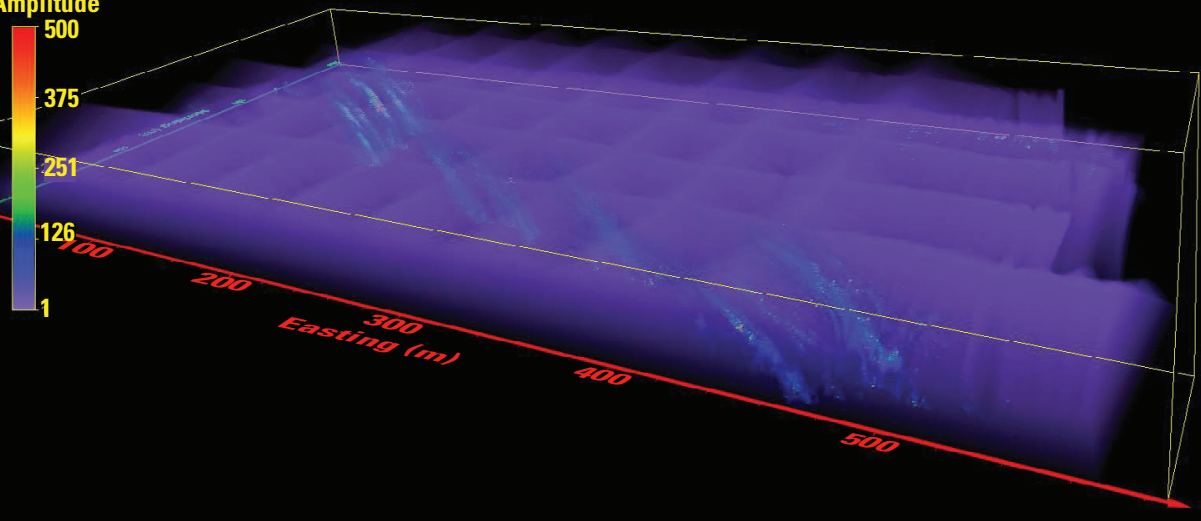
plume shapes bend down-current to the northwest in response to prevailing ocean currents.

Trilogy Seep, Coal Oil Point, Santa Barbara

June 18, 2010

USGS

Reson, Inc., 7125 Multibeam

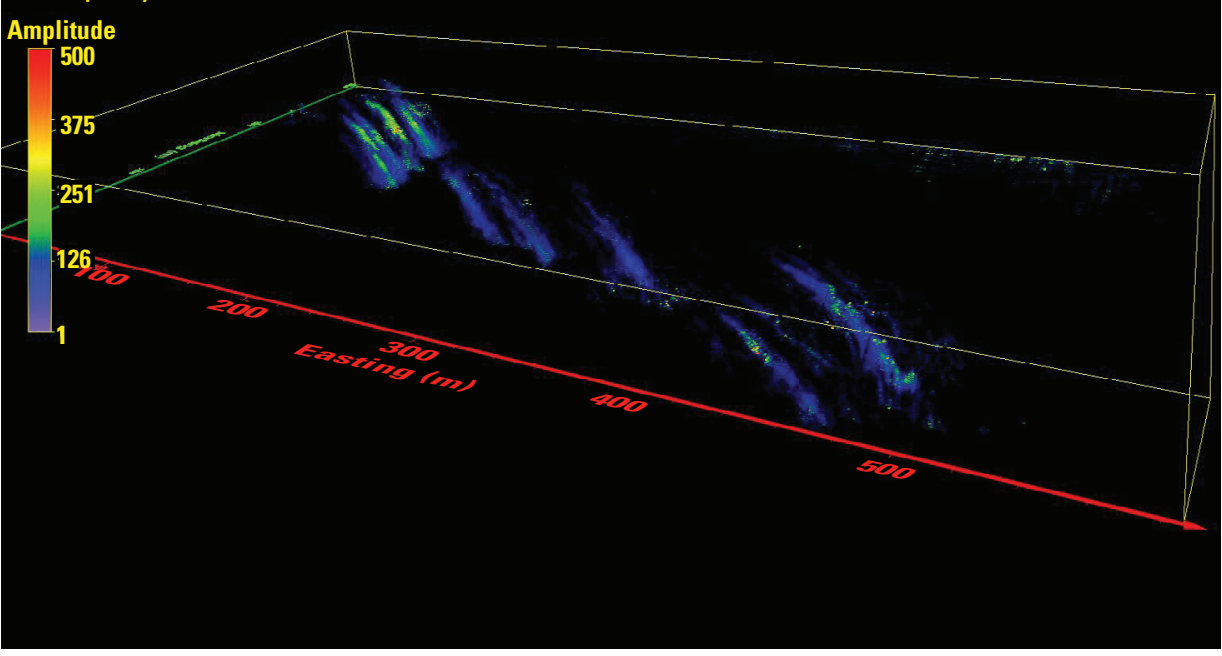


are partly documented in Bradley and others (2010) and partly summarized here.

Hourly total hydrocarbon (THC) data, collected from 1990 to 2008 by a California air pollution station located near the Coal Oil Point seep field, were analyzed and clearly showed geologic $\mathrm{CH}_{4}$ emissions as the dominant local source. The Santa Barbara Air Pollution Control District has monitored THC at the West Campus Station (lat $34^{\circ} 24.897^{\prime}$ N., long $119^{\circ} 52.770^{\prime}$ W.) since before 1991 . The West Campus Station is situated along a south-facing coastline at $11-\mathrm{m}$ elevation in coastal grass/scrub lands $\sim 0.5 \mathrm{~km}$ from the shoreline (fig. 7). The Coal Oil Point seep field lies within an 8-km arc of West Campus Station from $130^{\circ}$ to $240^{\circ}$, with strong inshore seeps, such as Horseshoe Seep, within $2 \mathrm{~km}$. Devereux Slough lies east of West Campus Station while the Ellwood Marine Terminal oil storage tanks and facility (Venoco, Inc.) are to the west-northwest (figs. 7, 24).

Variability in West Campus Station data arises from two sources, transport and emission, that both must be considered to understand the source strength component. The afternoon sea breeze has the narrowest range of wind directions (most consistent) of any time of day and the broadest wind speed range. The greatest THC variability in concentration occurs near 0900 and 2000 PST, while lower THC variability tends to occur in the afternoon (Bradley and others, 2010). Regarding seasonal trends and varying day length (which affects sea breeze duration), southwest winds are the most frequent in summer, while northeast winds are dominant in winter. Summer wind speed has a broader peak than in winter months; however, winds greater than $7 \mathrm{~m} \mathrm{~s}^{-1}$ are most frequent in the spring owing to weather systems. THC shows a more subtle seasonal pattern, with little variability in peak values, although summertime THC values generally were lower (Bradley and others, 2010). THC shows a comparatively dramatic shift in the long-term trend near 1997, with a decrease in probability for high values prior to this date and an increase afterwards (Bradley and others, 2010) with no corresponding inter-annual surface-wind trend. The multiyear trend, when viewed in terms of mean THC for $5^{\circ}$ winddirection bins, suggests that seep field emissions may have peaked in 2004-2005.

Not only does the angular distribution of seepage show very good correspondence with sonar-mapped seepage emissions (fig. 24), but THC levels for winds from the seep field directions have THC high concentrations. Peak values corresponded with the $215^{\circ}-245^{\circ}$ sector, which includes nearby (Shane seep) and more distant sources (HolOil seep and Platform Holly) (Bradley and others, 2010). The highest value was $\sim 152.5^{\circ}$ (La Goleta and inshore seeps). The highest THC values arise for winds from the seep-field direction (fig. 24), which demonstrates that the Coal Oil Point seep field is the dominant THC source at West Campus Station, especially considering that THC values for the marine sector would otherwise be expected to be lower than for terrestrial sectors.

In addition to the West Campus Station seep-data trends, other effects can alter subsurface hydrocarbon pressure (Fischer, 1977; Leifer and others, 2010), such as synoptic or geologic events that influence emission flux. Internal geologic processes likely are the dominant force for West Campus Station THC emissions on inter-annual time scales. Thus, a decrease in seepage implies seabed emissions are greater than resupply from the Monterey Formation, which leads to depressurization of near seabed reservoirs. Conversely, an emission increase must result from an increase in deep migration due to the opening of new pathways, possibly generated by earthquake processes. Observations since the 1940s (Fischer, 1977) suggest slow emission changes on decadal and longer time scales.

Likely external (environmental) processes with the potential to affect seep-field emissions are primarily storm related. Storms can scour the seabed, dislodging or opening tar caps that seal migration pathways. Storms also may affect seepage through swell-related hydrostatic pumping (I. Leifer, unpub. observations, 2009). An interesting hypothesis
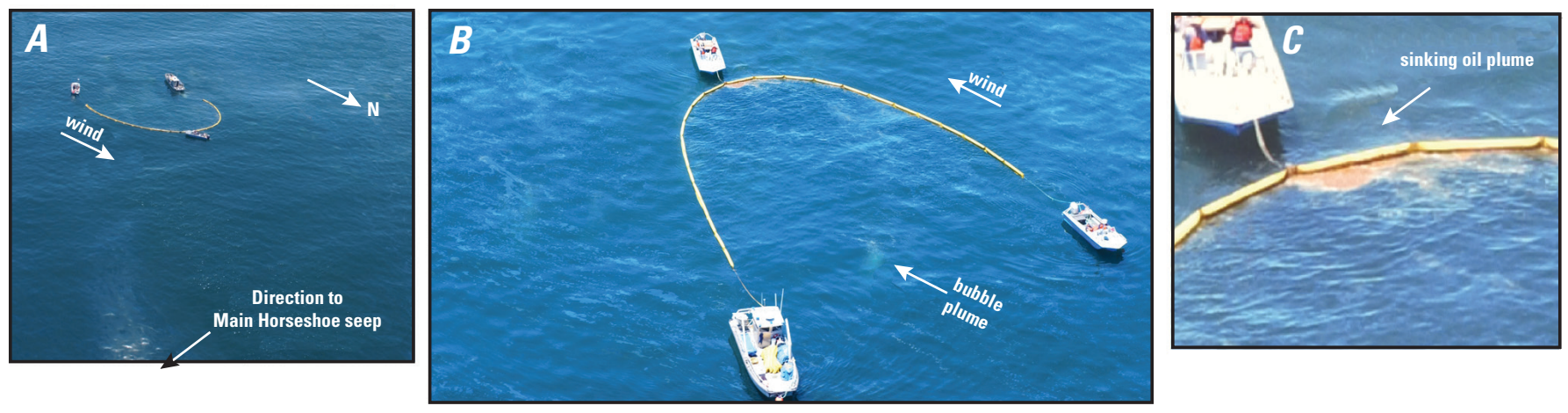

Figure 23. Aerial images of the oil boom collection experiment at Horseshoe seep, July 13, 2006. $A$ (see fig. 7 for location), Clean Seas vessels hold an oil boom in place as the wind blows the fresh oil slick into the boom. The main portion of Horseshoe seep is to the lower left. $B$, Closer view showing bubble plume source of oil. $C$, Enlarged image of collected oil, $\sim 1$ I. This enlargement was contrastenhanced to show sinking oil plume (reddish area above the plume). 
is that rains could affect seepage through aquifer recharge. Rock strata extends from the coastal plain under the seabed and is penetrated by faults onshore (Jackson and Yeats, 1982) and offshore (Leifer and others, 2010) that provide potential pathways for seep migration. Monthly probabilities of high THC events show peaks in November and in February-March, which could be related to storms and rainfall occurring during the winter rainy season.

\section{Tarball Accumulation Data}

Tar accumulation data on Coal Oil Point beaches were collected sporadically over the last four years. Prior to this study, a total of 57 days of tar collection spanning approximately one year (2007) were analyzed by Del Sontro and others (2007); statistical analysis of the tar data and environmental variables showed a very strong (order of magnitude) seasonal variation in tar accumulation and only 30 percent of the variability was explained by transport.

\section{Recommended Steps in Remotely Quantifying Seep Emissions}

\section{Multibeam Sonar}

One of the new technologies is multibeam sonar, which provides improvements in spatial resolution that are orders of magnitude higher than chirp sonar. This vastly higher spatial resolution allows far finer scale structure to be identified. Multibeam sonar also has the capability to address several geometric challenges that cannot be addressed by single-beam sonar. Rotating multibeam sonar can allow for discriminating seep bubbles from fish.

\section{Remote Sensing Derivation of Oil Thickness}

A multiagency/university effort (USGS, NOAA, UCSB, Desert Research Institute, U.C. Santa Cruz, and U.C. Davis) led by the National Aeronautics and Space Administration

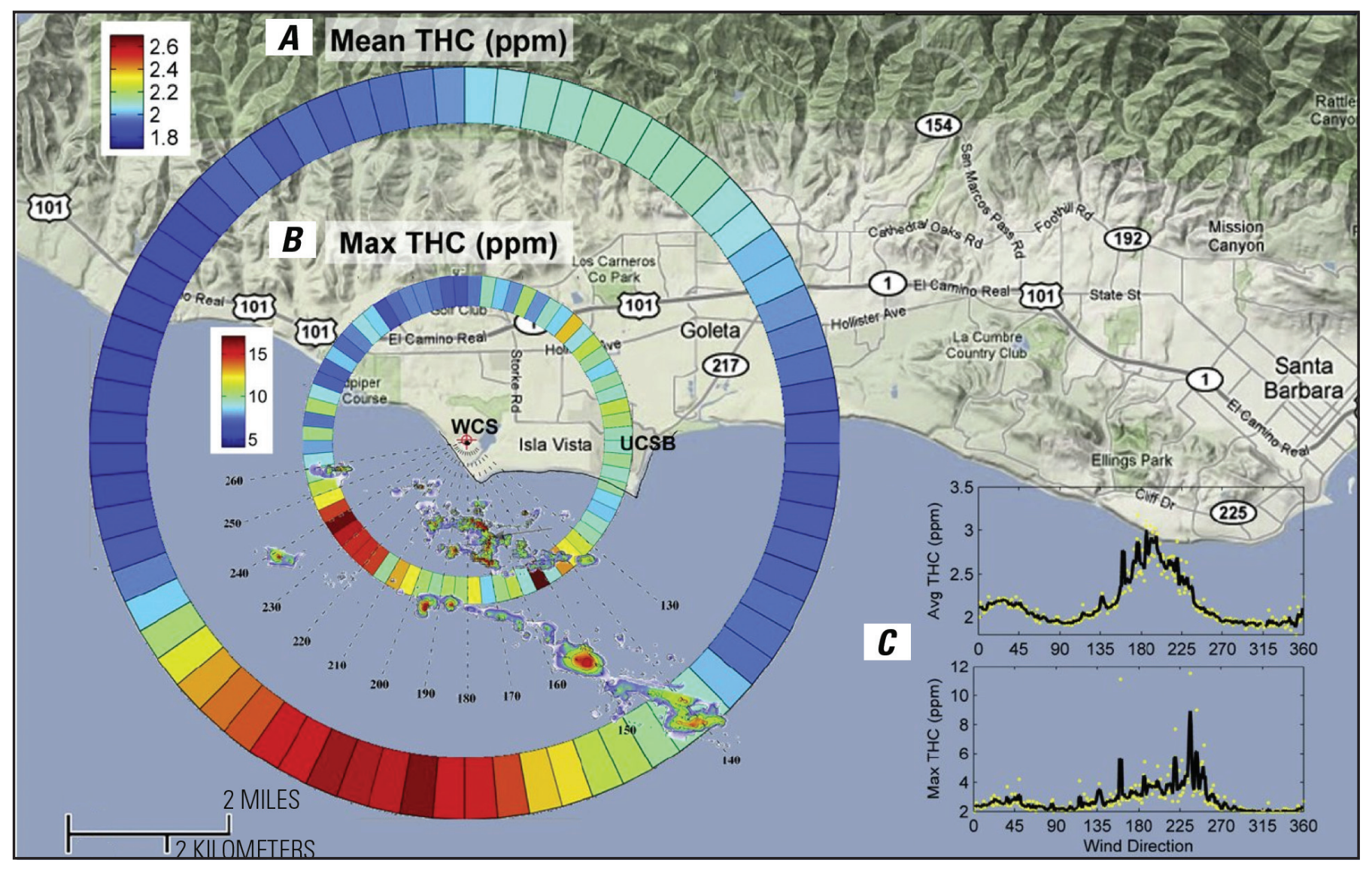

Figure 24. $A$, Mean and $B$, maximum total hydrocarbon (THC) concentrations for $5^{\circ}$ binned wind direction (outer and inner color wheel, respectively) overlain on Santa Barbara terrain map (Google Maps, 2010), with sonar contours representing relative gas seepage rates (fig. 7). Blue to red color scale for $A$ is 1.7 to $2.7 \mathrm{ppm}$ and for maximum values $B$ is 0 to $17 \mathrm{ppm}$. $C$, Plots of THC versus wind direction. Filtered data 2-4 $\mathrm{m} \mathrm{s}^{-1}$ for 2005 and 2006, unsmoothed $1^{\circ}$ data (yellow) and smoothed $3^{\circ}$ moving average (black). From Bradley and others (2010). 
(NASA) was mobilized to respond to oil spills. As part of this effort, a new physics-based, remote-sensing approach to quantify oil thickness was developed for imaging spectrometric data collected from the Airborne Visible/Infrared Imaging Spectrometer (AVIRIS) data flown on the NASA Lockheed ER-2 stratospheric airplane. AVIRIS collects the reflectance spectrum from 380 to 2,500 $\mathrm{nm}$ in 224 channels with a $\sim 10$ $\mathrm{nm}$ bandwidth (Green and others, 1998).

In reflectance, light at different wavelengths penetrates an absorbing layer to different depths owing to varying absorption and scattering (Clark, 1999), which enables different wavelengths to probe an oil or oil-emulsion layer to different depths (fig. 25). This creates a skew in an absorption feature, or "shoulderness," schematically illustrated in figure $25 A-D$. Furthermore, the continuum is shaped by nearby water absorptions, which are affected by the oil-to-water emulsion ratio. For thin oil, light for wavelengths spanning the absorption feature penetrates the oil and is absorbed by the underlying water (fig. 25B). For thick oil, light inside and outside of the feature is absorbed and scattered by the oil without reaching the underlying seawater, so there is no layer thickness effect on the spectra. For intermediate-thickness slicks, longer-wavelength light in the absorption bands penetrates better than shorter-wavelength light. As a result, enhanced absorption of longer-wavelength light in the feature by the underlying water (fig. $25 C$, wavelength b) skews the feature.

Clark and others (2010b) showed that the overall Nearinfrared (NIR) reflectance spectrum changes with oil thickness (fig. 25) and with the oil-to-water emulsion ratio (fig. 26A,B). Meanwhile, clear water is extremely absorbing in the NIR reflectance spectrum, and as a result, the spectral sensitivity to emulsification is also strongly sensitive to slick thickness.
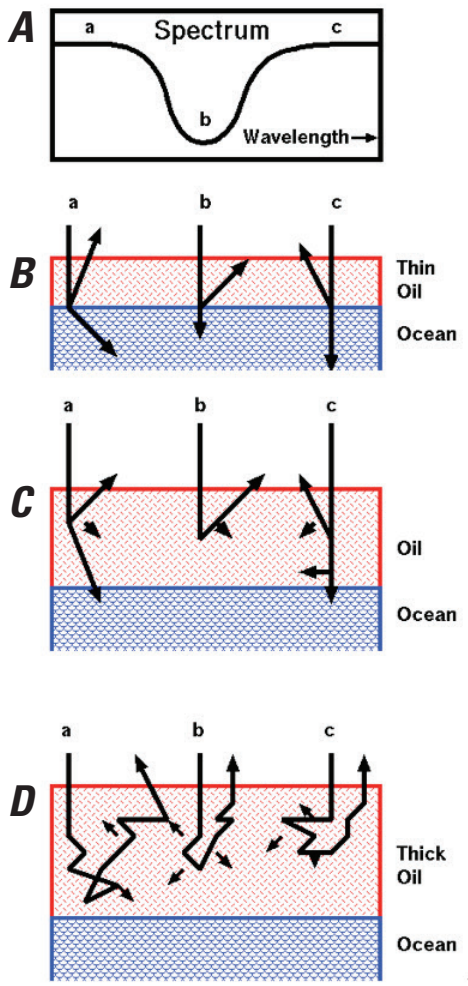

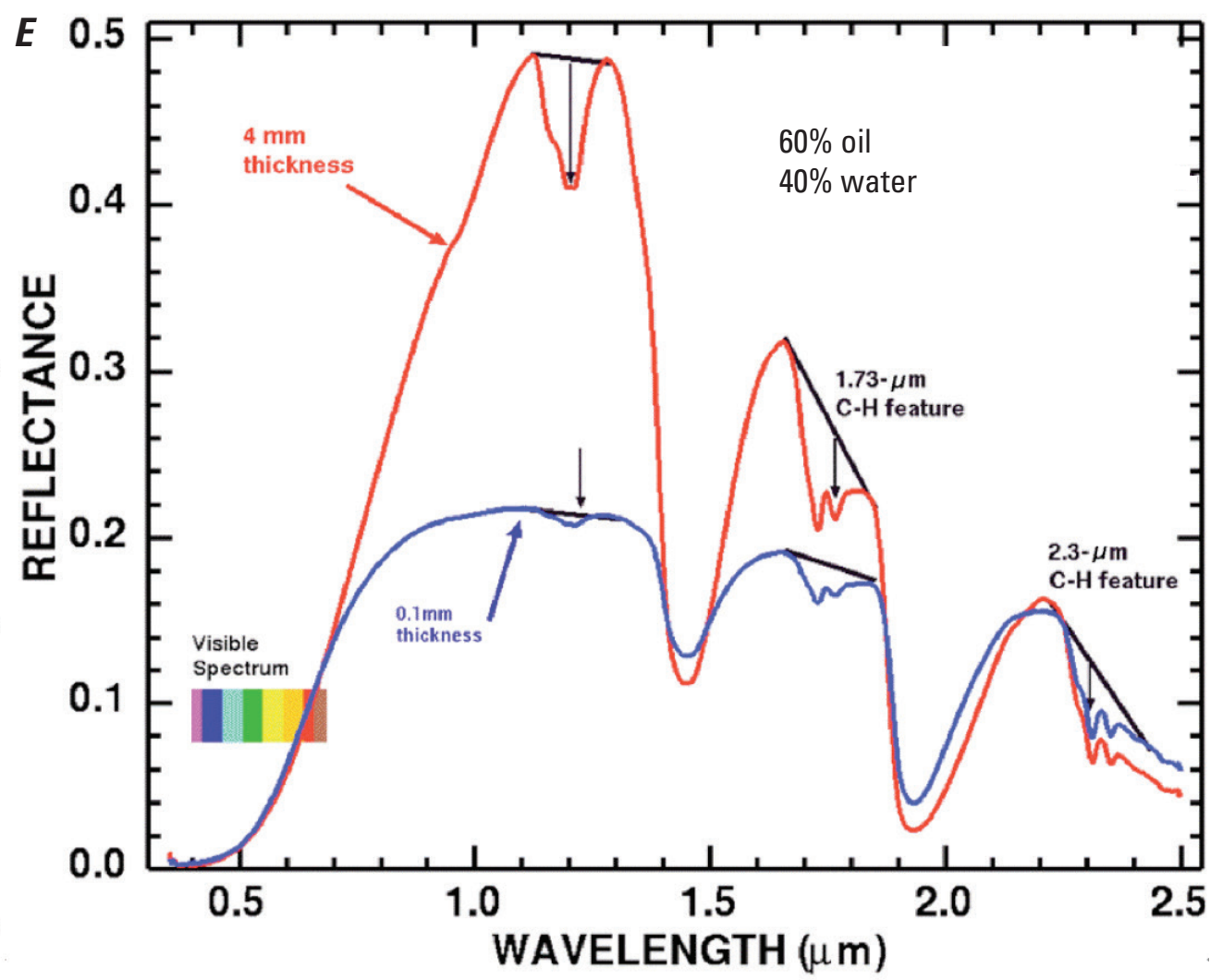

Figure 25. Illustrations showing light scattering in oil on water. Arrow length indicates amount of scattering intensity. $A$, Example spectrum with three wavelengths labeled a, b, and c. For thin oil $(B)$, light with wavelengths both in and out of absorption bands penetrates through the oil. For thicker oil $(C)$, light at wavelengths in absorption bands is absorbed before it penetrates very deeply (wavelength b). At less absorbing wavelengths, light penetrates deeper (wavelengths $\mathrm{a}, \mathrm{c})$. If the oil layer is thin ( $B$, all wavelengths; $C$, wavelengths a, c), light at some wavelengths will penetrate into the water. At infrared wavelengths, light that enters the water is mostly absorbed because of the combination of water's relatively strong absorption coefficient and relatively low density of scattering centers. The oil's thickness, spectral absorption features, and light scattering all contribute to the observed absorption band shapes and their depth in reflectance spectra of such surfaces. If the oil is very thick $(D)$, the total thickness is not probed at any wavelength-a, b, or $c$. $E$, Laboratory spectra of two different thicknesses of the same emulsions from an oil sample. Spectra were recorded for samples in a quartz-glass window cell over a water substrate contained in a glass jar painted flat black on the inside. Black lines illustrate continuum endpoints. From Clark and others (2010b). 

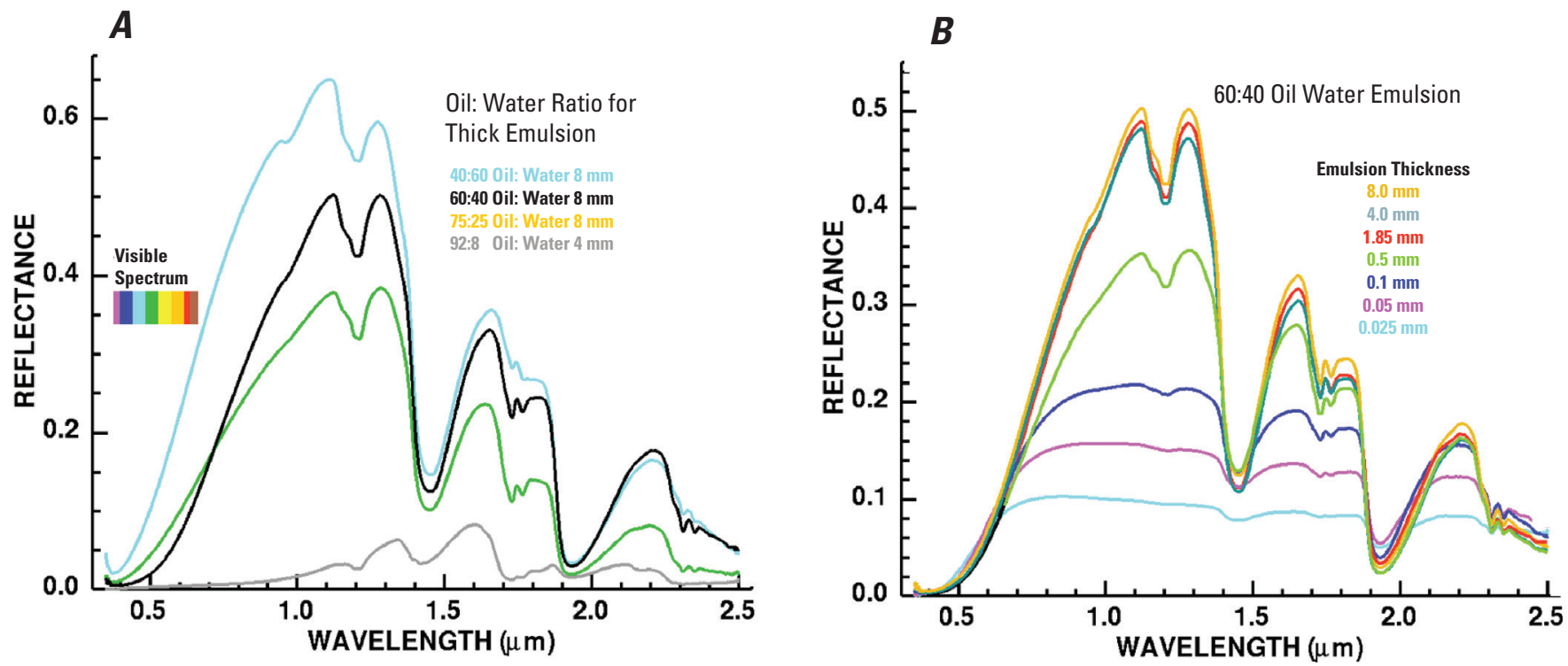

Figure 26. A, Oil:water emulsion spectra for a range of oil-to-water ratios for thick oil. $B$, Spectra of a 60:40 oil-to-water ratio emulsion over a range of thicknesses. From Clark and others (2010b).

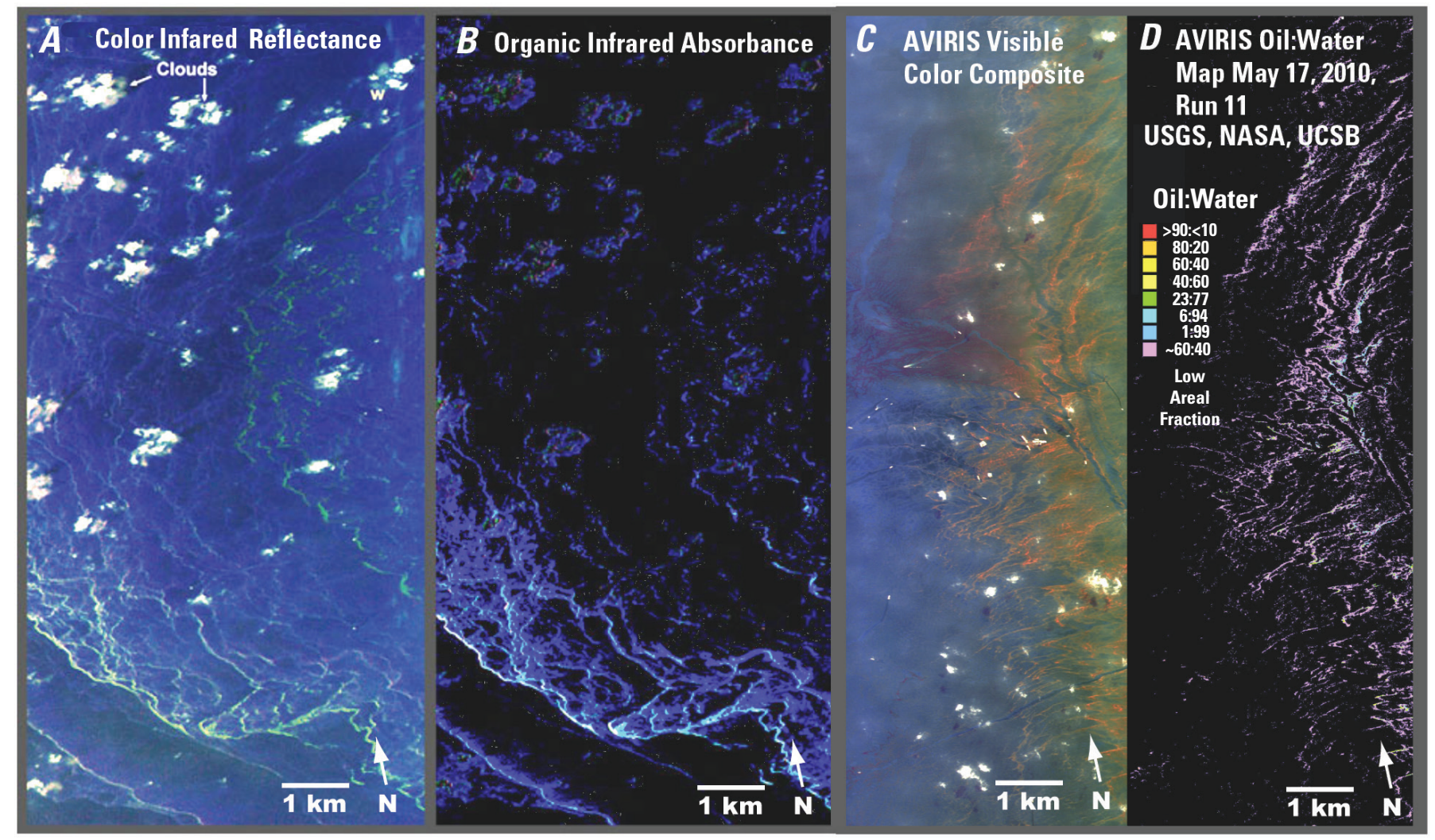

Figure 27. $A$, False color AVIRIS image, including clouds. Oil thickness: red, 2.46 microns; green, 1.60 microns; blue, 0.55 microns. $B$, RGB map of band absorption strength, which correlates with oil thickness. Oil thickness: red, 2.30 microns; green, 1.73 microns; blue, 1.20 microns. C, Visual AVIRIS oil scene. D, Tetracorder oil-to-water emulsion ratio map. From Clark and others, (2010b). 
Emulsion thickness has a small effect on visible reflectance spectra (fig. 26B). In contrast, the oil-to-water emulsion ratio strongly affects the visible reflectance spectrum (fig. 26A,B).

\section{Quantitative Oil-Spill Mapping}

Quantitative oil-spill mapping using remote sensing is an emergent technology that could be used at Coal Oil Point to quantify oil emission. Clark and others (2010b) mapped oil volume using the Tetracorder spectral identification software (Clark and others, 2003b), which identifies the best fit to a spectral library of oil-to-water emulsions and oil thicknesses for each AVIRIS pixel, after correcting for the solar spectrum, atmospheric gas absorptions, and aerosol scattering features based on Atmospheric Correction Now (ACORN) radiative transfer calculations and vegetation-free calibration beach/ airport tarmac spectra measured with a hand-portable spectrometer. The spectrometer probes different thicknesses of oil and translates the spatial patterns related to thickness into a colored map of the absorption features (fig. 27B). The resultant map captures the asymmetry caused by oil spreading and also documents hydrocarbons in clouds. Clearly the application of this technology to remotely quantify Coal Oil Point oil would be beneficial.

\section{Air Pollution Data}

The analysis of the West Campus Station 1-hour THC data was used to look at the relation between seepage and geology, as well as the effect of environmental forcing factors. Starting in 2008, 1-minute data were collected, improving the temporal resolution by a factor of 60 . Because of the need to segregate data according to wind direction, this is a highly

A

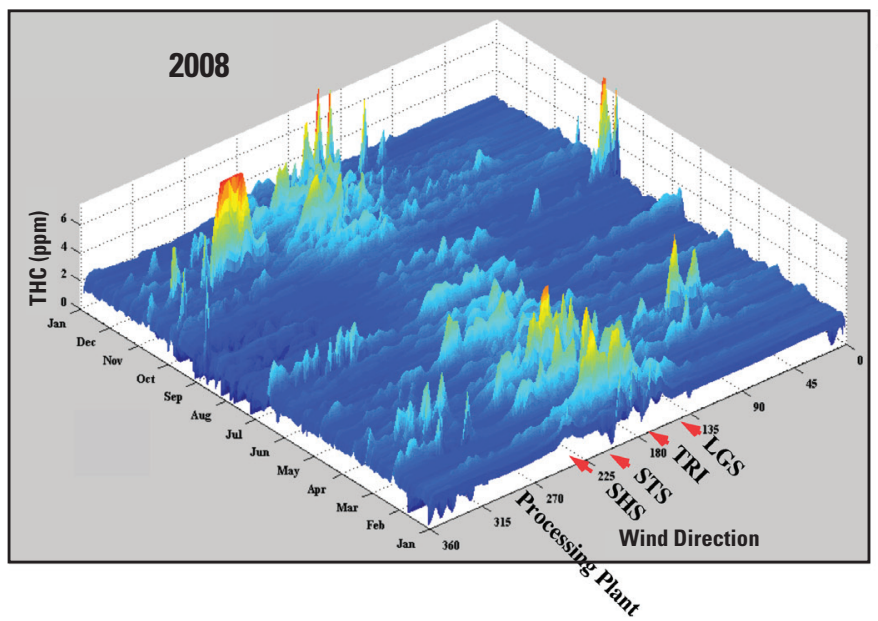

significant improvement in the data quality. The higher time resolution of the newer data allows analysis at far higher temporal resolution. For example, the data shows the importance of transient emissions (fig. 28), which was not discernable in the hourly data. It also shows how transient increases extend over a large portion of the seep field; the strongest increases are in the Seep Tent seep and Trilogy seep areas.

\section{Tarball Accumulation Data Analysis}

Tarball accumulation data on Coal Oil Point Beach should be analyzed to enable inter-annual trends that could not be identified in the data collection period analyzed in Del Sontro and others (2007), which covered less than a year. Further data collections would improve understanding of long-term trends, such as the effect of El Nino cycles.

\section{Conclusions}

We were successful in (1) documenting seep locations and geochemically fingerprinting natural seep oils or tar; (2) geochemically fingerprinting coastal tar residues and potential tar sources in the study area, both onshore and offshore; (3) establishing chemical correlations between offshore active seeps and coastal residues, thus linking seep sources to oil residues; and (4) interpreting some of the geological context influencing the location and emission of natural seeps.

Biomarker and stable-carbon-isotope ratios were used to infer the age, lithology, organic matter input, and depositional environment of the source rocks for 388 samples of produced crude oil, seep oil, and tarballs mainly from coastal southern California. These samples were used to construct a

Figure 28. Total Hydrocarbon Concentrations (THC) of 2008 sample from West Campus Station (WCS) as a function of wind direction showing high temporal variability in seep-field emissions. B, Reference wind-direction map. LGS, La Goleta seep; SHS, Shane seep; STS, Seep Tent seep; TRI, Trilogy seep. See fig. 7 for location. From Bradley and others (2010). 
chemometric fingerprint (multivariate statistics) decision tree to classify additional samples, including tarballs of unknown origin collected from Monterey County and San Mateo County beaches after a storm in early 2008. All active offshore platform oils and one inactive platform oil representing a few oil reservoirs from the western Santa Barbara Channel were used in this analysis. The chemometric model produces robust results for hydrocarbons associated with Miocene rocks in California that contain oil deposits and highlights those that do not.

The results identify three tribes of ${ }^{13} \mathrm{C}$-rich oil samples inferred to originate from thermally mature equivalents of the upper siliceous unit, middle shale unit, and lower calcareous unit of the Monterey Formation. Tribe 1 contains four oil families that have geochemical traits of clay-rich, marine-shale source rock. Tribe 2 contains four oil families with intermediate traits, except for abundant 28,30-bisnorhopane, that indicate suboxic to anoxic, marine-marl source rock. Tribe 3 contains five oil families with traits of distal marine-carbonate source rock. Tribes 1 and 2 occur mainly south of Point Conception in paleogeographic settings where deep burial of the Monterey Formation source rock favored oil generation from all three units or their equivalents. In this area, oil from the upper siliceous unit and middle shale unit (tribes 1 and 2) may overwhelm oil from the lower calcareous unit (tribe 3), because the latter is thinner and less oil-prone than the overlying units. Tribe 3 occurs mainly north of Point Conception, where shallow burial caused preferential generation from the underlying lower calcareous unit or another unit with similar characteristics.

We attempted to clearly distinguish the naturally occurring seep oils from the anthropogenically derived platform oils. Within the 388-sample training set of oils and tars, the biomarker parameters are sometimes sufficient to allow unique discrimination of individual platform oils. However, produced platform oil samples and seep samples from geographically close sources have biomarker parameters that are too similar to each other to definitively differentiate them using only biomarker parameters. In some cases, other parameters, related to the degree of biogeochemical degradation or weathering that the oils or tars have experienced, can be helpful. These parameters include the typical oil distribution of $n$-alkane hydrocarbons and isoprenoids pristane and phytane. All of the platform oils in our sample set contain these parameters.

Conversely, the seep oils have been exposed to significant biodegradation while in the near subsurface sediments. The majority, but not all, of seep tars in our sample set have been biodegraded to, or beyond, the point of loss of $n$-alkanes and isoprenoids. Seep oils found in the vicinity of Coal Oil Point are the least weathered samples, and a combination of chemometric fingerprinting and the presence or absence of $n$-alkanes and isoprenoids help to differentiate these two classes (anthropogenic production oils as opposed to natural seeps) of oils and tars.

The differentiation between anthropogenic production oils and natural seeps is not always definitive, because of the close chemical similarity of some samples and the variability in the biodegradation progression. This is the case near Coal Oil Point and the platforms of the Dos Cuadros Oil Field, where seep oils and platform oils are genetically very similar and cannot be definitively distinguished after a period of a few days of weathering. In contrast, oils from the platforms of the Point Arguello and Point Pedernales Oil Fields can be distinguished on the basis of chemometric fingerprinting alone. In the middle of this spectrum are oils from platforms such as Harmony, Heritage, and Hondo, where we expect that oil weathering would take on the order of 2 weeks to a month to produce tarballs similar to those seen near Point Conception.

Platform-produced oils are only classified in tribes 1 and 2 , within families $11,12,13,14,211,212,213$, and 22. Tribe 1 oils are restricted to the Los Angeles Basin and the eastern Santa Barbara-Ventura Basin. Family 13 is the most common family from this area and the most common oil family overall $(\sim 40 \%)$ that was analyzed in these studies. The western Santa Barbara-Ventura Basin (west of Platform Holly) and the Southern Santa Maria Basin oils are mainly in tribe 2. Tribe 3 is not represented by any oil in southern California and, therefore, must have sources outside this area, likely in littleexplored basins offshore of the central coast of California.

Tribe 3 tarballs have no known seep or oil source. The most frequent tarball family (22) occurs in 55.6 percent of the samples, in 36.5 percent of all seeps, and from 14.2 percent of produced oils. The most frequent oil family (13) comprises almost 40 percent of the produced oils, 9.1 percent of all seeps, and 0.4 percent of the tarballs, indicating that past oil spillage is very unlikely. Extreme biodegration prevented 51.7 percent of the seep samples from being classified by our model.

Surface oil slicks from the Coal Oil Point seep field weathered after a few hours and began sinking, suggesting that a significant amount of oil from the seep field sinks into the water column and is deposited on the seafloor.

We used the unique combination of 3-D seismic modeling and sonar-seepage mapping to elucidate details on the relation between seepage and geological structures. We noted that migrational recharge of the shallow seepage in Coal Oil Point is not only from deeper offshore Monterey Formation towards onshore but also from the east and west. Seepage is strongly controlled by the axes of anticlines, showing a strong relation between anticline depth and seepage strength. Seepage also was strongly delineated by the hanging wall of a reverse thrust fault.

Through the use of hourly atmospheric measurements at West Campus Station and sector analysis, we derived emission trends for the seep field spanning two decades, which showed that Hornafius and others (1999) measured emissions at a period of relative minimal activity and that current emissions are significantly larger. The spatial distribution of seepage also may have been reduced in extent to largely the Seep Tent seep during the time period of minimal seepage. Furthermore, results also supported the hypothesis that winter storms could correlate to strong emission events. Seasonal methaneemission trends were the opposite of those for tar, which were significantly greater in the summer than in the winter. 
Looking forward, several new technologies and applications show excellent potential for the remote sensing and quantification of seep gas and oil. When calibrated to gas flux in the water column, multibeam sonar can quantify gas emission and, when the oil-to-gas ratio is known, can quantify oil emission. New techniques are being developed using airborne infrared, and visual spectrometers can quantify the thickness of oil on the sea surface, allowing measurement of spilled oil and seep oil volume.

\section{Acknowledgments}

This study was funded in part by Interagency Agreement \#M08PG20013 NSL 06-03a between the Bureau of Ocean Energy Management (BOEM), Pacific OCS Region, and the U.S. Geological Survey, Pacific Coastal and Marine Science Center, and by Cooperative Agreement \#M07AP12407 NSL 06-03b between BOEMRE and the University of California, Santa Barbara.

Mary Elaine Helix (BOEM) helped to initiate this study with Keith Kvenvolden (USGS) and served deftly as the BOEM Contract Officer Representative. Dave Panzer (BOEM) arranged for and provided many of the offshore platform oil samples. Marida Martin at the California Department of Fish and Game, Office of Spill Prevention and Response, provided valuable collaboration with us in sharing, collecting, and analyzing selected tar residues. Ken Peters (Sclumberger) and L. Scott Ramos (Infometrix, Inc.) provided assistance with Pirouette and InStep and discussion of chemometrics applications.

Many people associated with UCSB and the USGS contributed in many ways to this project, and we thank them for their contributions. Of special note are the contributions of Jamie Glover, Jonathan Borden, Gerry Hatcher, and Sarah Doty (all USGS), who piloted the R/V Parke Snavely and the ROV used in this study and acted as electronic technicians among many other duties. Pete Dartnell, Jamie Conrad (both USGS), and Rick Kvitek (California State University, Monterey Bay) created most of the shaded-relief bathymetry used in this report. Pat Hart, Larry Kooker, Chuck Woorley, and Peter Triezenberg (all USGS) were participants in some cruises. Jackson Currie and Jane Reid assisted in tarball collection. Edna Huetton (IMF-Geomar, Keil, Germany) assisted in water collection and analysis. We also thank the captain and crews of the R/V Shearwater, the R/V Zephyr, and the R/V Garibaldi for their participation. This project also benefited greatly from the advice and ideas of members of the quality review board for this project: John Day (County of Santa Barbara, Energy Division) and Mark Kamerling (Venoco, Inc.). Bill Ussler III and Charlie Paul (MBARI) provided facilities for testing the acoustic response of the 424 Chirp single-beam profiler. Pete Swarzenski and Sam Johnson (both USGS) provided very helpful reviews of this manuscript.

\section{References Cited}

Allen, A.A., Schleuter, R.S., and Mikolaj, P.G., 1970, Natural oil seepage at Coal Oil Point, Santa Barbara, California: Science, no. 170, p. 974-977.

Bartlett. W.L., 1998, Elwood oil field, Santa Barbara County, California, in Structure and petroleum geology of Santa Barbara Channel, California: American Association of Petroleum Geologists, Pacific Section, Miscellaneous publication MP-46, p. 217-237.

Bence, A.E., Kvenvolden, K.A., and Kennicutt, M.C., II, 1996, Organic geochemistry applied to environmental assessments of Prince William Sound, Alaska, after the Exxon Valdez oil spill-A review: Organic Geochemistry v. 24, p. 7-42.

Boles, J.R., Clark, J.F., Leifer, I., and Washburn, L., 2001, Temporal variation in natural methane seep rate due to tides, Coal Oil point area, California: Journal Geophysical Research-Oceans, v. 106, no. C11, p. 27,077-27,086.

Boles, J.R., Eichhubl, P., Garven, G., and Chen, J., 2004, Evolution of a hydrocarbon migration pathway along basinbounding faults - Evidence from fault cement: American Association of Petroleum Geologists Bulletin, v. 88, no. 7, p. 947-970.

Boles, J.R., and Horner, S., 2009, Fault/fracture permeability estimated from response of a natural marine methane seep to underlying hydrocarbon production: American Association of Petroleum Geologists, Abstracts Volume, Annual Convention and Exhibition, Denver, Colorado, v. 18, p. 25-26.

Bradley, E.S., Leifer, I., and Roberts, D., 2010, Long-term monitoring of a marine geologic hydrocarbon source by a coastal air pollution station in southern California: Atmospheric Environments, v. 44, p. 4973-4981.

Christensen, K., Wracher, M., and Orr, G., 2000, South Ellwood Field, Santa Barbara Channel-New insight into structures, fractures, and seeps: American Association of Petroleum Geologists Bulletin, v. 84, no. 6, p. 862.

Clark, J.F., Leifer, I., Washburn, L., and Luyendyk, B.P., 2003a, Compositional changes in natural gas bubble plumes-Observations from the Coal Oil Point marine hydrocarbon seep field: Geo-Marine Letters, v. 23, no. 3-4, p. 187-193. doi:10.1007/s00367-003-0137-y.

Clark, J.F., Washburn, L., and Emery, K., 2010a, Variability of gas composition and flux intensity in natural marine hydrocarbon seeps: Geo-Marine Letters, v. 30, no. 3, p. 379-388.

Clark J.F., Washburn, L., Hornafius, J.S., Luyendyk, B.P., 2000, Dissolved hydrocarbon flux from natural marine seeps to the Southern California Bight: Journal of Geophysical Research, v. 105, no. C5, p. 11,509-11,522. 
Clark, R.N., 1999, Spectroscopy of rocks and minerals, and principles of spectroscopy, in Rencz, A.N., ed., Remote sensing for the earth sciences ( $3 \mathrm{~d}$ ed.): New York, John Wiley \& Sons, Inc., p. 3-58.

Clark, R.N., Swayze, G.A., Leifer, I. Livo, K.E., Kokaly, R., Hoefen, T., Lundeen, S., Eastwood, M., Green, R.O., Pearson, N., Sarture, C., McCubbin, I., Roberts, D., Bradley, E., Steele, D., Ryan, T., Dominguez, R., and the Air borne Visible/Infrared Imaging Spectrometer (AVIRIS) Team, 2010b, A method for quantitative mapping of thick oil spills using imaging spectroscopy: U.S. Geological Survey Open-File Report 2010-1167, $51 \mathrm{p}$.

Clark, R.N., Swayze, G.A., Livo, K.E., Kokaly, R.F., Sutley, S.J., Dalton, J.B., McDougal, R.R., and Gent, C.A., 2003b, Imaging spectroscopy - Earth and planetary remote sensing with the USGS Tetracorder and expert systems: Journal of Geophysical Research, v. 108, no. E12, 5131, doi:10.1029/2002JE001847, p. 5-1 to 5-44.

Clester, S.M., Hornafius, J.S., Scepan, J., and Estes, J.E., 1996, Remote sensing study of historical changes in natural oil slick volumes in the Santa Barbara Channel-Final Report 1995/1996: Berkeley, University of California Energy Institute, California Energy Study Project.

Curiale, J.A., Cameron, D., and Davis, D.V., 1985, Biological marker distribution and significance in oils and rocks of the Monterey Formation, California: Geochimica et Cosmochimica Acta, v. 49, p. 271-288.

Del Sontro, T.S., Leifer, I., Luyendyk, B.P., and Broitman, B.R., 2007, Beach tar accumulation, transport mechanisms, and sources of variability at Coal Oil Point, Califoria: Marine Pollution Bulletin, v. 54, p. 1461-1471.

Dibblee, T.W., Jr., 1966, Geology of the Central Santa Ynez Mountains, Santa Barbara County, California: California Division of Mines and Geology Bulletin 186, 99 p., map scales 1:62,500 and 1:31,680.

Draut, A.E., Hart, P.E., Lorenson, T.D., Ryan, H.F., Wong, F.L., Sliter, R.W., and Conrad, J.E., 2009, Late Pleistocene to Holocene sedimentation and hydrocarbon seeps on the continental shelf of a steep, tectonically active margin, southern California, USA: Marine Geophysical Researches, doi:10.1007/s11001-009-9076-y.

Drewry, S.D., 1997, Los Angeles Basin Province, in Dinkle, C.A., and Piper, K.A. eds., 1995 National assessment of United States oil and gas resources-Assessment of the Pacific Outer Continental Shelf Region: Minerals Management Service OCS Report MMS 97-0019, p. 116-119.

Ensminger, A., van Dorsselaer, A., Spykerelle, C., Albrecht, P., and Ourisson, G., 1974, Pentacyclic triterpanes of the hopane type as ubiquitous geochemical markers-Origin and significance, in Tissot, B., and Brenner, F., eds., Advances in Organic Geochemistry 1973: Paris, Editions Technip, p. 245-260.
Finkbeiner, T., Barton, C.A., and Zoback, M.D., 1997, Relationships among in-situ stress, fractures and faults, and fluid flow-Monterey Formation, Santa Maria Basin, California: American Association of Petroleum Geology Bulletin, v. 81, no. 12, p. 1975-1999.

Fischer, P.J., 1976, Late Neogene-Quaternary tectonics and depositional environments of the Santa Barbara Basin, California, in Fritsche, A.E., and others, eds., The Neogene symposium: Society of Economic Paleontologists and Mineralogists, Pacific Section Annual Meeting, p. 33-51.

Fischer, P.J., 1977, Natural gas and oil seeps, Santa Barbara Basin, California, in Everitts, D.J., Eaton, C.F., Paul, R.G., and Welday E.E., eds., California offshore gas, oil and tar seeps: California State Lands Commission Staff Report, Part A, 62 p.

Fischer, P.J., and Stevenson, A.J., 1973, Natural hydrocarbon seeps along the northern shelf of the Santa Barbara Basin, California, in Fischer, P.J., ed., Santa Barbara Channel revisited: Tulsa, Okla., American Association of Petroleum Geology, Pacific Section, Field Trip Guidebook, v. 3, p. 17-28.

Galloway, J., 1998a, Chronology of petroleum exploration and development in the Santa Barbara Channel area, offshore southern California, in Structure and petroleum geology of Santa Barbara Channel, California: American Association of Petroleum Geologists, Pacific Section, Miscellaneous publication MP-46, p. 1-12.

Galloway, J., 1998b, Santa Barbara-Ventura Basin province-1995 assessment of undiscovered oil and gas resources, in Structure and Petroleum Geology of Santa Barbara Channel, California: American Association of Petroleum Geologists, Pacific Section, Miscellaneous Publication MP-46, p. 63-71.

Grantham, P.J., and Wakefield, L.L., 1988, Variations in the sterane carbon number distributions of marine source rock derived crude oils through geological time: Organic Geochemistry, v. 12, p. 61-73.

Green, R.O., Eastwood, M.L., Sarture, C.M., Chrien, T.G., Aronsson, M., Chippendale, B.J., Faust, J. A., Pavri, B.E., Chovit, C.J., Solis, M., and Olah, M.R., 1998, Imaging spectroscopy and the Airborne Visible/Infrared Imaging Spectrometer (AVIRIS): Remote Sensing of Environment, v. 65 , no. 3., p. $227-248$.

Hornafius J.S., Quigley, D., and Luyendyk, B.P., 1999, The world's most spectacular marine hydrocarbon seeps, Coal Oil Point, Santa Barbara Channel, California-Quantification of emissions: Journal of Geophysical Research, v. 104, p. 20,703-20,711.

Horner, S., and Ershaghi, I., 2002, An advanced fracture characterization and well path navigation system for effec- 
tive re-development and enhancement of ultimate recovery from the complex Monterey Reservoir of the South Ellwood Field, offshore California: U.S. Department of Energy, Report no. DE-FC26-00BC15127, 17 p.

Hostettler, F.D., Rosenbauer, R.J., and Kvenvolden, K.A, 1999, PAH refractory index as a source discriminant of hydrocarbon input from crude oil and coal in Prince William Sound, Alaska: Organic Geochemistry, v. 30, p. 873-879.

Hostettler, F.D., Rosenbauer, R.J., Lorenson, T.D., and Dougherty, J., 2004, Geochemical characterization of tarballs on beaches along the California coast, Part I-Shallow seepage impacting the Santa Barbara Channel Islands, Santa Cruz, Santa Rosa, and San Miguel: Organic Geochemistry v. 35, p. 725-746.

Hsu, Y-K., VanCuren, T., Park, S., Jakober, C., Herner, J., FitzGibbon, M., Blake, D.R., and Parrish, D.D., 2009, Methane emissions inventory verification in southern California: Atmospheric Environment, v. 44, no. 1, p. 1-7.

Jackson, P.A., and Yeats, R.S., 1982, Structural evolution of Carpinteria Basin, western Transverse Ranges, California: American Association of Petroleum Geology Bulletin, v. 66, no.7, p. 805-829.

Kamerling, M.J., Horner, S., and Thompson, L., 2003, The Monterey Formation at South Ellwood Field, Santa Barbara Channel, California [abs.]: American Association of Petroleum Geology Pacific Section/Society of Petroleum Engineers Western Regional Joint Meeting, May 19-24, 2003, 1 p. (http://www.searchanddiscovery.net/abstracts/ pdf/2003/spe_aapg/ndx_kamerling.pdf).

Kaplan, I.R., Galperin, Y., Lu, S.T., and Lee, R.P., 1997, Forensic environmental geochemistry-differentiation of fuel-types, their sources and release times: Organic Geochemistry v. 27 , p. 289-317.

Kvenvolden, K.A., Hostettler, F.D., Carlson, P.R., Rapp, J.B., Threlkeld, C.N., and Warden, A., 1995, Ubiquitous tar balls with a California-source signature on the shorelines of Prince William Sound, Alaska: Environmental Science and Technology, v. 29, p. 2684-2694.

Landes, K.K., 1973, Mother nature as an oil polluter: American Association of Petroleum Geologists Bulletin, v. 57, p. 637-641.

Leifer, I., and Boles, J.R., 2005, Measurement of marine hydrocarbon seep flow through fractured rock and unconsolidated sediment: Marine and Petroleum Geology, v. 22, no. 4 , p. 551-568.

Leifer, I., Boles, J.R., Luyendyk, B.P., and Clark, J.F., 2004, Transient discharges from marine hydrocarbon seeps-Spatial and temporal variability: Environmental Geology v. 46, p. $1038-1052$.
Leifer, I., Kamerling, M.J., Luyendyk, B.P., and Wilson D.S., 2010, Geologic control of natural marine hydrocarbon seep emissions, Coal Oil Point seep field, California: GeoMarine Letters, v. 30, no. 3-4, p. 331-338.

Leifer, I., Luyendyk, B., Boles, J., and Clark, J.F., 2006b, Natural marine seepage blowout - Contribution to atmospheric methane: Global Biogeochemical Cycles, v. 20, GB3008, 9 p., doi:10.1029/2005GB002668.

Leifer, I., Luyendyk, B., and Broderick, K., 2006a, Tracking an oil slick from multiple natural sources, Coal Oil Point, California: Marine and Petroleum Geology, v. 23, no. 5, p. 621-630.

Leifer, I., and Wilson, K., 2007, The tidal influence on oil and gas emissions from an abandoned oil well, nearshore Summerland, California: Marine Pollution Bulletin, v. 54, no. 9, p. 1495-1506.

Lorenson, T.D., Dougherty, J.A., Hostettler, F.D., and Rosenbauer R.J., 2004, Natural seep inventory and identification for the County of Santa Barbara, California: Final Report, March 25, 2004, 84 p., at http://www.countyofsb.org/ energy/information/NaturalSeepInventoryFinalReport.htm.

Lorenson, T.D., Hostettler, F.A., Rosenbauer, R.J., Peters, K.A., Kvenvolden, K.A., Dougherty, J.A., Gutmacher, C.A., Wong, F., and Normark, W., 2009, Natural offshore seepage and related tarball accumulation on the California coastline-Santa Barbara Channel and the southern Santa Maria Basin; Source identification and inventory: U.S. Geological Survey Open-File Report 2009-1225 and Minerals Management Service report 2009-030, 260 p.

Mackenzie, A.S., 1984, Applications of biological markers in petroleum geochemistry, in Brooks, J., and Welte, D., eds., Advances in Petroleum Geochemistry (Vol. 1): London, Academic Press, p. 115-214.

Mackenzie, A.S., Patience, R.L., Maxwell, J.R., Vandenbroucke, M., and Durand, B., 1980, Molecular parameters of maturation in the Toarcian shales, Paris Basin, France-1. Changes in the configuration of acyclic isoprenoid alkanes, steranes, and triterpanes: Geochimica et Cosmochimica Acta, v. 44, p. 1709-1721.

Mau, S., Valentine, D.L., Clark, J.F., Reed, J., Camilli, R., and Washburn, L., 2007, Dissolved methane distributions and air-sea flux in the plume of a massive seep field, Coal Oil Point, California: Geophysical Research Letters, v. 34, p. L22603, doi:10.1029/2007GL031344.

Minor, S.A., Kellogg, K.S., Stanley, R.G., Gurrola, L.D., Keller, E.A., and Brandt, T.R., 2009, Geologic map of the Santa Barbara coastal plain area, Santa Barbara County, California: U.S. Geological Survey Scientific Investigations Map 3001, scale 1:25,000, 38 p. 
Ogle, B.A., Wallis, W.S., Heck, R.G., and Edwards, E.B., 1987, Petroleum geology of the Monterey Formation in the offshore Santa Maria/Santa Barbara areas, in Ingersoll, R.V., and Ernst, W.G., eds., Cenozoic basin development of coastal California: Englewood Cliffs, N.J., Prentice-Hall, p. 382-406.

Palacas, J.G., Anders, D.E., and King, J.D., 1984, South Florida Basin-A prime example of carbonate source rocks of petroleum, in Palacas, J.G., ed., Petroleum geochemistry and source rock potential of carbonate rocks: American Association of Petroleum Geologists, Studies in Geology No. 18, p. 71-96.

Peters K.E., Hostettler, F.D., Lorenson, T.D., and Rosenbauer, R.R., 2008, Families of Miocene Monterey crude oil, seep, and tarball samples, coastal California: American Association of Petroleum Geology Bulletin, v. 92, no. 9, p. 1131-1152.

Peters, K.E., and Moldowan, J.M., 1993, The biomarker guide: Englewood Cliffs, N.J., Prentice-Hall, 363 p.

Peters, K.E., Walters, C.C., and Moldowan, J.M., 2005, The biomarker guide: Cambridge, Cambridge University Press, $1155 \mathrm{p}$.

Quigley D.C., Hornafius, J.S., Luyendyk, B.P., Francis, R.D., Clark, J., and Washburn, L., 1999, Decrease in natural marine hydrocarbon seepage near Coal Oil Point, California, associated with offshore oil production: Geology. v. 27, p. $1047-1050$.

Seanz, J.M., 2002, Geological controls of hydrocarbon seeps in Santa Maria Basin, offshore California: Northridge, California State University at Northridge, M.S. thesis, 292 p.

Schouten, S., Sinninghe Damste, J.S., Schoell, M., and DeLeeuw, J., 1994, A novel sterane, 27-nor-24-methyl5a-cholestane, in sediments: Geochimica et Cosmochimica Acta, v. 58, p. 3741-3745.

Seifert, W.K., and Moldowan, J.M., 1978, Application of steranes, terpanes, and monoaromatics to the maturation, migration and source of crude oils: Geochimica et Cosmochimica Acta, v. 42, p. 77-95.
Sigalove J., 1985, Geochemical Identification of Resource Potential: Oil and Gas Journal, p. 164-168.

Sofer, Z., 1980, Preparation of carbon dioxide for stable carbon isotope analysis of petroleum fractions: Analytical Chemistry, v. 52, p. 1389-1391.

Tennyson, M.E., and Isaacs, C.M., 2001, Geologic setting and petroleum geology of Santa Maria and Santa Barbara Basins, in Isaacs, C.M., and Rullkötter, J., eds., The Monterey Formation-From rocks to molecules: New York, Columbia University Press, p. 206-229.

U.S. National Research Council, Committee on Oil in the Sea, 2003, Oil in the Sea III-Inputs, fates, and effects: Washington, D.C., National Academy Press, 265 p.

Vernon, J.W., and Slater, R.A., 1963, Submarine tar mounds, Santa Barbara County, California: American Association of Petroleum Geology Bulletin, v. 47, no. 8, p. 1624-1627.

Wang, Z., Fingas, M., Blenkinsopp, S., Sergy, G., Landriault, M., Sigouin, L., Foght, J., Semple, K. and Westlake, D.W.S., 1998, Comparison of oil composition changes due to biodegradation and physical weathering in different oils: Journal of Chromatography, v. A 809, p. 89-107.

Waples, D.W., and Curiale, J.A., 1999, Oil-oil and oil-source rock correlations, in Beaumont E.A., and Foster, N.H., eds., Exploring for oil and gas traps: Tulsa, Okla., American Association of Petroleum Geology, p. 8-1 to 8-71.

Waples, D.W., and Machihara, T., 1991, Biomarkers for geologists - A practical guide to the application of steranes and triterpanes in petroleum geology: American Association of Petroleum Geologists, Methods in Exploration No. 9, 91 p.

Washburn, L., Clark, J.F., and Kyriakidis, P., 2005, The spatial scales, distribution, and intensity of natural marine hydrocarbon seeps near Coal Oil Point, California: Marine and Petroleum Geology, v. 22, no. 4, p. 569-578.

Yerkes, R.F., Wagner, H.C., and Yenne, K.A, 1969, Petroleum development in the Santa Barbara Channel region, in Geology, petroleum development, and seismicity of the Santa Barbara Channel region, California: US Geological Survey Professional Paper 679B, p. 13-27. 
Appendix 1 


\section{Appendix 1. Geochemical Parameters used in Tarball Studies}

Parameters are organized by compound class then by order of elution. Parameters used for the chemometric analysis are indicated by red numbers.

\section{Whole oil}

1. $\delta^{13} \mathrm{C}$, the carbon isotopic composition of whole tar residues-These compositions are useful for oil and source rock correlations (Peters and Moldowan, 1993).

\section{Saturate fraction}

2. Alkanes-A descriptor where $0=$ no $n$-alkanes present in the tar/oil and $1=n$-alkanes present.

3. $\mathrm{Pr} / \mathrm{Ph}$, pristane/phytane - This is a widely used source parameter (Peters and Moldowan, 1993) based on the two most common isoprenoids in crude oils. These compounds are readily lost by degradation and are not present in most of the tarballs in this study, although they are prominent in unweathered production or crude oils.

Triterpanes (hopanes), $\mathbf{m} / \mathbf{z} 191$ SIM chromatograms

4. Ts/Tm, 18 $\alpha$-22,29,30-trisnorneohopane/17 $\alpha-22,29,30-$ trisnorhopane- This ratio is used as both a source and maturity parameter (Seifert and Moldowan, 1978).

5. Triplet, $\left(\mathrm{C}_{26}\right.$-tricyclic terpane ( $\mathrm{S}$ ?) $+\mathrm{C}_{26}$-tricyclic terpane $(\mathrm{R} ?) / \mathrm{C}_{24}$-tetracyclic terpane)-This source parameter was used to distinguish coastal tar residues in Prince William Sound (Kvenvolden and others, 1995). Abundant $\mathrm{C}_{24}$ tetracyclic is cited (Peters and others, 2005 ) as indicating carbonate and evaporite source facies, therefore lower values of this ratio (since $\mathrm{C}_{24}$ is the denominator) indicate this characteristic.

6. $23 \mathrm{Tri} / \mathrm{C}_{30}, \mathrm{C}_{23}$ tricyclic terpane/17 $\alpha, 21 \beta(\mathrm{H})$-hopane-This ratio is a source parameter adapted from Peters and Moldowan (1993).

7. $23 \mathrm{Tri} / \mathrm{C}_{29}, \mathrm{C}_{23}$ tricyclic terpane/17 $\alpha, 21 \beta(\mathrm{H})-30$-norho pane-This ratio is a source parameter adapted from Peters and Moldowan (1993).

8. 20Tri/23Tri, $\mathrm{C}_{20}$ tricyclic terpane/ $\mathrm{C}_{23}$ tricyclic terpaneSource parameter.

9. 22Tri/21Tri, $\mathrm{C}_{22}$ tricyclic terpane/ $\mathrm{C}_{21}$ tricyclic terpaneSource parameter, used by Peters and others (2005) to help distinguish lithofacies.

10. 24 Tri/23Tri, $\mathrm{C}_{24}$ tricyclic terpane/ $\mathrm{C}_{23}$ tricyclic terpaneSource parameter, used by Peters and others (2005) to help distinguish lithofacies.
11. 26Tri/25Tri, $\mathrm{C}_{26}$ tricyclic terpanes $/ \mathrm{C}_{25}$ tricyclic terpanes, peak areas - Source parameter; high values $(>1)$ indicate a lacustrine depositional environment, whereas lower values indicate a marine source.

12. 28 Tri/29Tri. $\mathrm{C}_{28}$ tricyclic terpanes $/ \mathrm{C}_{29}$ tricyclic terpanes, peak areas-Source parameter.

13. $\mathrm{C}_{29} / \mathrm{C}_{30}, 17 \alpha, 21 \beta(\mathrm{H})$-30-norhopane $/ 17 \alpha, 21 \beta(\mathrm{H})$ hopane-This ratio is a source parameter adapted from Palacas and others (1984).

14. 29D/29H, $18 \alpha(\mathrm{H})-30$-norneohopane/17 $\alpha, 21 \beta(\mathrm{H})-30$ norhopane-Source parameter

15. $\mathrm{C}_{31} \mathrm{~S} /(\mathrm{S}+\mathrm{R}), 17 \alpha, 21 \beta(\mathrm{H})$-homohopane $(22 \mathrm{~S}) / 17 \alpha, 21 \beta(\mathrm{H})$-homohopane $(22 \mathrm{~S}+22 \mathrm{R})$ - This epimer ratio is a hopane maturity parameter used extensively in petroleum geochemistry; the equilibrium ratio at full maturity is $\sim 0.6$ (Ensminger and others, 1974; Mackenzie, 1984).

16. $\mathrm{C}_{31} \mathrm{~S} / \mathrm{C}_{30}, 17 \alpha, 21 \beta(\mathrm{H})$-homohopane $(22 \mathrm{~S}) / 17 \alpha, 21 \beta(\mathrm{H})$ hopane-Source parameter.

17. $35 \mathrm{~S} / 34 \mathrm{~S}, 17 \alpha, 21 \beta(\mathrm{H})-29$-pentakishomohopane $(22 \mathrm{~S}) / 17 \alpha, 21 \beta(\mathrm{H})-29$-tetrakishomohopane (22S)Higher $\mathrm{C}_{35}$ than $\mathrm{C}_{34} 22 \mathrm{~S}$ homohopanes is an indication of carbonate/evaporite facies or anoxic depositional environment.

18. BI, Bisnorhopane Index, 28,30-bisnorhopane/17 $\alpha, 21 \beta(\mathrm{H})$-hopane-This source ratio has been used to characterize oils from the Monterey Formation. The presence of 28,30-bisnorhopane, in addition to indicating a marine, highly reducing depositional environment (Curiale and others, 1985), is reported to be passed on from bitumen rather than generated from kerogen and, therefore, decreases with thermal maturity (Peters and Moldowan, 1993). Therefore, this ratio would be higher in oils sourced from near-surface facies.

19. OI, Oleanane Index, $18 \alpha+\beta(\mathrm{H})$-oleanane $/ 17 \alpha, 21 \beta(\mathrm{H})$ hopane-This commonly used source parameter indicates a contribution from Cretaceous and younger plant material (Peters and Moldowan, 1993). In the California coastal tars, oleanane is generally present, but in low amounts. 
20. GI, Gammacerane Index, gammacerane/17 $\alpha, 21 \beta(\mathrm{H})-$ hopane-This ratio is used as a source parameter; abundant gammacerane is a carbonate/evaporite facies indicator and a marker for highly reducing, hypersaline depositional environments (Peters and Moldowan, 1993).

\section{Steranes, m/z 217 SIM chromatograms}

21. $\mathrm{C}_{29} \mathrm{~S} /(\mathrm{S}+\mathrm{R}), 24$-ethyl-5 $\alpha, 14 \alpha, 17 \alpha(\mathrm{H})$-cholestane (20S)/ 24-ethyl-5 $\alpha, 14 \alpha, 17 \alpha(\mathrm{H})$-cholestane (20S+20R)This sterane epimer ratio is commonly used as a maturity parameter; the equilibrium value at full maturity is $\sim 0.5$ (Mackenzie and others, 1980).

22. $\mathrm{C}_{28} / \mathrm{C}_{29}, 24$-methyl-5 $\alpha, 14 \alpha, 17 \alpha(\mathrm{H})$-cholestane (20R)/ 24-ethyl-5 $\alpha, 14 \alpha, 17 \alpha(\mathrm{H})$-cholestane (20R) -This source parameter has been modified from discussions in Grantham and Wakefield (1988) and Waples and Machihara (1991).

23. Dominant sterane(s) - This descriptor indicates the sterane(s) that is most prominent in the $\mathrm{m} / \mathrm{z} 217$ chromatogram. The $\mathrm{m} / \mathrm{z} 217$ chromatogram may also include a fragment of bisnorhopane (BN), which is noted if it is one of the most prominent peaks. This gives information on the extent of sterane degradation in these systems.

24. $\alpha 27 \mathrm{R} / \mathrm{Hop}$, a Sterane Index, $5 \alpha, 14 \alpha, 17 \alpha(\mathrm{H})-$ cholestane $/ 17 \alpha, 21 \beta(\mathrm{H})$-hopane - This parameter gives an indication of relative proportions of a common regular sterane to hopane. In this study it helps track sterane biodegradation.

25. nor26\&27/Hop, another Sterane Index, two tentatively identified steranes, $\mathrm{C}_{26}$ 24-nor-5 $\alpha$-cholestane (Moldowan and others, 1991) and $\mathrm{C}_{27} 27$-nor24-methyl-5 $\alpha$-cholestane (Schouten and others, 1994), indexed to hopane-This is a source parameter and may serve as a maturity parameter, particularly in subsequent studies when deeper production oils are considered.
26. $\alpha 27 \mathrm{R} /$ nor $27,5 \alpha, 14 \alpha, 17 \alpha(\mathrm{H})$-cholestane $/ \mathrm{C}_{27} 27$-nor24-methyl-5 $\alpha$-cholestane-A sterane parameter that also tracks sterane biodegradation.

\section{Aromatic Fraction}

27. PAH-RI, Polycyclic Aromatic Hydrocarbon-Refractory Index-This index is a source parameter, the ratio of the second, usually major, peak containing the $\mathrm{C}_{26} \mathrm{R}$ and $\mathrm{C}_{27} \mathrm{~S}$ members in the highly refractory $\mathrm{C}_{26}$ to $\mathrm{C}_{28}$ triaromatic sterane suite (TAS, $\mathrm{m} / \mathrm{z} 231$ ) to that of the first, usually dominant, peak in the monomethyl chrysenes (m/z 242) (Hostettler and others, 1999). In this very large data set, this previously descriptive-only parameter does reflect a specific facies characteristic. PAH-RI goes from low values in shale, intermediate values in marl, and high values in carbonate (increasingly anoxic facies) environ ments. Since PAH-RI compares TAS to a typical petrogenic $\mathrm{C}_{1} \mathrm{PAH}$, high value indicate higher levels of TAS. TAS are known to be a stable product of diagenesis of steranes in a reducing or anoxic environment. Therefore, PAH-RI is another indicator of the anoxic nature of the source environment.

28. $\mathrm{T} /(\mathrm{T}+\mathrm{M}) . \mathrm{T}=$ triaromatic steranes (areas), $\mathrm{C}_{26}$ to $\mathrm{C}_{28}$, $\mathrm{m} / \mathrm{z} 231 ; \mathrm{M}=$ monoaromatic steranes (areas), $\mathrm{C}_{26}$ to $\mathrm{C}_{28}, \mathrm{~m} / \mathrm{z} 253$ - Aromatic steroid parameter. This is a thermal maturity and source parameter, widely used, modified from that described in Peters and Moldowan (1993). Low values, reflecting relatively higher levels of the monoaromatic steroids, indicate low thermal maturity.

29. $\Sigma \mathrm{C} 2 \mathrm{D} / \Sigma \mathrm{C} 2 \mathrm{P}$, dimethyl dibenzothiophenes $(\mathrm{m} / \mathrm{z} 212) /$ dimethyl phenanthrenes (m/z 206)-Source parameter indicating relative levels of sulfur-containing PAH to regular PAH (Kaplan and others, 1997; Bence and others, 1996).

30. $\Sigma \mathrm{C} 3 \mathrm{D} / \Sigma \mathrm{C} 3 \mathrm{P}$, trimethyl dibenzothiophenes $(\mathrm{m} / \mathrm{z} 226) /$ trimethyl phenanthrenes (m/z 220)-Source parameter as $\# 29$. 
This page left blank intentionally. 
Produced in the Western Region, Menlo Park, California Manuscript approved for publication, November 14, 2011

Text edited by J.L. Zigler Layout and design by Judy Weathers 
